\title{
Caracterización de la flora vascular de Altos de Chicauma, Chile $\left(33^{\circ} \mathrm{S}\right)$
}

\section{Characterization of the vascular flora of Altos de Chicauma, Chile $\left(33^{\circ} \mathrm{S}\right)$}

\author{
Nicolás García ${ }^{1,2}$ \\ ${ }^{1}$ Department of Biology, University of Florida, Gainesville, FL 32611, USA. \\ 'Laboratorio de Flora y Vegetación, Departamento de Silvicultura, Facultad de Ciencias Forestales, Universidad de Chile, \\ Casilla 9206, Santiago, Chile. \\ nicogarcia@ufl.edu
}

\section{RESUMEN}

\begin{abstract}
Se reporta una riqueza total de 602 taxones específicos e infraespecíficos para la localidad de Altos de Chicauma, ubicada

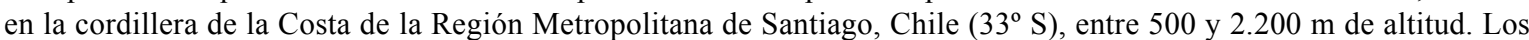
taxones endémicos de Chile constituyen $41 \%$ y los endémicos del Cono Sur de Sudamérica equivalen a $66 \%$ de la flora total, mientras que un $14 \%$ corresponde a flora alóctona. La flora total es caracterizada respecto a su presencia en siete tipos de hábitats. Se presenta una lista sistemática comentada donde cada taxón es caracterizado respecto a su hábito de crecimiento, origen geográfico, frecuencia relativa, presencia por tipo de hábitat en Chicauma, y para 572 taxones $(95 \%)$ se indica material de referencia que respalda su presencia en dicha localidad. La flora total y las floras parciales de cada hábitat fueron caracterizadas según su riqueza, composición de orígenes y tipos biológicos. Un análisis de similitud entre la flora nativa de cada hábitat indica que la composición de especies difiere significativamente al resto en los ámbitos de "ambientes hídricos altomontanos", "quebradas", "xérico", y en los pares, "esclerofilo de valle - esclerofilo montano" y "caducifolio - altomontano". Para esta localidad se indica la presencia de 14 especies propuestas en categoría de conservación, nueve endémicas de la cordillera de la Costa de Chile central, 13 endémicas de las cordilleras de las regiones de Valparaíso y Metropolitana, y cinco límites de distribución.
\end{abstract}

Palabras clave: Chile central, cordillera de la Costa, riqueza, composición, endemismo.

\begin{abstract}
A total richness of 602 specific and infra-specific taxa is reported for the locality of Altos de Chicauma, situated in the Metropolitan Region's Coastal mountain range, Chile $\left(33^{\circ} \mathrm{S}\right)$, between 500 and $2.200 \mathrm{~m}$ of altitude. Chile's endemic taxa constitute $41 \%$ and the Southern Cone endemics equal $66 \%$ of the total flora, while $14 \%$ corresponds to alien flora. The total flora is characterized according to its presence in seven habitat-types. A commented systematic list is presented where each taxon is characterized according to its growth habit, geographic origin, relative frequency, and presence per habitat-type in Chicauma. Herbarium material supporting the presence in this locality is indicated for 572 taxa (95\%). The total flora and the habitat-types' partial floras were characterized according to their richness, origin and biologictypes compositions. A similarity analysis between the habitats' native floras indicates that the species composition differs significantly to the rest in "high-mountainous hydric environments", "creeks and ravines", "xeric", and in the pairs, "valley sclerophyllous - montane sclerophyllous" and "deciduous - high-mountainous" habitats. The presence of 14 endangered species, nine Central Chile's Coastal mountain range endemics, 13 Metropolitan-Valparaiso regions' mountain endemics, and five distributional limits are reported for this locality.
\end{abstract}

KEYwords: Central Chile, Coastal mountain range, richness, composition, endemism.

\section{INTRODUCCIÓN}

La Región Metropolitana de Santiago está situada en la zona de clima de tipo mediterráneo de Chile central (di Castri \& Hajek 1976, Luebert \& Pliscoff 2006), cuyos sistemas naturales presentan altos niveles de endemismo y riqueza de especies (Cowling et al. 1996, Arroyo \& Cavieres 1997). Por otro lado, ésta corresponde a la zona más poblada de Chile y con una larga historia de intervención y reemplazo de los sistemas naturales, que incluso data desde antes 
de la Conquista española (Cunill 1971, Fuentes \& Hajek 1979). Por estas razones, el territorio ubicado en Chile central es considerado como una de las zonas prioritarias para la conservación a nivel mundial (Arroyo et al. 1999, Myers et al. 2000). Las investigaciones que aportan al conocimiento de la biota de esta zona geográfica de Chile son de alto interés y de gran relevancia para mejorar nuestra comprensión y valoración de los ecosistemas locales, y proporcionan información básica para el establecimiento de prioridades de conservación y toma de decisiones a nivel regional.

La cuenca de Santiago de Chile incluye una superficie aproximada de $4.000 \mathrm{~km}^{2}$. Geográficamente está limitada al norte por el cordón transversal de El Manzano, cerca de las localidades de Batuco y Colina; al sur, por el cordón tranversal de Paine; al oriente, por los contrafuertes de la cordillera de los Andes; y al occidente, por la cordillera de la Costa (Navas 1973) (Fig. 1). La referencia más relevante para el conocimiento de la flora de Santiago es la obra "Flora de la Cuenca de Santiago de Chile" de la botánica Luisa Eugenia Navas (Navas 1973, 1976, 1979). En dicha obra se da cuenta de 963 taxones específicos e infraespecíficos de plantas vasculares para toda la superficie de la cuenca, de los que 720 son autóctonos o nativos de Chile, es decir el $75 \%$ del total.

Otros trabajos han contribuido al conocimiento de la flora de la precordillera andina de Santiago, tales como las floras del Santuario de la Naturaleza Yerba Loca (Aravena 2002, Arroyo et al. 2002), cordillera de Las Condes (Looser 1932), Quebrada de Ramón (Teillier \& Tomé 2004) y Reserva Nacional Río Clarillo (Teillier et al. 2005). Estos trabajos han incrementado el conocimiento de la flora de los alrededores de Santiago respecto a los trabajos de Navas, destacando la singularidad de la flora vascular nativa del sector y su alta riqueza en comparación a otras localidades de Chile central.
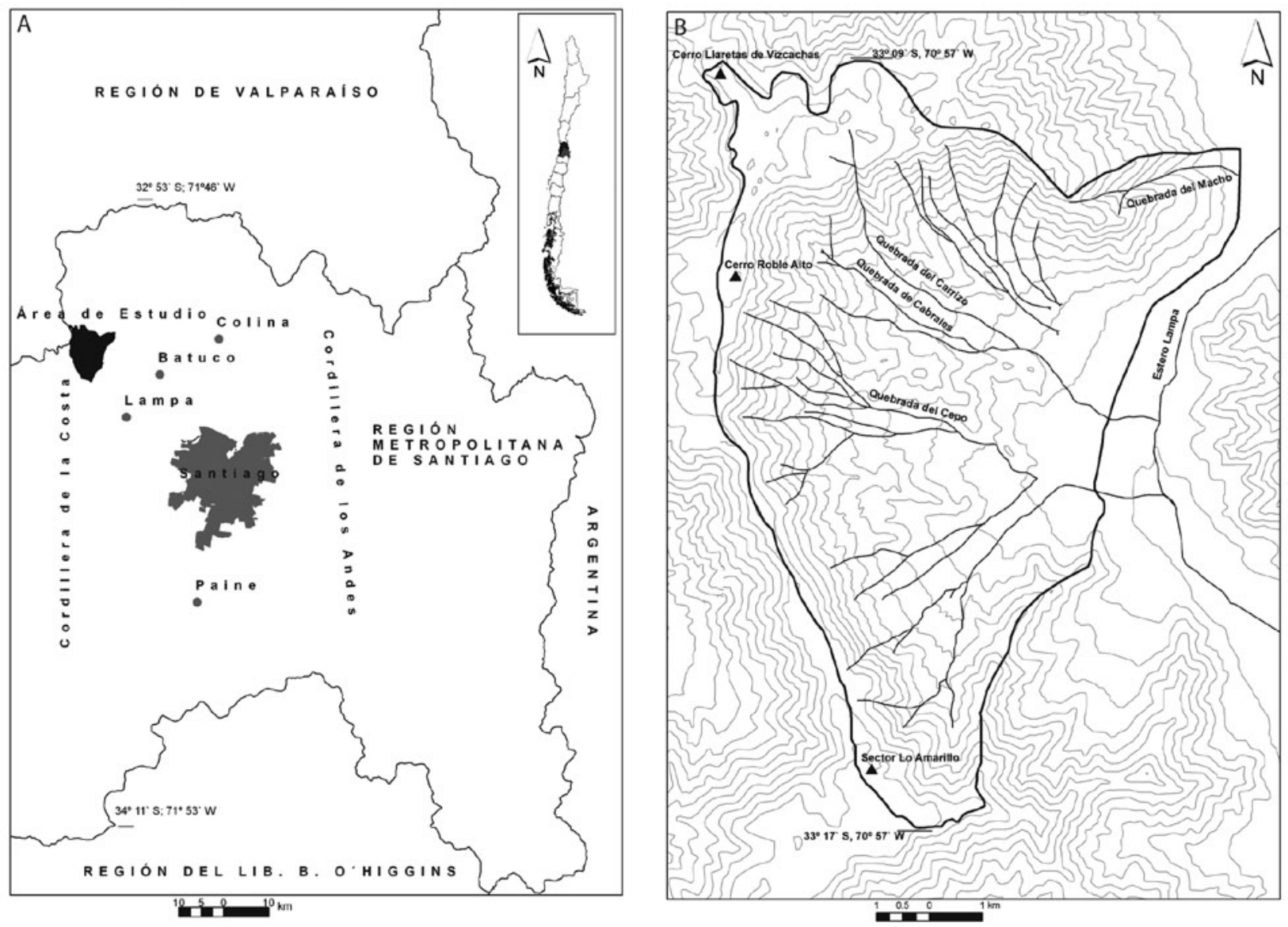

FIgURA 1. Ubicación geográfica del área de estudio. A: Contexto geográfico de la cuenca de Santiago. B: Esquema del área de estudio.

FIGURE 1. Geographic location of the study area. A: Geographic context of the Santiago basin. B: Diagram of the study area. 
Sin embargo, la información publicada respecto a la flora de la cordillera de la Costa de la cuenca de Santiago es muy escasa, y sólo se cuenta con la flora de la quebrada de La Plata, Maipú (Schlegel 1963, 1966), y la flora de las cumbres de Altos de Chicauma (García 2006). Fuera de la cuenca de Santiago, los trabajos florísticos en la cordillera de la Costa de Chile central son también escasos, y se restringen al valle del Marga-Marga (Jaffuel \& Pirion 1921), una breve alusión a los altos de Tiltil (Reiche 1907), Parque Nacional La Campana (Villaseñor \& Serey 1980/81, Luebert et al. 2002), Cerro El Roble de Caleu (Espinosa 1927, Muñoz 1999) y sistema Altos de Cantillana (Avilez 2001, Romero 2002, Universidad de Chile 2007, Romero $\&$ Teillier 2009).

La localidad de Altos de Chicauma, ubicada en la cordillera de la Costa de la cuenca de Santiago, fue propuesta como sitio con Prioridad III: De Interés para su Conservación (Muñoz et al. 1996), principalmente por sus robledales (i.e. bosques de Nothofagus macrocarpa (A.DC.) F.M.Vázquez \& R.A.Rodr.) (Espinosa 1935, Gajardo 2001). Actualmente, este sector es parte del sitio prioritario "El Roble" de la Estrategia para la Conservación de la Biodiversidad en la Región Metropolitana de Santiago (CONAMA 2004). Estos antecedentes de interés, sumados al casi nulo conocimiento que se tenía de la flora del sector (M.T.K. Arroyo com. pers., C. Marticorena com. pers.), fueron la base para motivar el estudio de la composición de plantas vasculares en esta localidad.

En el contexto de la vegetación natural de Chile (Gajardo 1994), el sector de la cordillera de la Costa en el que se inserta Altos de Chicauma, contiene tres unidades de vegetación: bosque esclerofilo pre-cordillerano, bosque caducifolio montano y estepa altoandina mediterránea. A una escala regional, y considerando el concepto de piso de vegetación, aplicado para Chile por Luebert y Pliscoff (2006), en Altos de Chicauma se puede distinguir tres pisos: bosque esclerofilo interior de Quillaja saponaria y Lithrea caustica, bosque caducifolio costero de Nothofagus macrocarpa y Ribes punctatum, y por último, matorral bajo costero de Chuquiraga oppositifolia y Mulinum spinosum.

El propósito del presente trabajo es dar a conocer la flora vascular de Altos de Chicauma, con el fin de incrementar el conocimiento y valoración de los espacios naturales de la cuenca de Santiago y de la cordillera costera de Chile central.

\section{MATERIALES Y MÉTODOS}

\section{Área DE EsTUdio}

Altos de Chicauma (Región Metropolitana de Santiago, $33^{\circ} \mathrm{S}$ ) corresponde a un macizo montañoso de la cordillera de la Costa, que forma parte de un sistema cordillerano mayor que va desde el río Aconcagua hasta el río Maipo (García 2006). Este sector se ubica en la provincia de Chacabuco (Fig. 1), entre las localidades de Lampa y Polpaico, aproximadamente $25 \mathrm{~km}$ al noroeste de la periferia de la ciudad de Santiago.

El área estudiada comprende dos predios principales: el fundo Chicauma (Reserva Cora $\mathrm{N}^{\mathrm{o}} 2$ ) y el fundo Las Mercedes de Chicauma. El terreno es de propiedad privada y tiene un área total aproximada de 8.000 ha. El sector muestreado corresponde a la vertiente oriental y altas cumbres de un macizo montañoso de la cordillera de la Costa con orientación N-S, que comprende altitudes desde 520 hasta más de $2.000 \mathrm{~m}$. La cumbre más alta corresponde al cerro Roble Alto que cuenta con 2.200 m s.m., seguida por el cerro Llaretas de Vizcachas, con $2.105 \mathrm{~m}$ de altitud. El sector estudiado está comprendido entre las coordenadas $33^{\circ} 00^{\prime}-33^{\circ} 17^{\prime} \mathrm{S}$ y $70^{\circ} 53^{\prime}-71^{\circ} 00^{\prime} \mathrm{W}$ (Fig. 1 ).

\section{Toma DE DATOS}

El trabajo de recolección en terreno y de determinación taxonómica en laboratorio se realizó entre los años 2002 y 2009. El primer gran impulso para este estudio fue el proyecto "Flora de Altos de Chicauma", que implicó la realización de tres campañas a terreno en las que se registró alrededor del $90 \%$ de la flora que se reporta aquí: 27-30 de septiembre de 2002, 7-10 de noviembre de 2002 y 4-10 de enero de 2003. Luego, otra campaña de suma importancia para el conocimiento de los ambientes de alta montaña, fue la realizada entre el 21 y 23 de diciembre de 2004. Finalmente, se pueden considerar al menos cinco campañas adicionales, cada una de ellas aportó con nuevos registros para la flora local: 21-22 de octubre de 2006, 910 de septiembre de 2007, 1-3 de marzo de 2008, 7-9 de marzo de 2008 y 29-31 de mayo de 2009. Considerando todas las visitas, el muestreo se realizó en alrededor de 30 días de trabajo distribuidos a lo largo del año, excepto en invierno.

En cada campaña de terreno se recolectó material vegetal para ser herborizado y determinado posteriormente utilizando bibliografía taxonómica especializada. De manera complementaria, se revisó material depositado en los herbarios del Museo Nacional de Historia Natural de Chile (SGO) y de la Universidad de Concepción (CONC). En algunos casos fue necesario revisar material tipo depositado en SGO (especialmente para taxones descritos por Rodulfo Philippi), y en otros, se envió material a especialistas extranjeros. Todo el material recolectado en este trabajo quedará depositado en CONC, con algunos duplicados en EIF, SGO, MIN, MVFA y SI, siglas según Holmgren et al. (1981).

TIPOS DE HÁBITATS

Según Rivas-Martínez (2005) un hábitat es un “espacio y ambiente (conjunto de factores mesológicos: luz, clima, 
suelo, etc.) en el que se desarrollan las comunidades bióticas o alguna de sus especies constituyentes". En el presente trabajo un tipo de hábitat o ámbito de flora es considerado como internamente homogéneo en cuanto a su composición florística y heterogéneo en cuanto a las formaciones de vegetación que alberga. En términos geobotánicos clásicos (Villar 1929), un tipo de hábitat corresponde a un medio estacional individualizado por una composición general de especies.

\section{CARACTERIZACIÓN DE LA FLORA}

Se presenta una lista comentada de la flora total, donde la nomenclatura específica sigue en general a Zuloaga et al. (2008a, 2008b, 2008c) y, en el caso de los helechos, a Rodríguez (1995). Tanto la secuencia sistemática de la lista, como la nomenclatura y circunscripción de órdenes y familias de angiospermas, se basan en la propuesta del APG III (2009). Se ha adoptado esta perspectiva filogenética ya que refleja de manera más adecuada la posición evolutiva de cada orden y familia en el sistema de clasificación taxonómico (Judd et al. 2008). La posición ordinal de Boraginaceae no está resuelta, por lo tanto, su ubicación en el orden Boraginales es tentativa (APG III, 2009).

Se indica el origen geográfico de los taxones (i.e. alóctono o introducido, autóctono o nativo de Chile, endémico del Cono Sur de Sudamérica, endémico de Chile) según Matthei (1996) y Zuloaga et al. (2008a, 2008b, 2008c). En este trabajo los términos "endémico" y "endemismo" se refieren a taxones con distribución restringida a un área geográfica determinada (e.g. Cono Sur, Chile, cordillera de la Costa, Región Metropolitana). Las cuatro categorías de origen consideradas dan una referencia general de la extensión de los rangos de distribución geográfica de los taxones y no constituyen elementos fitogeográficos en sentido estricto. El área geográfica denominada "Cono Sur" corresponde al extremo sur del continente sudamericano, incluye los territorios de Argentina, el sur de Brasil (estados de Paraná, Santa Catarina y Rio Grande do Sul), Chile, Paraguay y Uruguay (Zuloaga et al. 2008a).

Sólo cinco taxones nativos pudieron ser determinados hasta el nivel de género (i.e. Phycella sp., Sisyrinchium sp., Eleocharis sp., Poa sp., Adesmia sp., Centaurium sp.). En vista que el género Phycella es endémico de Chile continental (Hunziker 1985, Ravenna 2003), se ha considerado a Phycella sp. como endémica de Chile. Las cuatro especies restantes fueron consideradas entre las autóctonas no-endémicas para realizar los cálculos.

Cada taxón fue caracterizado respecto a su hábito de crecimiento en la lista comentada con base en las categorías propuestas por Zuloaga et al. (2008a, 2008b, 2008c) (i.e. AA: arbusto arrosetado; AC: arbusto acojinado; AP: arbusto parásito; AR: árbol o arbusto arborescente; AS: arbusto suculento; AT: arbusto; EN: enredadera; HA: hierba anual o bianual; HL: hierba subleñosa; HP: hierba perenne;
HS: hierba suculenta; LI: liana; PA: parásita anual; SA: subarbusto; SC: suculenta columnar). Para caracterizar la proporcionalidad de tipos biológicos en la flora total y por tipo de hábitat, las categorías de hábitos se agruparon en tipos biológicos generales según la propuesta de Arroyo et al. (2002) (i.e. Herbáceo anual: HA + PA; Herbáceo perenne: $\mathrm{EN}+\mathrm{HP}+\mathrm{HS}$; Arbustivo: $\mathrm{AA}+\mathrm{AC}+\mathrm{AP}+\mathrm{AS}$ $+\mathrm{AT}+\mathrm{HL}+\mathrm{LI}+\mathrm{SA}$; Arbóreo: AR + SC).

Todos los taxones fueron caracterizados en la lista comentada respecto a su frecuencia general en el área y en los hábitats donde fueron registrados, y para la flora nativa total (i.e. autóctono + endémico del Cono Sur + endémico de Chile), se indica también el rango de altitud de cada taxón en Altos de Chicauma. Finalmente se indican los materiales de herbario que respaldan la presencia de los taxones citados, salvo en los casos en que su mención se basa sólo en registro visual (i.e. no recolectada).

Se caracterizó la riqueza de especies de la flora total y por tipo de hábitat. Cada hábitat fue caracterizado en cuanto a la proporción de orígenes considerando su flora total parcial y de tipos biológicos respecto a su flora nativa parcial. Se da cuenta del estado de conservación de algunas especies mediante la revisión de las clasificaciones oficiales

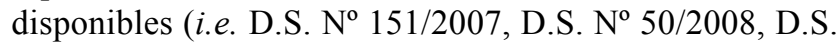
$\mathrm{N}^{\mathrm{o}} 51 / 2008$ del MINSEGPRES), y según la propuesta de Benoit (1989) para las especies leñosas, Baeza et al. (1998) para los helechos y Ravenna et al. (1998) para las geófitas de perianto vistoso. Mediante la revisión de bibliografía especializada, se determinó aquellos taxones que constituyen endemismos estrechos, restringidos a la cordillera de la Costa de Chile central entre los ríos Petorca y Cachapoal (García 2006) y a las regiones de Valparaíso y Metropolitana de Santiago, además de aquéllos cuya población en el área de estudio constituye un límite en su distribución.

Con el fin de analizar la similitud entre los tipos de hábitats definidos, se realizó un análisis de conglomerados (Krebs 1989) considerando sólo los taxones nativos. Para esto se construyó una matriz de presencia-ausencia, a partir de la que se calculó las similitudes utilizando el índice de Baroni-Urbani y Buser (Baroni-Urbani \& Buser 1976). Este índice de similitud tiene una buena aplicación en análisis de agrupamiento florístico con una connotación biogeográfica (e.g. Márquez et al. 1997, 2001), puesto que al considerar las dobles ausencias para determinar la similitud entre las unidades operacionales, genera una topología de relaciones más ajustada al contexto de la flora local. El análisis se realizó utilizando el algoritmo UPGMA, con el que se obtuvo un dendrograma de similitud entre tipos de hábitats. Se determinó si las similitudes calculadas para los nodos del dendrograma son significativas con respecto a lo esperado por efecto del azar, para las probabilidades menores a 0,01 (i.e. muy significativamente diferentes o "límites débiles") y mayores a 0,99 (i.e. significativamente 
similares o "límites fuertes"), utilizando la tabla de valores críticos de Baroni-Urbani y Buser (1976).

\section{RESULTADOS}

TIPOS DE HÁBITAT

Con el objetivo de caracterizar los distintos ambientes donde se desarrolla la flora en el área de estudio, se identificó siete tipos de hábitats, que se describen a continuación.

Esclerofilo de valle: Se caracteriza por la presencia de matorral arborescente y bosque esclerofilo cerrado, donde los árboles dominantes son Lithrea caustica (Molina) Hook. \& Arn., Quillaja saponaria Molina y Cryptocarya alba (Molina) Looser. También se han incluido aquí sectores muy degradados y usados históricamente para ganadería, donde actualmente existen formaciones de Acacia caven (Molina) Molina. Se desarrolla sobre un plano levemente inclinado con orientación hacia el este, y en lomajes y laderas bajas expuestas hacia el sur, entre 500 y $1.200 \mathrm{~m}$ de altitud.

Esclerofilo montano: Se caracteriza por la presencia de matorral arborescente y bosque esclerofilo abierto, donde los árboles típicos son Quillaja saponaria y Cryptocarya alba, y donde la hierba perenne dominante es Festuca acantophylla E.Desv. Se desarrolla en laderas de la montaña media con diferentes orientaciones, entre 1.100 y $1.700 \mathrm{~m}$ de altitud. En laderas con exposición ecuatorial, también es relevante la presencia de Puya coerulea Lindl. y Retanilla stricta Hook. \& Arn., mientras que en las laderas sombrías son importantes Porlieria chilensis I.M.Johnst. y Colliguaja salicifolia Gillies \& Hook.

Quebradas: Se desarrolla en quebradas con cursos de agua permanentes o estacionales, entre 600 y 1.700 $\mathrm{m}$ de altitud aproximadamente. En la parte baja, hasta $1.200 \mathrm{~m}$ s.m., las quebradas presentan márgenes pronunciados y trayecto de pendiente suave, con cubierta de bosque esclerofilo denso dominado principalmente por Cryptocarya alba y Lithrea caustica. Algunos árboles son exclusivos de este hábitat, como Luma chequen (Molina) Gray, Otholobium glandulosum (L.) J.W.Grimes y Drimys winteri J.R.Forst. \& G.Forst. var. chilensis (DC.) A.Gray. Sobre los $1.200 \mathrm{~m}$ de altitud, la quebrada queda expuesta o se cubre por bosque caducifolio y se desarrollan árboles pequeños o arbustos arborescentes característicos como Escallonia myrtoidea Bertero ex DC. y Discaria trinervis (Gillies ex Hook. \& Arn.) Reiche. Algunas especies frecuentes en todo este hábitat son los arbustos Escallonia illinita K.Presl y Baccharis confertifolia Colla, así como las hierbas perennes Equisetum bogotense DC., Eleocharis bonariensis Nees y Scirpus asper J.Presl \& C.Presl.

Xérico: Se desarrolla exclusivamente en laderas con exposición ecuatorial entre 600 y $1.500 \mathrm{~m} \mathrm{s.m.,} \mathrm{y} \mathrm{por} \mathrm{la}$ presencia de un matorral alto donde la especie dominante es Colliguaja odorifera Molina. Otros arbustos que son relevantes en este hábitat son Flourensia thurifera (Molina) DC., Adesmia confusa Ulibarri y, ocasionalmente, Bridgesia incisifolia Bertero ex Cambess. También es importante la suculenta Trichocereus chiloensis (Colla) Britton \& Rose y Puya berteroniana Mez.

Caducifolio: Se caracteriza por la presencia de matorral arborescente caducifolio, puesto que el bosque original ha desaparecido por explotación histórica, donde la especie arbórea dominante es Nothofagus macrocarpa. Se desarrolla exclusivamente en laderas expuestas hacia el sur entre 1.200 y $2.000 \mathrm{~m}$ de altitud. Hasta los $1.500 \mathrm{~m}$ s.m. también es relevante la presencia de Cryptocarya alba, mientras que Azara petiolaris (D.Don) I.M.Johnst. lo es sobre dicha altitud. Otras especies que son muy frecuentes en el bosque caducifolio son Festuca acanthophylla, Carex andina Phil., Ribes punctatum Ruiz \& Pav. y Calceolaria meyeniana Phil.

Altomontano: Corresponde a un matorral bajo donde las especies más relevantes son el arbusto Chuquiraga oppositifolia D.Don y la gramínea en champa Festuca acanthophylla. Se desarrolla en la alta montaña, en laderas y cumbres entre 1.800 y 2.200 m s.m., aunque en ciertas laderas desciende hasta los $1.500 \mathrm{~m}$ s.m. Otros arbustos muy frecuentes en este ámbito son Baccharis neaei DC., Mulinum spinosum (Cav.) Pers. y Tetraglochin alatum (Gillies ex Hook. \& Arn.) Kuntze. En algunas laderas sombrías se desarrolla un matorral dominado de manera exclusiva por Adesmia resinosa (Phil. ex Reiche) Martic., mientras que en sectores de afloramientos rocosos se desarrolla otra comunidad en la que Puya coerulea es muy característica.

Ambientes hídricos altomontanos: En este tipo de hábitat se incluye diferentes ambientes con alta disponibilidad de humedad en el sector de alta montaña, tales como vegas, matorrales de periferia de vegas, pequeños esteros y un espejo de agua artificial (conocido como "El Tranque"), ubicados entre 1.800 y $2.100 \mathrm{~m}$ s.m. Se caracteriza por la presencia de varias especies de Poaceae, Cyperaceae, Juncaceae rizomatosas y otras hierbas que sólo habitan en este tipo de ambientes. Por otro lado, en la periferia de vegas se desarrolla un matorral dominado casi exclusivamente por Discaria trinervis.

RiQUEZA Y COMPOSICIÓN GENERAL

La flora vascular total registrada en Altos de Chicauma está constituida por 602 taxones específicos e infraespecíficos, que corresponden a 597 especies, cinco de las que presentan un par de taxones infraspecíficos en el área de estudio. El total de taxones con material de referencia llega a 572 (95\%), lo que implica que los 30 restantes han sido registrados sólo de manera visual en el área de estudio.

A un nivel taxonómico mayor, la flora vascular del área de estudio está representada por 94 familias. En la Tabla I 
se presentan las familias representadas por un número de 11 o más taxones a nivel local. Sobre todas destaca la familia Asteraceae, la que representa un $18 \%$ de la flora total, con un número importante de especies endémicas de Chile.

A su vez, la flora total está distribuida en 293 géneros. Una lista de aquellos con siete o más especies nativas se presenta en la Tabla II. De estos géneros listados, sólo Senecio presenta una especie alóctona adicional (i.e. Senecio vulgaris L.). Destacan los géneros Calceolaria, Adesmia y Senecio, que además de estar representados por más de 10 taxones, poseen un alto grado de restricción a Chile continental. En los casos de Calceolaria, Senecio, Chaetanthera, Haplopappus y Valeriana, todas las especies nativas registradas están presentes en el Cono Sur de Sudamérica. El género Adesmia también pertenecería a este grupo, ya que Adesmia DC. ser. Confertae Burkart, grupo al que pertenece el taxón citado como Adesmia sp., tiene una distribución restringida a esta zona geográfica (Burkart 1967).

Tabla I. Familias con mayor riqueza de taxones en Altos de Chicauma. EC: endémico de Chile; ES: endémico del Cono Sur; AU: autóctono; AL: alóctono.

TABLE I. Families with highest richness of taxa in Altos de Chicauma. EC: Chile endemic; ES: Southern Cone endemic; AU: autochtonous taxa; AL: alien taxa.

\begin{tabular}{lccccc}
\hline Familia & $\mathrm{N}^{\circ} \mathrm{EC}$ & $\mathrm{N}^{\circ} \mathrm{ES}$ & $\mathrm{N}^{\circ} \mathrm{AU}$ & $\mathrm{N}^{\mathrm{o}} \mathrm{AL}$ & TотAL \\
\hline Asteraceae & 59 & 24 & 13 & 12 & 108 \\
Poaceae & 8 & 19 & 17 & 17 & 61 \\
Fabaceae & 20 & 4 & 5 & 7 & 36 \\
Apiaceae & 4 & 4 & 6 & 3 & 17 \\
Calceolariaceae & 16 & 1 & 0 & 0 & 17 \\
Cyperaceae & 2 & 5 & 10 & 0 & 17 \\
Boraginaceae & 3 & 4 & 5 & 2 & 14 \\
Montiaceae & 5 & 5 & 0 & 1 & 11 \\
Oxalidaceae & 4 & 4 & 3 & 0 & 11 \\
Plantaginaceae & 2 & 3 & 0 & 6 & 11 \\
Solanaceae & 1 & 7 & 2 & 1 & 11 \\
\hline
\end{tabular}

TABla II. Géneros con mayor riqueza de taxones nativos en Altos de Chicauma. EC: endémico de Chile; ES: endémico del Cono Sur; AU: autóctono.

TABLE II. Genera with highest richness of native taxa in Altos de Chicauma. EC: Chile endemics; ES: Southern Cone endemics; AU: autochtonous taxa.

\begin{tabular}{|c|c|c|c|c|}
\hline GÉNERO & $\mathrm{N}^{\mathrm{o}} \mathrm{EC}$ & $\mathrm{N}^{\mathrm{o}} \mathrm{ES}$ & $\mathrm{N}^{\mathrm{o}} \mathrm{AU}$ & $\begin{array}{c}\text { Nativas } \\
\text { Total }\end{array}$ \\
\hline Calceolaria & 16 & 1 & 0 & 17 \\
\hline Adesmia & 11 & 2 & 1 & 14 \\
\hline Oxalis & 4 & 4 & 3 & 11 \\
\hline Senecio & 8 & 3 & 0 & 11 \\
\hline Baccharis & 2 & 5 & 1 & 8 \\
\hline Chaetanthera & 6 & 2 & 0 & 8 \\
\hline Haplopappus & 7 & 1 & 0 & 8 \\
\hline Adiantum & 3 & 3 & 1 & 7 \\
\hline Carex & 1 & 4 & 2 & 7 \\
\hline Valeriana & 4 & 3 & 0 & 7 \\
\hline
\end{tabular}


De la flora total, el 41\% (247 taxones) es endémica de Chile y otro $25 \%$ (149 taxones) es endémica del Cono Sur de Sudamérica, mientras que un 14\% (85 taxones) corresponde a flora de origen alóctono. Ya que los taxones endémicos de Chile son un subconjunto de los endemismos del Cono Sur, un 66\% (397 taxones) de la flora total registrada en el área de estudio tiene una distribución restringida a dicha zona geográfica de Sudamérica. El $20 \%$ (121 taxones) restante está constituido por entidades autóctonas de Chile, distribuidas de manera natural en América más allá de los límites del Cono Sur.

En la Tabla III se presenta la cantidad y porcentaje de taxones por tipo biológico general para la flora total, flora nativa y flora alóctona. Tanto en el espectro de la flora total como en el de la flora nativa se destaca que las hierbas perennes predominan por sobre los demás tipos biológicos, correspondiendo a más del $45 \%$ en ambos casos. También se aprecia que un $81 \%$ de la flora alóctona está constituido por hierbas anuales, lo que explica la diferencia de casi 10 puntos porcentuales más para este tipo biológico en el espectro de la flora total (i.e. 30\%) con respecto al de la flora nativa (i.e. $21 \%$ ). Los arbustos representan alrededor de un $20 \%$, tanto en la flora total como en la nativa, mientras que están representados por sólo una especie alóctona (i.e. Rubus constrictus P.J. Müll. \& Lefèvre). Los árboles o arbustos arborescentes están representados por 30 especies nativas, tres introducidas y una cactácea columnar de gran tamaño (i.e. Trichocereus chiloensis), los que en conjunto constituyen entre 4 y $6 \%$ de los espectros analizados.

TABLA III. Riqueza de taxones y composición de tipos biológicos para la flora nativa, alóctona y total de Altos de Chicauma.

TABLE III. Taxa richness and biologic-type composition for the native, alien and total flora of Altos de Chicauma.

\begin{tabular}{lcccccc}
\hline & $\begin{array}{c}\text { Nativas Total } \\
(\mathrm{n}=517)\end{array}$ & \multicolumn{2}{c}{$\begin{array}{c}\text { Alóctonas } \\
(\mathrm{n}=85)\end{array}$} & \multicolumn{2}{c}{$\begin{array}{c}\text { Flora Total } \\
(\mathrm{n}=602)\end{array}$} \\
Tipo Biológico & $\mathrm{n}$ & $\%$ & $\mathrm{n}$ & $\%$ & $\mathrm{n}$ & $\%$ \\
\hline Herbáceo anual & 109 & 21 & 69 & 81 & 178 & 30 \\
Herbáceo perenne & 264 & 51 & 12 & 14 & 276 & 46 \\
Arbustivo & 113 & 22 & 1 & 1 & 114 & 19 \\
Arbóreo & 31 & 6 & 3 & 4 & 34 & 5 \\
\hline
\end{tabular}

ESPECIES EN CATEGORÍA DE CONSERVACIÓN

De acuerdo a las referencias bibliográficas consultadas, en el área de estudio existen 14 especies propuestas en alguna categoría de conservación (Tabla IV). De éstas, sólo tres han sido evaluadas de manera oficial por el Comité de Clasificación de la Comisión Nacional de Medio Ambiente (CONAMA), y otras cuatro fueron incluidas en Benoit (1989), cuyas propuestas también son consideradas oficiales para efectos de la Ley del Bosque Nativo (Ley No 20.283/2008 del MINAGRI, Artículo Transitorio $2^{\circ}$ ). De las tres especies propuestas como "en peligro", la más crítica a nivel local es la bulbosa Rhodophiala tiltilensis (Traub \& Moldenke) Traub, puesto que se han registrado escasos grupos poblacionales con muy pocos individuos cada uno y están ubicados bajo los $1.000 \mathrm{~m}$ de altitud, en la zona más propensa a ser intervenida.
ENDEMISMOS ESTRECHOS Y LÍMITES DE DISTRIBUCIÓN Se ha registrado nueve especies con distribución restringida a la cordillera de la Costa de Chile central (Tabla V). Adesmia trifoliata Phil. y Alstroemeria zoellneri Bayer están presentes en los tres grandes sistemas montañosos de la cordillera de la Costa (i.e. cordillera del Melón, sistema Aconcagua-Maipo, Altos de Cantillana; sensu García 2006), mientras que seis taxones son exclusivos del sistema Aconcagua-Maipo de la cordillera costera. La presencia de Oxalis campanensis Lourteig y Senecio pseuderucoides Cabrera en Altos de Chicauma constituye la segunda localidad conocida para estas especies (Cabrera 1949, Lourteig 2000). Cabe destacar que estas nueve especies se presentan en el área de estudio sólo en los ámbitos caducifolio y/o altomontano. 
Gayana Bot. 67(1), 2010

TABLA IV. Especies en categorías de conservación de la flora de Altos de Chicauma.

TABLE IV. Threatened species of the flora of Altos de Chicauma.

\begin{tabular}{llll}
\hline EsPECIE & FAMILIA & EstADO DE CONSERVACIÓN & NiVEL GEOGRÁFICO \\
\hline Adesmia resinosa & Fabaceae & Rara (3) & Nacional \\
Adiantum gertrudis & Adiantaceae & En peligro (4) & Nacional \\
Alstroemeria zoellneri & Alstroemeriaceae & Rara (5) & Nacional \\
Blechnum chilense & Blechnaceae & Insuficientemente conocida (4) & Regional \\
Cryptocarya alba & Lauraceae & Vulnerable (3) & Regional \\
Haplopappus taeda & Asteraceae & Vulnerable (1) & Nacional \\
Kageneckia angustifolia & Rosaceae & Vulnerable (3) & Nacional \\
Laretia acaulis & Apiaceae & Fuera de peligro (2), Vulnerable (3) & Nacional \\
Nothofagus macrocarpa & Nothofagaceae & Vulnerable (3) & Regional \\
Pellaea myrtillifolia & Adiantaceae & Rara (4) & Nacional \\
Placea germainii & Amaryllidaceae & Rara (5) & Nacional \\
Porlieria chilensis & Zygophyllaceae & Vulnerable (2,3) & Nacional \\
Rhodophiala tiltilensis & Amaryllidaceae & En peligro (5) & Nacional \\
Speea humilis & Alliaceae & En peligro (5) & Nacional \\
\hline
\end{tabular}

(1) D.S. No 50/2008 del Minsegpres, (2) D.S. No 51/2008 del Minsegpres, (3) Benoit 1989, (4) Baeza et al. 1998, (5) Ravenna et al. 1998.

Tabla V. Taxones endémicos de la cordillera de la Costa de Chile central en la flora de Altos de Chicauma.

TABLE V. Central Chile's Coastal Mountain Range endemic taxa in the flora of Altos de Chicauma.

\begin{tabular}{|c|c|c|}
\hline TAXÓN & FAMILIA & DistRIBUCIÓN \\
\hline Adesmia resinosa & Fabaceae & Sistema Aconcagua-Maipo \\
\hline Adesmia trifoliata & Fabaceae & $\begin{array}{l}\text { Cordillera del Melón, Sistema Aconcagua-Maipo, Altos de } \\
\text { Cantillana }\end{array}$ \\
\hline Alstroemeria zoellneri & Alstroemeriaceae & Cordillera del Melón, Aconcagua-Maipo, Altos de Cantillana \\
\hline Calceolaria ascendens subsp. exigua & Calceolariaceae & Cordillera del Melón, Sistema Aconcagua-Maipo \\
\hline Calceolaria campanae & Calceolariaceae & Sistema Aconcagua-Maipo \\
\hline Oxalis campanensis & Oxalidaceae & Sistema Aconcagua-Maipo \\
\hline Placea germainii & Amaryllidaceae & Sistema Aconcagua-Maipo, Altos de Cantillana \\
\hline Pyrrhocactus engleri & Cactaceae & Sistema Aconcagua-Maipo, Altos de Cantillana \\
\hline Senecio pseuderucoides & Asteraceae & Sistema Aconcagua-Maipo \\
\hline
\end{tabular}


Por otro lado, hay 13 especies cuya distribución está restringida a las regiones de Valparaíso y Metropolitana de Santiago, que también están presentes en la cordillera de los Andes y/o en cordones montañosos transversales (Tabla VI). Se destaca siete taxones endémicos de la Región Metropolitana, incluyendo a Senecio pseuderucoides (Tabla V), que es endémico de la cordillera de la Costa de dicha Región.

Sólo cinco especies encuentran un límite distribucional en la localidad de Altos de Chicauma, dos con límite sur y tres con límite norte (Tabla VII).
RIQUEZA Y COMPOSICIÓN POR HÁBITAT

En la Tabla VIII se presenta un resumen de la riqueza y proporción de orígenes, y riqueza total por tipo de hábitat. Se destaca que el hábitat esclerofilo de valle aparece como el más rico, no obstante un $25 \%$ de su flora está constituida por especies alóctonas. Respecto a la importancia relativa de especies alóctonas, le siguen los ambientes hídricos altomontanos con 20 especies introducidas que constituyen $17 \%$ de la flora registrada para ese hábitat. Ambos hábitats constituyen los más influenciados por la actividad ganadera en el área de estudio, la que actualmente es marginal, pero que fue más importante en el siglo pasado. En cambio, el hábitat con menor cantidad e importancia relativa de especies alóctonas es el caducifolio, donde se registró sólo dos especies introducidas.

Tabla VI. Taxones endémicos de las cordilleras de las regiones de Valparaíso y Metropolitana de Santiago en la flora de Altos de Chicauma.

TABLE VI. Metropolitan and Valparaíso regions' mountain endemic taxa in the flora of Altos de Chicauma.

\begin{tabular}{lll}
\hline ESPECIE & FAMILIA & REGIÓN(Es) \\
\hline Aphanes looseri & Rosaceae & Metropolitana \\
Calceolaria densifolia subsp. laxa & Calceolariaceae & Metropolitana, Valparaíso \\
Calceolaria purpurea & Calceolariaceae & Metropolitana, Valparaíso \\
Conyza bustillosiana & Asteraceae & Metropolitana \\
Gamochaeta oligantha & Asteraceae & Metropolitana, Valparaíso \\
Haplopappus ochagavianus & Asteraceae & Metropolitana, Valparaíso \\
Phycella angustifolia & Amaryllidaceae & Metropolitana \\
Poa acinaciphylla & Poaceae & Metropolitana \\
Polygonum bowenkampii & Polygonaceae & Metropolitana \\
Ribes nubigenum & Grossulariaceae & Metropolitana, Valparaíso \\
Senecio davilae & Asteraceae & Metropolitana, Valparaíso \\
Tristagma leichtlinii & Alliaceae & Metropolitana, Valparaíso \\
Viola germainii & Violaceae & Metropolitana \\
\hline
\end{tabular}

TABLA VII. Especies con límite distribucional en Altos de Chicauma.

TABLE VII. Species with distributional limit in Altos de Chicauma.

\begin{tabular}{lll}
\hline ESPECIE & FAMILIA & TIPO DE LÍMITE \\
\hline Bridgesia incisifolia & Sapindaceae & Sur \\
Corrigiola crassifolia & Caryophyllaceae & Sur \\
Nassella juncea & Poaceae & Norte \\
Schinus patagonica & Anacardiaceae & Norte \\
Senecio gayanus & Asteraceae & Norte \\
\hline
\end{tabular}


Gayana Bot. 67(1), 2010

TABLA VIII. Riqueza de taxones y composición de orígenes por tipo de hábitat para la flora total de Altos de Chicauma. EC: endémico de Chile; ES: endémico del Cono Sur; AU: autóctono; AL: alóctono.

TABLE VIII. Taxa richness and origin composition per habitat-type for the total flora of Altos de Chicauma. EC: Chile endemics; ES: Southern Cone endemics; AU: autochtonous taxa; AL: alien taxa.

\begin{tabular}{|c|c|c|c|c|c|c|c|c|c|c|c|c|c|c|}
\hline \multirow[b]{2}{*}{ ORIGEN } & \multicolumn{2}{|c|}{$\begin{array}{l}\text { ESCLEROFILO DE } \\
\text { VALLE } \\
(\mathrm{n}=262)\end{array}$} & \multicolumn{2}{|c|}{$\begin{array}{l}\text { ESCLEROFILO } \\
\text { MONTANO } \\
(\mathrm{n}=135)\end{array}$} & \multicolumn{2}{|c|}{$\begin{array}{l}\text { QUEBRADAS } \\
(\mathrm{n}=112)\end{array}$} & \multicolumn{2}{|c|}{$\begin{array}{l}\text { XÉRICO } \\
(\mathrm{n}=88)\end{array}$} & \multicolumn{2}{|c|}{$\begin{array}{l}\text { CADUCIFOLIO } \\
(\mathrm{n}=100)\end{array}$} & \multicolumn{2}{|c|}{$\begin{array}{l}\text { AltOMONTANO } \\
(\mathrm{n}=207)\end{array}$} & \multicolumn{2}{|c|}{$\begin{array}{l}\text { AMB. HÍDRICOS } \\
\text { ALTOMONTANOS } \\
(\mathrm{n}=115)\end{array}$} \\
\hline & $\mathrm{n}$ & $\%$ & $\mathrm{n}$ & $\%$ & $\mathrm{n}$ & $\%$ & $\mathrm{n}$ & $\%$ & $\mathrm{n}$ & $\%$ & $\mathrm{n}$ & $\%$ & $\mathrm{n}$ & $\%$ \\
\hline $\mathrm{EC}$ & 111 & 42 & 77 & 57 & 46 & 41 & 51 & 58 & 47 & 47 & 71 & 34 & 15 & 13 \\
\hline ES & 37 & 14 & 33 & 24 & 24 & 21 & 12 & 14 & 34 & 34 & 89 & 43 & 34 & 30 \\
\hline $\mathrm{AU}$ & 49 & 19 & 19 & 14 & 28 & 25 & 15 & 17 & 17 & 17 & 34 & 17 & 46 & 40 \\
\hline $\mathrm{AL}$ & 65 & 25 & 6 & 5 & 14 & 13 & 10 & 11 & 2 & 2 & 13 & 6 & 20 & 17 \\
\hline
\end{tabular}

En la Figura 2 se muestra la representatividad de orígenes para cada tipo de hábitat, considerando sólo la flora nativa. Destaca la alta participación de especies endémicas de Chile, que supera el $55 \%$ en los ámbitos esclerofilo de valle, esclerofilo montano y xérico, mientras que en los hábitats de quebradas y caducifolio disminuye al $47 \%$ y $48 \%$, respectivamente. Sólo en los ámbitos altomontano y de ambientes hídricos altomontanos se observa que los taxones endémicos de Chile no son predominantes: en el primero su participación alcanza un $37 \%$ y las especies endémicas del Cono Sur se alzan hasta $46 \%$; mientras que en el segundo presentan su valor más bajo $(16 \%)$ y son superadas por las especies de distribución más amplia en Sudamérica, que representan el $48 \%$ de la flora nativa de dicho hábitat. No obstante, la suma de los taxones endémicos de Chile y los endémicos del Cono Sur siempre es superior a la participación de aquellos autóctonos no-endémicos, aunque casi se equiparan en el espectro del hábitat de ambientes hídricos altomontanos.

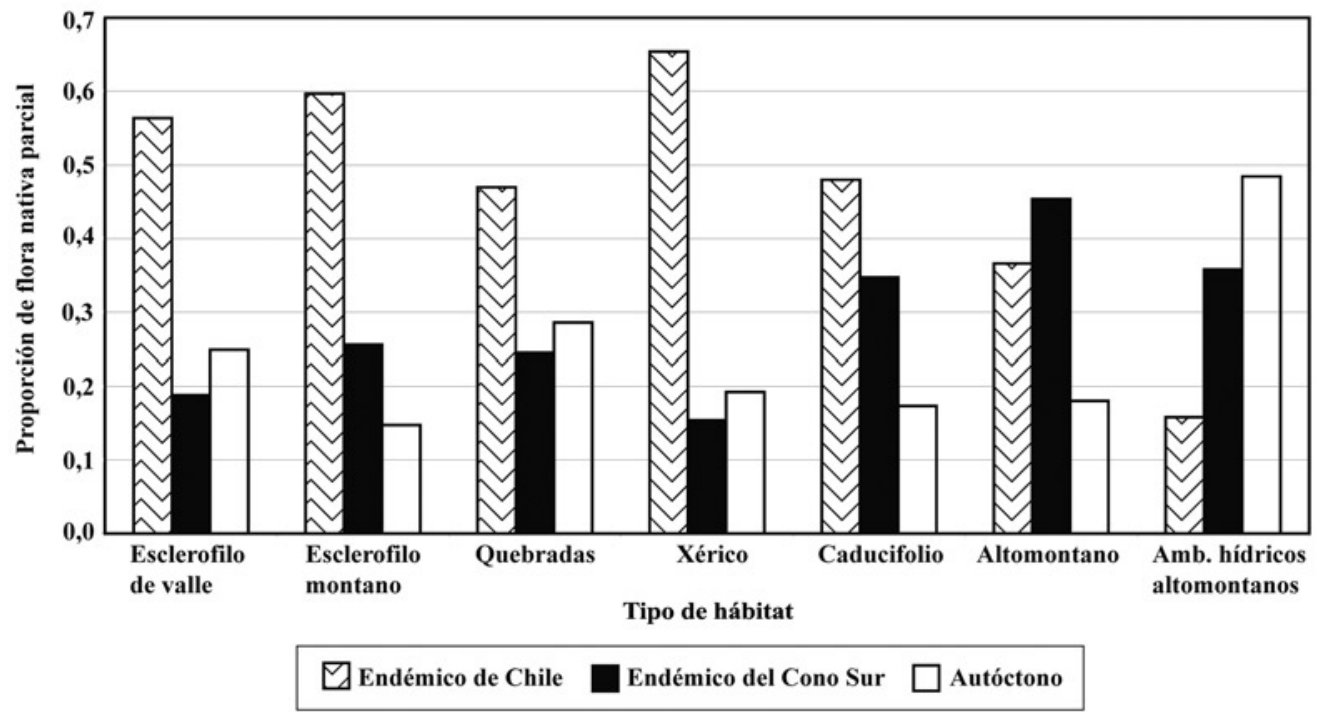

Figura 2. Composición de orígenes por tipo de hábitat para la flora nativa de Altos de Chicauma.

FIGURE 2. Origin composition per habitat type for the native flora of Altos de Chicauma. 
$\mathrm{Al}$ analizar la riqueza de especies nativas por tipo de hábitat, se advierte que las riquezas de los ámbitos esclerofilo de valle (197 taxones) y altomontano (194 taxones) son muy similares y las más altas, mientras que el hábitat xérico es aquel donde se registró una menor cantidad de especies nativas (78 taxones). En la Tabla IX se presentan los valores registrados de riqueza de taxones nativos por forma de vida general para cada hábitat y en la Figura 3 se representan los espectros de forma de vida para la flora nativa parcial de cada hábitat. Las hierbas perennes constituyen el tipo biológico dominante en todos los hábitats, su participación fluctúa desde $41 \%$ en el xérico hasta $57 \%$ en los ambientes hídricos altomontanos. Respecto a la flora anual nativa se aprecia que es más rica en el hábitat esclerofilo de valle (56 taxones), donde representa un $28 \%$, pero adquiere un nivel relativo de participación aún mayor en los ambientes xérico (32\%) e hídrico altomontano (37\%). El tipo biológico arbustivo parece más relevante en el hábitat esclerofilo montano, donde representa un $34 \%$ con 44 especies; le sigue el ámbito altomontano, que presenta la mayor riqueza de arbustos con 57 especies que representan el $30 \%$ de la flora nativa de este hábitat. El espectro de ambientes hídricos altomontanos está constituido en un $92 \%$ por hierbas anuales o perennes, mientras que los arbustos y árboles están representados por sólo seis y dos especies, respectivamente. Por último, los árboles o arbustos arborescentes presentan su mayor riqueza y grado de participación en la flora nativa de quebradas, donde se ha registrado 19 especies que representan $19 \%$ de dicha flora.

TABLA IX. Riqueza de taxones por tipo biológico y tipo de hábitat para la flora nativa de Altos de Chicauma.

TABLE IX. Taxa richness per biologic-type and habitat-type for the native flora of Altos de Chicauma.

\begin{tabular}{|c|c|c|c|c|c|c|c|}
\hline & $\begin{array}{c}\text { ESCLEROFILO DE } \\
\text { VALLE } \\
(\mathrm{n}=197)\end{array}$ & $\begin{array}{c}\text { ESCLEROFILO } \\
\text { MONTANO } \\
(\mathrm{n}=129)\end{array}$ & $\begin{array}{l}\text { QuebraDAS } \\
(\mathrm{n}=98)\end{array}$ & $\begin{array}{l}\text { XÉRICO } \\
(\mathrm{n}=78)\end{array}$ & $\begin{array}{l}\text { CAducifolio } \\
(\mathrm{n}=98)\end{array}$ & $\begin{array}{l}\text { Altomontano } \\
\quad(\mathrm{n}=194)\end{array}$ & $\begin{array}{l}\text { AMB. HÍDRICOS } \\
\text { ALTOMONTANOS } \\
\quad(\mathrm{n}=95)\end{array}$ \\
\hline TIPO BIOLÓGICO & $\mathrm{n}$ & $\mathrm{n}$ & $\mathrm{n}$ & $\mathrm{n}$ & $\mathrm{n}$ & $\mathrm{n}$ & $\mathrm{n}$ \\
\hline Herbáceo anual & 56 & 13 & 12 & 25 & 9 & 26 & 35 \\
\hline Herbáceo perenne & 94 & 58 & 47 & 32 & 53 & 103 & 52 \\
\hline Arbustivo & 34 & 44 & 20 & 16 & 26 & 57 & 6 \\
\hline Arbóreo & 13 & 14 & 19 & 5 & 10 & 8 & 2 \\
\hline
\end{tabular}

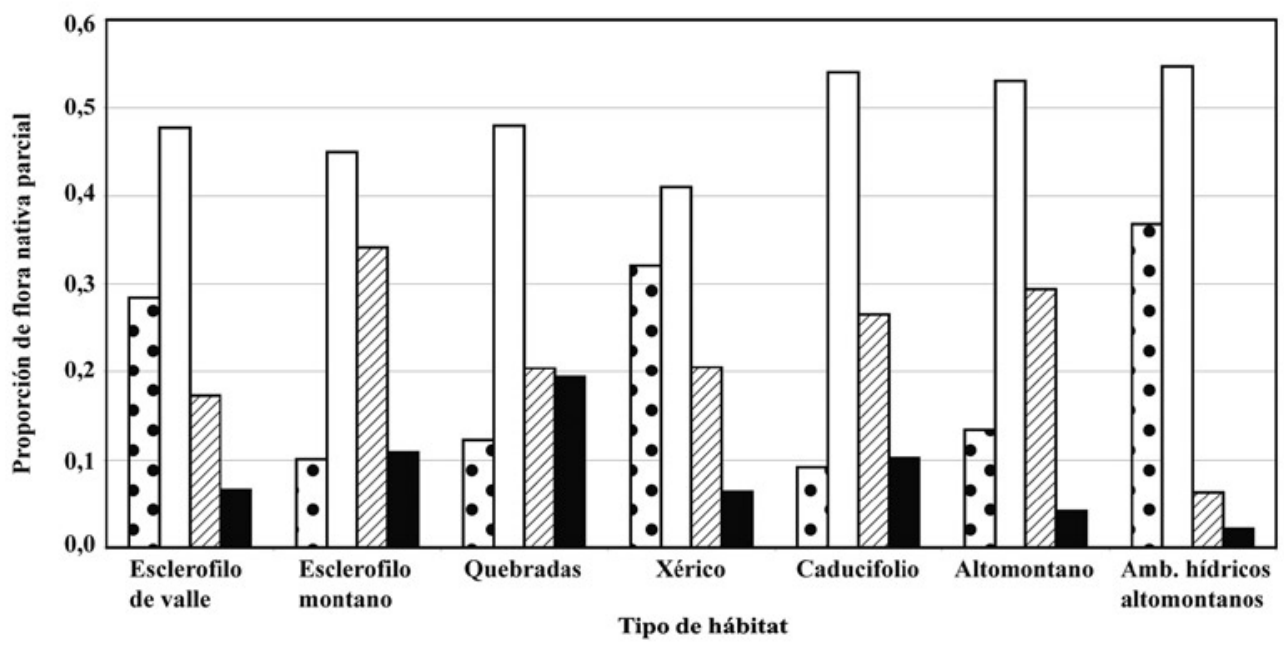

$\square$ Herbáceo anual $\square$ Herbáceo perenne $\square$ Arbustivo $\square$ Arbóreo

Figura 3. Composición de tipos biológicos por tipo de hábitat para la flora nativa de Altos de Chicauma.

FIGURE 3. Biologic-types composition per habitat-type for the native flora of Altos de Chicauma. 
Similitud ENTRE TIPOS DE HÁBITATS

Al observar el dendrograma obtenido a partir del análisis de conglomerados efectuado con la flora nativa de cada tipo de hábitat (Fig. 4), se advierte la formación de dos grupos bien marcados: por un lado los hábitats de quebradas y de ambientes hídricos altomontanos, y por el otro, los cinco tipos de hábitats restantes. Esta agrupación resulta lógica cuando se considera que el primer grupo está integrado por los hábitats azonales o intrazonales, mientras que el otro lo componen aquéllos de carácter zonal. Sin embargo, la similitud entre ambos hábitats azonales es muy baja $(S=0,358)$ y presentan una diferencia estadística muy significativa. Las unidades de flora que son significativamente distintas al resto son los hábitats xérico, de quebradas y de ambientes hídricos altomontanos $(p<0,01)$. También son significativamente distintos los conglomerados formados por los ámbitos esclerofilo de valle y esclerofilo montano, y aquel compuesto por los hábitats caducifolio y altomontano; sin embargo, las similitudes entre ambos pares no son distinguibles de lo esperado por el azar (i.e. no son significativamente diferentes ni significativamente similares).

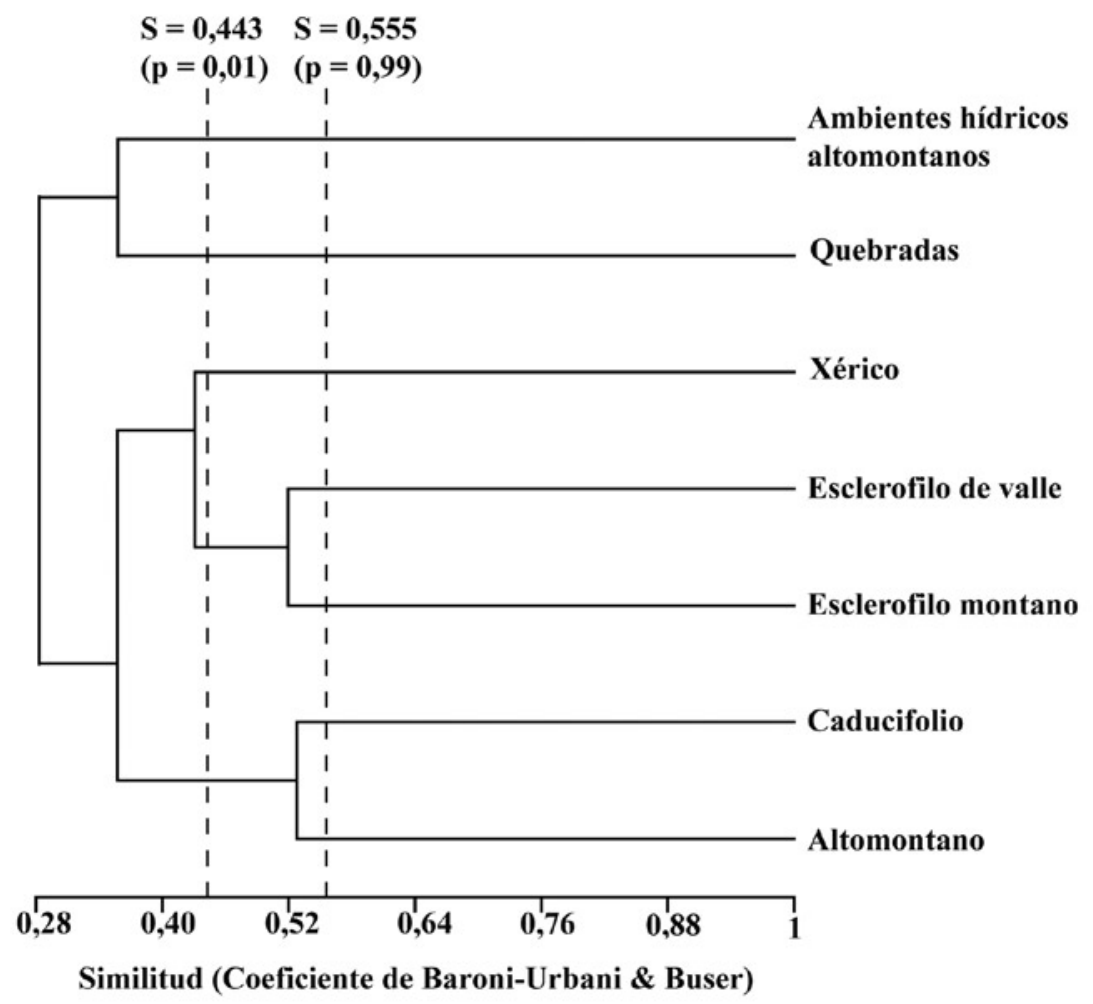

FIgURA 4. Dendrograma de similitud (coeficiente de Baroni-Urbani \& Buser) entre tipos de hábitats de Altos de Chicauma considerando sólo la flora nativa.

FIGURE 4. Similarity dendrogram (Baroni-Urbani \& Buser coefficient) of Altos de Chicauma's habitat-types considering only the native flora.

\section{DISCUSIÓN}

La riqueza general de 517 taxones nativos registrados en 8.000 ha evaluadas en la localidad de Altos de Chicauma es comparable a la flora nativa de otras localidades de Chile central con una amplitud ambiental equivalente, como el Parque Nacional La Campana con 545 especies en 8.000 ha (valor incluye especies alóctonas, F. Luebert com.pers.; Hoffmann \& Herrera-MacBryde 1997); Reserva Nacional Río Clarillo con 480 especies aproximadas en 13.000 ha (Teillier et al. 2005); Santuario de la Naturaleza Yerba Loca con 500 taxones en 10.500 ha (Arroyo et al. 2002); y Altos de Cantillana con 580 especies en 200.000 ha (Universidad de Chile 2007). Los taxones restringidos a Chile en la flora vascular nativa del área de estudio corresponden a $48 \%$ y equivalen a lo registrado en localidades andinas de Chile central, donde este valor fluctúa entre 35 y $50 \%$ (Arroyo et al. 2002; Teillier et al. 2005). Los valores observados de riqueza, endemismo y espectro de tipos biológicos en la flora vascular local podrían estar reflejando el pool regional de especies de Chile mediterráneo (Cowling et al. 1996, Caley \& Schluter 1997).

Se ha mencionado que las regiones Metropolitana y de Valparaíso son las más diversas de Chile en cuanto a flora 
vascular, tanto a nivel específico como genérico (Zuloaga et al. 2008a); sin embargo, esta zona es de las menos representadas en el Sistema Nacional de Áreas Silvestres Protegidas de Estado (SNASPE), puesto que la mayor parte de los territorios naturales de Chile central son de propiedad privada y ésta es el área más poblada del país (Armesto et al. 1992, Luebert \& Becerra 1998, Arroyo et al. 2002, Luebert \& Pliscoff 2006). Con estos antecedentes se pretende destacar el alto valor de conservación para la naturaleza que tienen las serranías montañosas de Chile central, en general, y en particular, los tres grandes sistemas montañosos de la cordillera de la Costa (sensu García 2006), los que todavía constituyen ambientes naturales en su mayoría.

Se destaca que el presente trabajo constituye una caracterización de la flora a nivel local y que los resultados obtenidos no pueden ser extrapolables a todo Chile central o a un nivel regional. No obstante, la localidad estudiada contiene una buena representación de las comunidades vegetales presentes en la cordillera de la Costa de Chile central, así como la convergencia entre comunidades de distribución más amplia y comunidades relictuales (e.g. bosque deciduo de Nothofagus, matorral de Adesmia resinosa, matorral altomontano costero), por lo que resulta de especial interés para considerarse en el estudio de la geobotánica de Chile central.

La mayor riqueza de especies registrada en los hábitats esclerofilo de valle y altomontano se podría deber a una mayor superficie local de éstos respecto al resto, a una mayor heterogeneidad ambiental, o a una combinación de ambos factores. Cabe destacar que estos ambientes han sido los más intensamente muestreados en el área de estudio, lo que también podría estar influyendo los resultados obtenidos. Al respecto, los hábitats esclerofilo montano, xérico y caducifolio son los menos muestreados en relación a su superficie local, por lo que deberían concentrar los esfuerzos al momento de complementar la lista de la flora vascular de Altos de Chicauma y la composición de sus hábitats. Un aspecto pendiente por estudiar respecto a la definición de hábitats de flora en Chile central, es la singularidad de las comunidades que se desarrollan en ambientes de roqueríos o rupícolas, que podrían constituir un tipo de hábitat individualizado por una composición particular de especies.

Cabe destacar que las especies restringidas a Chile pierden preponderancia hacia los hábitats ubicados a mayor altitud (i.e. altomontano y ambientes hídricos altomontanos), lo que se explica por la presencia de varias especies de distribución andina compartidas entre Chile y Argentina o de distribución andina amplia (Arroyo et al. 2002, Muñoz et al. 2000). Por otro lado, en este trabajo se pone de relevancia al grupo de especies endémicas del Cono Sur, las que representan un $77 \%$ de la flora nativa total y son preponderantes en la flora nativa de todos los hábitats estudiados en Chicauma. Este último grupo está conformado principalmente por especies distribuidas sólo en Chile o en la cordillera de los Andes y/o Patagonia de Chile y Argentina.

El estudio de la fitogeografía de Chile central en la actualidad está obstaculizado por la falta de un mayor número de recolecciones botánicas sistemáticas y revisiones taxonómicas críticas de algunos géneros presentes en esta zona. En este estudio, resultó de gran dificultad la determinación específica para varios géneros que están poco estudiados en Chile central, entre los que sobresalen Poa (Poaceae), Carex (Cyperaceae), Eleocharis (Cyperaceae), Conyza (Asteraceae), Gamochaeta (Asteraceae) y Gnaphalium (Asteraceae). Resulta destacable la presencia de una reciente rehabilitación taxonómica en el área de estudio (i.e. Calceolaria ascendens subsp. exigua; García 2010) y de varios taxones de determinación específica incierta, algunos de los que podrían revelarse como novedosos para la ciencia con un estudio más profundo (e.g. Haplopappus aff. decurrens J. Remy, Centaurium sp., Adesmia sp.).

Con el estudio de la flora vascular de Altos de Chicauma, se advirtió la existencia en la flora de Chile central de algunos grupos poco comprendidos o con controversias sistemáticas vigentes en todos los niveles taxonómicos. Se puede señalar el caso de algunos helechos, que constituyen un grupo con un tratamiento taxonómico reciente para Chile (Rodríguez 1995). Por ejemplo, Adiantum chilense Kaulf. var. hirsutum Hook. \& Grev. es tratado en trabajos de Argentina como A. thalictroides Willd. ex Schltdl. var. hirsutum (Hook. \& Grev.) de la Sota, mientras que los taxones A. scabrum Kaulf. y A. sulphureum Kaulf. son tratados como variedades de $A$. chilense (Sota 1972, Giúdice 1999, Ponce et al. 2008). Se aprecian otros ejemplos en la familia Adiantaceae que es tratada como parte de Pteridaceae (e.g. Giúdice 1999, Ponce et al. 2008), o en el caso de Blechnum chilense (Kaulf.) Mett. que es referido reiteradamente como sinónimo de Blechnum cordatum (Desv.) Hieron. (e.g. Ponce et al. 2008), con el que de todos modos conforma un complejo de taxones que requieren de una revisión (Tryon \& Stolze 1993). Incluso se aprecian problemas en grupos arbóreos como el género Schinus, que pese a contar con un tratamiento taxonómico vigente (Barkley 1957) requiere de una revisión crítica de ciertos complejos de especies, como aquéllos conformados por S. latifolia (Gillies ex Lindl.) Engl. - S. velutina (Turcz.) I.M.Johnst. y S. montana (Phil.) Engl. $-S$. patagonica (Phil.) I.M.Johnst. - S. kauselii F.A.Barkley (ver comentarios en Lista de la Flora).

Las deficiencias o controversias en la definición de especies o en el tratamiento de ciertos grupos taxonómicos, sumado a la escasez de información de distribución de los taxones y de una mayor cobertura de catastros locales de flora, implican una seria dificultad para la comprensión 
de los elementos fitogeográficos e historia de la flora vascular de Chile central. Por ende, resulta imperativo el fomento de más estudios florísticos de campo y revisiones taxonómicas críticas de algunos géneros, lo que tendría implicancias positivas tanto para la valoración biológica de la naturaleza de Chile central como para la elaboración de estrategias de conservación de la diversidad biológica y evaluación del estado de conservación de nuestra flora.

\section{LISTA DE LA FLORA VASCULAR DE ALTOS DE CHICAUMA}

\section{Equisetales \\ EquiseTACEAE \\ Equisetum bogotense Kunth}

Hierba perenne, autóctona. Muy frecuente en quebradas entre 500 y 1.500 m s.m. Exs.: N. García 3203 (CONC).

\section{Polypodiales \\ Adiantaceae}

Adiantum chilense Kaulf. var. chilense

Hierba perenne, endémica del Cono Sur. Muy frecuente en el hábitat esclerofilo de valle, pero muy escasa en roqueríos del sector altomontano, entre 700 y 2.100 m s.m. Exs.: N. García 3133 (CONC).

Adiantum chilense Kaulf. var. hirsutum Hook. \& Grev. Hierba perenne, autóctona. Frecuente en los hábitats esclerofilo de valle y esclerofilo montano, entre 900 y $1.500 \mathrm{~m}$ s.m. No recolectada.

\section{Adiantum excisum Kunze}

Hierba perenne, endémica de Chile. Frecuente en quebradas de la zona baja y sectores húmedos del bosque esclerofilo de valle, entre 700 y1.200 m s.m. Exs.: N. García 3140(CONC).

\section{Adiantum gertrudis Espinosa}

Hierba perenne, endémica de Chile. Frecuente en quebradas de la zona baja y sectores húmedos del bosque esclerofilo de valle, entre 700 y 1.200 m s.m. Probablemente forma parte del complejo $A$. chilense-A. scabrum-A. sulphureum$A$. thalictroides, por lo que su validez como especie podría ser evaluada con un estudio taxonómico crítico de dicho grupo (ver Discusión). Exs.: N. García 3137, 3394 (CONC).

\section{Adiantum scabrum Kaulf.}

Hierba perenne, endémica del Cono Sur. Frecuente en los hábitats esclerofilo de valle y xérico, pero escasa en roqueríos de la zona altomontana, entre 700 y $2.000 \mathrm{~m} \mathrm{s.m.}$ Exs.: N. García 3152 (CONC).

\section{Adiantum sulphureum Kaulf.}

Hierba perenne, endémica del Cono Sur. Frecuente en quebradas y sectores húmedos del bosque esclerofilo de valle, entre 700 y 1.200 m s.m. Exs.: N. García 3154 (CONC).

\section{Adiantum philippianum Espinosa}

Hierba perenne, endémica de Chile. Frecuente en roqueríos del bosque caducifolio y zona altomontana, entre 1.700 y $2.100 \mathrm{~m}$ s.m. Este taxón ha sido mencionado para la flora de Santiago por Navas (1973) como Adiantum scabrum Kaulf. var. philippianum (Espinosa) Looser, sin embargo fue pasado a la sinonimia de $A$. scabrum (Rodríguez 1995). Es muy similar a este taxón, del cual se diferencia por los glomérulos estipitados de color amarillo, no blancos como en A. scabrum (Espinosa 1936, Looser 1940, Navas 1973). Acá se trata al nivel específico en vista que la taxonomía del complejo $A$. chilense-A. scabrum-A. sulphureum-A. thalictroides no está bien resuelta (ver Discusión). Exs.: N. García 3527, 3790 (CONC).

Cheilanthes glauca (Cav.) Mett. Hierba perenne, endémica del Cono Sur. Frecuente en roqueríos de los hábitats xérico, esclerofilo montano y caducifolio, pero muy escasa en la zona altomontana, entre 800 y 2.000 m s.m. Exs.: N. García 3525 (CONC).

Cheilanthes hypoleuca (Kunze) Mett.

Hierba perenne, endémica del Cono Sur. Frecuente en roqueríos de los hábitats xérico y esclerofilo de valle, entre 700 y 1.200 m s.m. Exs.: N. García 3136 (CONC).

Pellaea myrtillifolia Mett. ex Kuhn

Hierba perenne, endémica de Chile. Poco frecuente en roqueríos sombríos del hábitat esclerofilo montano, entre 1.200 y 1.500 m s.m. Exs.: F. Díaz s.n. (CONC 169330).

\section{Blechnum chilense (Kaulf.) Mett.}

Subarbusto, autóctono. Muy poco frecuente en el área de estudio, se ha registrado en sectores muy húmedos de pocas quebradas, alrededor de $1.000 \mathrm{~m} \mathrm{s.m.} \mathrm{No} \mathrm{recolectada.}$

\section{Blechnum hastatum Kaulf.}

Hierba perenne, endémica del Cono Sur. Muy frecuente en quebradas boscosas entre 700 y 1.200 m s.m. Exs.: N. García 3214 (CONC).

Blechnum microphyllum (Goldm.) C.V.Morton Hierba perenne, endémica del Cono Sur. Poco frecuente en sectores rocosos y sombríos de la zona altomontana, entre 2.100 y 2.200 m s.m. Exs.: N. García 3731 (CONC). 


\section{DRYOPTERIDACEAE}

Cystopteris fragilis (L.) Bernh.

Hierba perenne, autóctona. Poco frecuente en los hábitats de quebradas boscosas, esclerofilo de valle y caducifolio, muy escasa en roqueríos sombríos de la zona altomontana, entre 800 y $2.000 \mathrm{~m}$ s.m. Exs.: N. García 3242 (CONC).

Polystichum plicatum (Poepp. ex Kunze) Hicken Hierba perenne, endémica del Cono Sur. Poco frecuente en roqueríos sombríos de la zona altomontana a $2.100 \mathrm{~m} \mathrm{s.m}$. Exs.: N. García 3684 (CONC).

\section{THELYPTERIDACEAE}

Thelypteris argentina (Hieron.) Abbiatti

Hierba perenne, autóctona. Muy poco frecuente en quebradas boscosas entre 900 y 1.100 m s.m. Exs.: N. García 4292 (CONC).

\section{Gnetales}

EPHEDRACEAE

\section{Ephedra chilensis C.Presl}

Arbusto, endémico del Cono Sur. Muy frecuente en los hábitats esclerofilo de valle, esclerofilo montano y altomontano, entre 1.000 y 2.200 m s.m. Exs.: N. García 3167 (CONC).

\section{Canellales}

WinTERACEAE

Drimys winteri J.R.Forst. \& G.Forst. var. chilensis (DC.) A.Gray

Árbol o arbusto arborescente, endémico de Chile. Frecuente en quebradas boscosas entre 700 y $1.500 \mathrm{~m}$ s.m. Exs.: N. García 3199 (CONC).

\section{Laurales \\ LAURACEAE}

Cryptocarya alba (Molina) Looser

Árbol o arbusto arborescente, endémico de Chile. Muy frecuente, dominante en bosques de quebradas y sectores más húmedos de los hábitats esclerofilo de valle $\mathrm{y}$ esclerofilo montano; también presente en zona baja de los bosques caducifolios. Desde 500 hasta alrededor de 1.500 m s.m. Exs.: N. García 3304, 3398 (CONC).

\section{Peumus boldus Molina}

\section{MONIMIACEAE}

Árbol o arbusto arborescente, endémico de Chile. Muy poco frecuente, se ha registrado pocos ejemplares en la quebrada del Cepo, a 800 m s.m. Exs.: N. García 4293 (CONC, EIF).
Dioscoreales

Dioscoreaceae

Dioscorea humifusa Poepp.

Enredadera, endémica de Chile. Frecuente en los hábitats esclerofilo de valle y xérico, entre 700 y $1.200 \mathrm{~m}$ s.m. Exs.: N. García 3163, 3198 (CONC).

Dioscorea humile Colla

Hierba perenne, endémica de Chile. Poco frecuente en quebradas $\mathrm{y}$ sectores húmedos del bosque esclerofilo de valle, entre 700 y 1.000 m s.m. Exs.: N. García 3314 (CONC).

\section{Dioscorea pedicellata Phil.}

Enredadera, endémica de Chile. Poco frecuente en los hábitats esclerofilo de valle y caducifolio, entre $800 \mathrm{y}$ 1.500 m s.m. Exs.: N. García 3220, 3490 (CONC).

Dioscorea saxatilis Poepp.

Enredadera, endémica de Chile. Frecuente en los hábitats esclerofilo de valle y xérico, entre 700 y 1.000 m s.m. Exs.: N. García 3156, 3340 (CONC).

\section{Dioscorea variifolia Bertero ex Colla}

Enredadera, endémica de Chile. Muy poco frecuente en el bosque esclerofilo de valle a $700 \mathrm{~m}$ s.m. Exs.: N. García 3317 (CONC).

\section{Liliales \\ Alstroemeriaceae \\ Alstroemeria angustifolia Herb.}

Hierba perenne, endémica de Chile. Poco frecuente en los hábitats esclerofilo de valle y caducifolio, entre 800 y 1.500 m s.m. Exs.: N. García 3811 (CONC).

Alstroemeria ligtu L. subsp. simsii (Spreng.) Bayer Hierba perenne, endémica de Chile. Muy frecuente en el hábitat del bosque esclerofilo de valle entre 500 y $1.200 \mathrm{~m}$ s.m. Exs.: N. García 3585 (CONC).

\section{Alstroemeria pallida Graham}

Hierba perenne, endémica de Chile. Muy frecuente en el matorral altomontano, entre 1.800 y 2.200 m s.m. Las poblaciones costeras de esta especie se han tratado como A. garaventae Bayer (Bayer 1987, Muñoz \& Moreira 2003, Luebert et al. 2002); sin embargo, el fenotipo con todos los tépalos manchados ha sido registrado también en la cordillera andina de las provincias de Chacabuco (García 2006) y de Petorca (Novoa 2007), lo que hace probable que las variaciones en el patrón de manchas no sean lo suficientemente estables para que correspondan a especies distintas. Su validez taxonómica podría ser resuelta a través de estudios morfológicos y/o moleculares al nivel de poblaciones. Exs.: N. García 3652 (CONC). 


\section{Alstroemeria pulchra Sims}

Hierba perenne, endémica de Chile. Muy poco frecuente en el hábitat esclerofilo de valle a $900 \mathrm{~m}$ s.m. No recolectada.

Alstroemeria revoluta Ruiz \& Pav.

Hierba perenne, endémica de Chile. Muy poco frecuente, sólo se ha registrado en el matorral altomontano en el sector de Lo Amarillo, a 2.000 m s.m. Exs.: F. Díaz s.n. (CONC 169336).

\section{Alstroemeria zoellneri Bayer}

Hierba perenne, endémica de Chile. Frecuente en quebradas boscosas y, principalmente, en el bosque caducifolio. Muy poco frecuente en el matorral altomontano; entre $1.500 \mathrm{y}$ $2.000 \mathrm{~m}$ s.m. Es un endemismo de la cordillera de la Costa, donde habita desde la cordillera del Melón hasta Altos de Cantillana. Exs.: N. García 3791 (CONC).

\section{Asparagales \\ Alliaceae}

Gethyum atropurpureum Phil.

Hierba perenne, endémica de Chile. Poco frecuente en quebradas húmedas con bosque esclerofilo a $900 \mathrm{~m}$ s.m. Exs.: I.L. Escobar 125 (CONC).

Leucocoryne alliacea Lindl.

Hierba perenne, endémica de Chile. Poco frecuente en los hábitats esclerofilo de valle y caducifolio, muy escasa en el matorral altomontano, entre 900 y 2.100 m s.m. Exs.: N. García 3021, 3172, 3239, 3758 (CONC).

Leucocoryne ixioides (Hook.) Lindl.

Hierba perenne, endémica de Chile. Muy frecuente en los hábitats esclerofilo de valle, esclerofilo montano y xérico, escasa en el matorral altomontano, entre 500 y $2.100 \mathrm{~m}$ s.m. Exs.: N. García 3191, 3415, 3540, 3704, 3709, 3755 (CONC).

\section{Miersia leporina Ravenna}

Hierba perenne, endémica de Chile. Muy poco frecuente en quebradas boscosas a 700 m s.m. Exs.: N. García 3262, 3321 (CONC).

Nothoscordum cf. gracile (Dryand. ex Aiton) Stearn Hierba perenne, autóctona. Muy poco frecuente en vegas altomontanas entre 1.900 y 2.000 m s.m. Exs.: N. García 3697 (CONC).

Speea humilis (Phil.) Loes. ex Krause Hierba perenne, endémica de Chile. Frecuente en la zona alta del bosque esclerofilo de valle y en el bosque caducifolio, entre 1.000 y $1.600 \mathrm{~m}$ s.m. A partir de material proveniente de Altos de Chicauma se describió Speea triloba Ravenna
(1978), la cual se considera igual a $S$. humilis en este trabajo. No obstante, en la cuenca de Santiago y alrededores se ha observado que las poblaciones costeras de Speea presentan una corola que tiende a la zigomorfía y a la coloración purpúrea, a diferencia de las andinas, que son más actinomorfas y verdosas. Estas diferencias parecen no ser lo suficientemente constantes como para justificar la separación de un taxón andino y otro costero. Exs.: N. García 3236 (CONC).

\section{Tristagma leichtlinii (Baker) Ravenna}

Hierba perenne, endémica de Chile. Frecuente en el sector alto de los bosques caducifolios y en el matorral altomontano, entre 1.800 y 2.200 m s.m. Exs.: N. García 3018, 3524, 3725 (CONC).

\section{Tristagma sessile (Phil.) Traub}

Hierba perenne, endémica de Chile. Muy poco frecuente, sólo se ha registrado en terrenos muy húmedos alrededor del tranque, a $2.000 \mathrm{~m}$ s.m. Este taxón ha sido citado como Ipheion sessile (Phil.) Traub en Zuloaga et al. (2008a), indicando que también habita en Uruguay. El origen de esta confusión se remonta al trabajo de Guaglianone (1972) y se debe a una clara convergencia fenotípica entre el taxón chileno, que correponde al género Tristagma, y el uruguayo, cuyo nombre correcto es Ipheion recurvifolium (C.H. Wright) Traub (Crosa \& Marchesi 2002). Exs.: N. García 4169 (CONC, MVFA).

Zoellnerallium andinum (Poepp.) Crosa

Hierba perenne, endémica del Cono Sur. Frecuente en el matorral altomontano entre 1.900 y 2.200 m s.m. Exs.: N. García 3705, 3730 (CONC).

\section{Phycella angustifolia Phil}

\section{Amaryllidaceae}

Hierba perenne, endémica de Chile. Frecuente en los hábitats de quebradas boscosas, esclerofilo de valle y caducifolio, también en roqueríos húmedos altomontanos, entre 1.100 y 2.100 m s.m. Exs.: N. García 3247 (CONC).

Phycella cf. cyrtanthoides (Sims) Lindl.

Hierba perenne, endémica de Chile. Poco frecuente en sectores abiertos del bosque esclerofilo de valle entre 700 y 800 m s.m. Exs.: N. García 3186 (CONC).

\section{Phycella sp.}

Hierba perenne, endémica de Chile. Muy poco frecuente en quebradas húmedas con bosque esclerofilo a $900 \mathrm{~m} \mathrm{s.m.}$ Exs.: N. García 4165 (CONC).

Placea arzae Phil.

Hierba perenne, endémica de Chile. Poco frecuente en los hábitats esclerofilo montano y caducifolio, entre $1.300 \mathrm{y}$ 1.600 m s.m. Exs.: N. García 3542, 3552, 3560 (CONC). 
Placea germainii Phil.

Hierba perenne, endémica de Chile. Poco frecuente en el matorral altomontano entre 2.000 y $2.100 \mathrm{~m}$ s.m. Es un endemismo de la cordillera de la Costa, donde habita desde el La Campana hasta Altos de Cantillana. Exs.: N. García 619 (CONC).

Rhodolirium montanum Phil.

Hierba perenne, endémica del Cono Sur. Frecuente en el matorral altomontano entre 2.000 y $2.200 \mathrm{~m}$ s.m. Exs.: N. García 3659 (CONC).

\section{Rhodophiala andina Phil.}

Hierba perenne, endémica del Cono Sur. Poco frecuente en el matorral altomontano entre 2.000 y 2.200 m s.m. Exs.: N. García 3763 (CONC).

Rhodophiala tiltilensis (Traub \& Moldenke) Traub Hierba perenne, endémica de Chile. Muy poco frecuente en sectores abiertos del bosque esclerofilo de valle entre 800 y 1.000 m s.m. Exs.: N. García 3090, 3587 (CONC).

\section{Hemerocallidaceae}

\section{Pasithea caerulea (Ruiz \& Pav.) D.Don}

Hierba perenne, autóctona. Muy frecuente en sectores abiertos de los hábitats esclerofilo de valle, esclerofilo montano y xérico, entre 600 y 1.500 m s.m. Exs.: N. García 3277 (CONC).

\section{Hyacinthaceae \\ Ozyrö̈ arida (Poepp.) Speta}

Hierba perenne, endémica de Chile. Muy frecuente en praderas del hábitat esclerofilo de valle entre 600 y 1.000 m s.m. Exs.: N. García 3170 (CONC).

\section{IRIDACEAE}

Olsynium junceum (E.Mey. ex K.Presl) Goldblatt subsp. junceum

Hierba perenne, autóctona. Frecuente en los hábitats esclerofilo montano, caducifolio y altomontano, entre 1.200 y 2.100 m s.m. Exs.: N. García 3237 (CONC).

Olsynium philipii (Klatt) Goldblatt subsp. philippii Hierba perenne, endémica de Chile. Frecuente en los hábitats esclerofilo de valle, caducifolio y altomontano, entre 800 y 2.100 m s.m. Exs.: N. García 3528 (CONC).

Olsynium scirpoideum (Poepp.) Goldblatt subsp. scirpoideum

Hierba perenne, endémica de Chile. Frecuente en el matorral altomontano entre 1.800 y 2.200 m s.m. Exs.: N. García 3148, 3235 (CONC).

\section{Sisyrinchium adenostemon Phil.}

Hierba perenne, endémica del Cono Sur. Muy frecuente en los hábitats esclerofilo de valle, esclerofilo montano y altomontano, entre 1.100 y 2.200 m s.m. Exs.: N. García 3447, 3531, 3564, 3635 (CONC).

Sisyrinchium cuspidatum Poepp.

Hierba perenne, endémica del Cono Sur. Frecuente en los hábitats esclerofilo de valle y esclerofilo montano, entre 500 y 1.700 m s.m. Exs.: N. García 3409 (CONC).

Sisyrinchium graminifolium Lindl.

Hierba perenne, endémica del Cono Sur. Poco frecuente en praderas del hábitat esclerofilo de valle entre 500 y 1.000 m s.m. Exs.: N. García 3223 (CONC).

Sisyrinchium striatum J.E.Sm.

Hierba perenne, endémica del Cono Sur. Poco frecuente en quebradas y en roquerios altomontanos entre 700 y 2.100 m s.m. Exs.: N. García 626, 3440 (CONC).

Solenomelus pedunculatus (Gillies ex Hook.) Hochr. Hierba perenne, endémica de Chile. Muy frecuente, elemento dominante del sotobosque en los hábitats de quebradas boscosas, esclerofilo de valle y esclerofilo montano, entre 600 y 1.500 m s.m. Exs.: N. García 3392 (CONC).

Solenomelus segethii (Phil.) Kuntze

Hierba perenne, endémica del Cono Sur. Poco frecuente en el matorral altomontano entre 2.100 y 2.200 m s.m. Exs.: N. García 3724 (CONC).

\section{LAXMANIACEAE}

Trichopetalum plumosum (Ruiz \& Pav.) J.F.Macbr. Hierba perenne, endémica de Chile. Frecuente en praderas del hábitat esclerofilo de valle entre 600 y 1.000 m s.m. Exs.: N. García 3276 (CONC).

Bipinnula plumosa Lindl.

ORCHIDACEAE

Hierba perenne, endémica de Chile. Poco frecuente en el bosque caducifolio entre 1.300 y $1.500 \mathrm{~m}$ s.m. Exs.: N. García 3226, 3253 (CONC).

\section{Chloraea bletioides Lindl.}

Hierba perenne, endémica de Chile. Muy frecuente en los hábitats esclerofilo de valle y esclerofilo montano, muy escasa en el matorral altomontano, entre 600 y $2.100 \mathrm{~m}$ s.m. Exs.: N. García 3557, 3566 (CONC).

\section{Chloraea chrysantha Poepp.}

Hierba perenne, endémica de Chile. Poco frecuente en sectores abiertos del bosque esclerofilo de valle entre 900 y 1.200 m s.m. Exs.: N. García 3246, 3446 (CONC). 
Chloraea cylindrostachya Poepp.

Hierba perenne, endémica del Cono Sur. Poco frecuente en el bosque caducifolio y matorral altomontano, entre 1.200 y 2.200 m s.m. Exs.: N. García 3471, 3720 (CONC).

Chloraea galeata Lindl.

Hierba perenne, endémica de Chile. Poco frecuente en sectores abiertos del hábitat esclerofilo montano entre 1.200 y 1.700 m s.m. Exs.: N. García 3547, 3559 (CONC).

Chloraea picta Phil. ex Kraenzl.

Hierba perenne, endémica del Cono Sur. Poco frecuente en el bosque caducifolio y matorral altomontano, entre 1.500 y 2.200 m s.m. Exs.: N. García 3487, 3663 (CONC).

Gavilea venosa (Lam.) Garay \& Ormerod

Hierba perenne, endémica de Chile. Muy frecuente en sectores húmedos de los hábitats de quebradas boscosas, esclerofilo de valle y caducifolio, entre 900 y $1.500 \mathrm{~m}$ s.m. Exs.: N. García 3240, 3396 (CONC).

\section{Tecophilaeaceae}

Conanthera campanulata (D.Don) Lindl.

Hierba perenne, endémica de Chile. Muy frecuente en praderas de los hábitats esclerofilo de valle y esclerofilo montano, entre 500 y 1.500 m s.m. Exs.: N. García 3366 (CONC).

\section{Poales \\ Bromeliaceae}

\section{Puya berteroniana $\mathrm{Mez}$}

Arbusto arrosetado, endémico de Chile. Muy frecuente en sectores rocosos de los hábitats esclerofilo de valle, esclerofilo montano y xérico, entre 500 y $1.500 \mathrm{~m}$ s.m. Exs.: N. García 3326 (CONC).

Puya caerulea Lindl.

Arbusto arrosetado, endémico de Chile. Muy frecuente en roqueríos de los hábitats xérico, esclerofilo montano y altomontano, entre 1.000 y 2.200 m s.m. Exs.: N. García 3118,3541 (CONC).

\section{Carex andina Phil.}

\section{Cyperaceae}

Hierba perenne, endémica del Cono Sur. Frecuente en el bosque caducifolio y matorral altomontano, entre $1.500 \mathrm{y}$ 2.100 m s.m. Exs.: N. García 3515, 3736 (CONC).

\section{Carex argentina Barros}

Hierba perenne, endémica del Cono Sur. Muy poco frecuente en el hábitat altomontano a $2.100 \mathrm{~m}$ s.m. Este es el segundo registro de $C$. argentina en Chile, que antes había sido citado para la precordillera andina de Talca (García 2007). Exs.: N. García 3739 (CONC, MIN).
Carex bracteosa Kunze ex Kunth

Hierba perenne, endémica de Chile. Poco frecuente en vegas de baja altitud a los $1.200 \mathrm{~m}$ s.m. Exs.: N. García 3572, 4302 (CONC).

Carex excelsa Poepp. ex Kunth

Hierba perenne, endémica del Cono Sur. Poco frecuente en el borde de quebrada a $1.200 \mathrm{~m}$ s.m. Exs.: N. García 3815 (CONC).

Carex macrorrhiza Boeck.

Hierba perenne, autóctona. Muy poco frecuente en vega altomontana a 2.000 m s.m. Exs.: N. García 3603 (CONC, MIN).

Carex pleioneura G.A.Wheeler

Hierba perenne, endémica del Cono Sur. Muy poco frecuente en vega altomontana, creciendo bajo árboles de Maytenus boaria, a 2.000 m s.m. Exs.: N. García 3700 (CONC, MIN).

\section{Carex setifolia Kunze}

Hierba perenne, autóctona. Muy frecuente en los hábitats xérico, esclerofilo de valle, esclerofilo montano y altomontano, entre 500 y 2.000 m s.m. Exs.: N. García $3153,3243,3328$ (CONC).

Cyperus eragrostis Lam.

Hierba perenne, autóctona. Frecuente en el borde de cursos de agua entre 500 y 1.000 m s.m. Exs.: N. García 3818 (CONC).

Cyperus reflexus Vahl

Hierba perenne, autóctona. Muy poco frecuente en la orilla de quebrada a 900 m s.m. Exs.: N. García 4291 (CONC).

\section{Cyperus squarrosus L.}

Hierba anual, autóctona. Frecuente en periferia de vegas altomontanas entre 2.000 y 2.100 m s.m. Exs.: N. García 3641 (CONC).

\section{Eleocharis bonariensis Nees}

Hierba perenne, autóctona. Muy frecuente en la orilla de cursos de agua y quebradas boscosas, entre 500 y $1.500 \mathrm{~m}$ s.m. Exs.: N. García 3094, 3310, 3496, 3579, 4269, 4290, 4306 (CONC).

Eleocharis macrostachya Britton

Hierba perenne, autóctona. Muy poco frecuente en vega de baja altitud a 1.200 m s.m. Exs.: N. García 3571 (CONC).

Eleocharis cf. melanostachys (d'Urv.) C.B.Clarke Hierba perenne, endémica del Cono Sur. Poco frecuente en vegas altomontanas a 2.000 m s.m. Exs.: N. García 3615, 3621 (CONC). 
Eleocharis radicans (Poir.) Kunth

Hierba perenne, autóctona. Poco frecuente en vegas altomontanas a 2.000 m s.m. Exs.: N. García 3612, 3783 (CONC).

\section{Eleocharis sp.}

Hierba perenne. Muy poco frecuente en vega altomontana a 2.000 m s.m. Exs.: N. García 3794 (CONC, SI).

Isolepis cernua (Vahl) Roem. \& Schult.

Hierba anual, autóctona. Frecuente en quebradas de baja altitud y vegas altomontanas, entre 500 y $2.100 \mathrm{~m}$ s.m. Exs.: N. García 3606, 4270 (CONC).

Scirpus asper J.Presl \& C.Presl

Hierba perenne, endémica de Chile. Frecuente en la orilla de cursos de agua y quebradas boscosas, entre 500 y 1.900 m s.m. Exs.: N. García 3702 (CONC).

\section{JUNCACEAE}

Juncus balticus Willd. subsp. andicola (Hook.) Snogerup Hierba perenne, autóctona. Muy frecuente en vegas altomontanas entre 1.900 y 2.100 m s.m. Exs.: N. García 3608 (CONC).

\section{Juncus bufonius L.}

Hierba anual, autóctona. Frecuente en sitios húmedos del hábitat esclerofilo de valle y en vegas altomontanas, entre 500 y 2.100 m s.m. Exs.: N. García 3259, 3370 (CONC).

\section{Juncus cyperoides Lah.}

Hierba perenne, autóctona. Poco frecuente en quebradas entre 1.000 y 1.500 m s.m. Exs.: N. García 3441, 3499 (CONC).

\section{Juncus imbricatus Lah.}

Hierba perenne, autóctona. Muy frecuente en los hábitats esclerofilo de valle y caducifolio, escasa en matorrales y vegas altomontanas, desde 600 hasta $2.100 \mathrm{~m}$ s.m. Exs.: N. García 3382, 3423, 3742 (CONC).

\section{Juncus stipulatus Nees \& Meyen}

Hierba perenne, autóctona. Poco frecuente en vega altomontana a 2.000 m s.m. Exs.: N. García 3602 (CONC).

Juncus tenuis Willd. var. congestus Engelm. ex Buch. Hierba perenne, autóctona. Muy poco frecuente en vega altomontana a $2.000 \mathrm{~m}$ s.m. Exs.: N. García 3832 (CONC).

Luzula leiboldii Buchenau

Hierba perenne, endémica del Cono Sur. Frecuente en el bosque caducifolio entre 1.200 y $1.500 \mathrm{~m}$ s.m. Exs.: N. García 3245, 4168 (CONC).

\section{Poaceae}

Agrostis inconspicua Kunze ex E.Desv.

Hierba perenne, endémica del Cono Sur. Poco frecuente en el matorral altomontano entre 2.000 y 2.200 m s.m. Exs.: N. García 3746 (CONC).

Agrostis mertensii Trin.

Hierba perenne, autóctona. Muy poco frecuente en vega altomontana a $2.000 \mathrm{~m}$ s.m. Exs.: N. García 3605 (CONC).

Agrostis philippiana Parodi ex Rúgolo \& De Paula Hierba perenne, endémica del Cono Sur. Muy poco frecuente en vega altomontana a $2.000 \mathrm{~m}$ s.m. Exs.: $\mathrm{N}$. García 3792 (CONC).

\section{Aira caryophyllea L.}

Hierba anual, alóctona. Muy frecuente en los hábitats esclerofilo de valle y esclerofilo montano. Exs.: N. García 3097 (CONC).

Apera interrupta (L.) P.Beauv.

Hierba anual, alóctona. Muy poco frecuente en quebrada altomontana. Exs.: N. García 3776 (CONC).

\section{Avena barbata Pott ex Link}

Hierba anual, alóctona. Muy frecuente en los hábitats esclerofilo de valle, esclerofilo montano, xérico y altomontano. Exs.: N. García 3184 (CONC).

\section{Briza minor L.}

Hierba anual, alóctona. Poco frecuente en el hábitat esclerofilo de valle. Exs.: N. García 3282 (CONC).

\section{Bromus berteroanus Colla}

Hierba anual, autóctona. Muy frecuente, dominante en praderas de los hábitats esclerofilo de valle y xérico, también presente en los hábitat esclerofilo montano, caducifolio y altomontano, entre 500 y $2.200 \mathrm{~m}$ s.m. Exs.: N. García 3193, 3286 (CONC).

Bromus coloratus Steud.

Hierba perenne, endémica del Cono Sur. Frecuente en el bosque caducifolio entre 1.200 y $1.800 \mathrm{~m}$ s.m. Exs.: $\mathrm{N}$. García 3476 (CONC).

\section{Bromus hordeaceus L.}

Hierba anual, alóctona. Muy frecuente en el hábitat esclerofilo de valle. Exs.: N. García 3388 (CONC).

Bromus lithobius Trin.

Hierba perenne, endémica del Cono Sur. Poco frecuente en los hábitats esclerofilo de valle y de vegas altomontanas, entre 500 y 2.100 m s.m. Exs.: N. García 3307, 3626 (CONC). 


\section{Bromus rigidus Roth}

Hierba anual, alóctona. Frecuente en los hábitats esclerofilo de valle y caducifolio. Exs.: N. García 3473 (CONC).

\section{Bromus scoparius L.}

Hierba anual, alóctona. Poco frecuente en los hábitats esclerofilo de valle, xérico y altomontano. Exs.: N. García 3183 (CONC).

Bromus setifolius J.Presl var. brevifolius Nees Hierba perenne, endémica del Cono Sur. Frecuente y abundante en el matorral altomontano entre 2.000 y 2.200 m s.m. Exs.: N. García 3649 (CONC).

\section{Bromus tunicatus Phil.}

Hierba perenne, endémica del Cono Sur. Poco frecuente en vegas altomontanas a 2.100 m s.m. Exs.: N. García 3749 (CONC).

Chascolytrum subaristatum (Lam.) Desv.

Hierba perenne, autóctona. Muy frecuente en los hábitats esclerofilo de valle, esclerofilo montano y xérico, entre 500 y 1.500 m s.m. Exs.: N. García 3356 (CONC).

\section{Chusquea cumingii Nees}

Hierba subleñosa, endémica de Chile. Poco frecuente en quebradas entre 800 y 1.500 m s.m. Exs.: N. García 3238 (CONC).

\section{Cortaderia rudiuscula Stapf}

Hierba perenne, autóctona. Poco frecuente en quebradas entre 1.200 y $1.500 \mathrm{~m}$ s.m. No recolectada.

Deschampsia airiformis (Steud.) Benth. \& Hook.f. Hierba anual, endémica del Cono Sur. Muy poco frecuente en vegas altomontanas a $2.000 \mathrm{~m}$ s.m. Exs.: N. García 3598 (CONC).

Deschampsia berteroana (Kunth) Trin.

Hierba anual, endémica del Cono Sur. Frecuente en praderas del hábitat esclerofilo de valle entre 500 y 1.000 m s.m. Exs.: N. García 3258, 3381 (CONC).

Elymus cf. angulatus J.Presl

Hierba perenne, autóctona. Poco frecuente en el hábitat esclerofilo montano y en vegas altomontanas entre $1.500 \mathrm{y}$ 2.000 m s.m. Exs.: N. García 3688, 3701 (CONC).

Elymus aff. magellanicus (E.Desv.) A.Löve

Hierba perenne, endémica del Cono Sur. Muy poco frecuente en el matorral altomontano entre 2.000 y 2.100 m s.m. Exs.: N. García 3680 (CONC).
Festuca acantophylla E.Desv.

Hierba perenne, autóctona. Muy frecuente, dominante en los hábitats esclerofilo montano y altomontano, también presente en el bosque caducifolio, entre 1.100 y $2.200 \mathrm{~m}$ s.m. Exs.: N. García 3431, 3477 (CONC).

Hordeum chilense Roem. \& Schult.

Hierba perenne, endémica del Cono Sur. Frecuente en el hábitat esclerofilo de valle, en quebradas, vegas y matorral altomontano, entre 800 y 2.100 m s.m. Exs.: N. García 3390, 3609, 3820 (CONC).

Hordeum comosum J.Presl

Hierba perenne, autóctona. Muy frecuente en el matorral altomontano entre 2.000 y 2.200 m s.m. Exs.: N. García 3650 (CONC).

Hordeum marinum Huds. subsp. gussoneanum (Parl.) Thell.

Hierba anual, alóctona. Muy poco frecuente en espinales de Acacia caven. No recolectada.

Hordeum murinum L.

Hierba anual, alóctona. Muy frecuente en el hábitat esclerofilo de valle. Exs.: N. García 3208 (CONC).

Hordeum aff. patagonicum (Hauman) Covas

Hierba perenne, endémica del Cono Sur. Muy poco frecuente en vega altomontana a $2.100 \mathrm{~m}$ s.m. Exs.: N. García 3781 (CONC).

Jarava chrysophylla (E.Desv.) Peñailillo var. chrysophylla

Hierba perenne, autóctona. Muy frecuente, dominante en algunos sectores del matorral altomontano, entre $1.800 \mathrm{y}$ 2.200 m s.m. Exs.: N. García 3651 (CONC).

Jarava plumosula (Nees ex Steud.) F.Rojas

Hierba perenne, autóctona. Poco frecuente en el matorral xérico entre 500 y 1.500 m s.m. Exs.: N. García 3583 (CONC).

Jarava pogonathera (E.Desv.) Peñailillo

Hierba perenne, endémica del Cono Sur. Poco frecuente en el matorral altomontano entre 2.000 y 2.200 m s.m. Exs.: N. García 3826 (CONC).

Jarava speciosa (Trin. \& Rupr.) Peñailillo var. speciosa Hierba perenne, autóctona. Frecuente en el matorral altomontano entre 2.000 y 2.200 m s.m. Exs.: N. García 3664 (CONC).

Lolium multiflorum Lam.

Hierba anual, alóctona. Poco frecuente en el hábitat esclerofilo de valle. Exs.: N. García 3452 (CONC). 
Melica argentata E.Desv.

Hierba perenne, endémica de Chile. Frecuente en los hábitats esclerofilo de valle y esclerofilo montano, entre 700 y 1.500 m s.m. Exs.: N. García 3581 (CONC).

Melica commersonii Nees ex Steud.

Hierba perenne, endémica de Chile. Frecuente en el matorral xérico entre 700 y 1.700 m s.m. Exs.: N. García 3308, 3551, 3555 (CONC).

Melica longiflora Steud.

Hierba perenne, endémica de Chile. Frecuente en los hábitats esclerofilo montano y xérico, entre 700 y $1.500 \mathrm{~m}$ s.m. Exs.: N. García 3256 (CONC).

Nassella chilensis (Trin.) E.Desv.

Hierba perenne, endémica del Cono Sur. Muy frecuente, dominante en hábitats esclerofilo de valle y xérico, también presente en ambientes de quebrada, esclerofilo montano y matorral altomontano, entre 500 y 2.100 m s.m. Exs.: N. García 3115 (CONC).

Nassella juncea Phil.

Hierba perenne, endémica de Chile. Muy poco frecuente en periferia de matorral de Adesmia resinosa a $2.000 \mathrm{~m}$ s.m. Exs.: N. García 3762 (CONC).

Nassella lachnophylla (Trin.) Barkworth

Hierba perenne, endémica de Chile. Muy poco frecuente en el hábitat esclerofilo de valle a $700 \mathrm{~m}$ s.m. Exs.: N. García 3095 (CONC).

Nassella neesiana (Trin. \& Rupr.) Barkworth

Hierba perenne, autóctona. Poco frecuente en hábitat esclerofilo de valle a 900 m s.m. Exs.: N. García 3422 (CONC).

Phalaris amethystina Trin.

Hierba anual, endémica de Chile. Frecuente en praderas del hábitat esclerofilo de valle entre 500 y 1.000 m s.m. Exs.: N. García 3383 (CONC).

Piptochaetium panicoides (Lam.) E.Desv.

Hierba perenne, autóctona. Muy poco frecuente en el hábitat esclerofilo de valle a 1.000 m s.m. Exs.: N. García 3432 (CONC).

Poa acinaciphylla E.Desv.

Hierba perenne, endémica de Chile. Frecuente en vegas altomontanas entre 2.000 y 2.100 m s.m. Exs.: N. García 3593, 3759 (CONC).

Poa aff. bonariensis (Lam.) Kunth

Hierba perenne, autóctona. Frecuente en el hábitat esclerofilo de valle entre 600 y $1.100 \mathrm{~m}$ s.m. Exs.: N. García 3006, 3161, 3330, 3419, 3424 (CONC).

\section{Poa infirma Kunth}

Hierba anual, alóctona. Poco frecuente en quebradas a 700 m s.m. Exs.: N. García 3309 (CONC).

Poa cf. gayana E.Desv.

Hierba perenne, endémica del Cono Sur. Poco frecuente en los hábitats esclerofilo de valle y esclerofilo montano, entre 1.000 y 1.700 m s.m. Exs.: N. García 3460 (CONC).

Poa nemoralis L.

Hierba perenne, alóctona. Poco frecuente en vegas altomontanas. Exs.: N. García 3777 (CONC).

Poa aff. resinulosa Nees ex Steud.

Hierba perenne, endémica del Cono Sur. Muy frecuente en bosque caducifolio y matorral altomontano, entre $1.500 \mathrm{y}$ 2.200 m s.m. Exs.: N. García 646, 650, 3020, 3806 (CONC).

Poa sp.

Hierba perenne. Poco frecuente en el hábitat esclerofilo de valle entre 800 y 1.000 m s.m. Exs.: N. García 3127, 3178 (CONC).

Polypogon australis Brongn.

Hierba perenne, autóctona. Poco frecuente en quebradas y vegas altomontanas, entre 1.200 y 2.100 m s.m. Exs.: N. García 3610, 4304 (CONC).

\section{Polypogon elongatus Kunth}

Hierba perenne, autóctona. Muy poco frecuente en quebrada a 1.300 m s.m. Exs.: N. García 4303 (CONC).

\section{Polypogon interruptus Kunth}

Hierba perenne, autóctona. Poco frecuente en quebradas y vegas altomontanas, entre 1.200 y $2.100 \mathrm{~m}$ s.m. Exs.: N. García 3629, 3455 (CONC).

\section{Rostraria cristata (L.) Tzvelev}

Hierba anual, alóctona. Muy frecuente en praderas del hábitat esclerofilo de valle. Exs.: N. García 3113, 3157, 3268 (CONC).

Rytidosperma pictum (Nees \& Meyen) Nicora var. pictum Hierba perenne, endémica del Cono Sur. Frecuente en matorral altomontano entre 2.000 y $2.200 \mathrm{~m}$ s.m. Exs.: N. García 3733 (CONC).

Rytidosperma virescens (E.Desv.) Nicora var. virescens Hierba perenne, endémica del Cono Sur. Poco frecuente en la periferia de vega altomontana a $2.100 \mathrm{~m}$ s.m. Exs.: N. García 3740 (CONC). 
Schismus barbatus (L.) Thell.

Hierba anual, alóctona. Poco frecuente en matorral xérico a 1.000 m s.m. Exs.: N. García 3345 (CONC).

Trisetum caudulatum Trin.

Hierba perenne, endémica del Cono Sur. Muy frecuente en los hábitats esclerofilo de valle, esclerofilo montano, caducifolio, además en matorrales y vegas altomontanas, entre 800 y 2.200 m s.m. Exs.: N. García 3463, 3599, 3657, 4278 (CONC).

Vulpia antucensis Trin.

Hierba anual, endémica del Cono Sur. Frecuente en praderas de los hábitats esclerofilo de valle y esclerofilo montano, entre 800 y 1.500 m s.m. Exs.: N. García 3386, 3456, 3538 (CONC).

Vulpia bromoides (L.) Gray

Hierba anual, alóctona. Frecuente en hábitat esclerofilo de valle, muy escasa en vegas altomontanas. Exs.: N. García 3387 (CONC).

Vulpia myuros (L.) C.C.Gmel. var. megalura (Nutt.) Auquier

Hierba anual, alóctona. Muy frecuente en hábitats esclerofilo de valle, esclerofilo montano, xérico y vegas altomontanas. Exs.: N. García 3111, 3299, 3427, 3537 (CONC).

Vulpia myuros (L.) C.C.Gmel. var. myuros

Hierba anual, alóctona. Muy frecuente en hábitats esclerofilo de valle, esclerofilo montano, ocasionalmente en matorrales y vegas altomontanas. No recolectada.

\section{Ranunculales BERBERIDACEAE}

Berberis actinacantha Mart.

Arbusto, endémico de Chile. Poco frecuente en hábitats esclerofilo de valle y esclerofilo montano, y presente en matorrales de periferia de vegas altomontanas, entre 1.100 y 2.100 m s.m. Exs.: N. García 3250, 3505 (CONC).

Berberis chilensis Gillies ex Hook. \& Arn. var. chilensis Arbusto, endémico de Chile. Frecuente en el hábitat esclerofilo montano entre 1.200 y $1.600 \mathrm{~m}$ s.m. Exs.: N. García 3449, 3546 (CONC).

Berberis empetrifolia Lam.

Arbusto, endémico del Cono Sur. Frecuente en el matorral altomontano entre 1.900 y 2.200 m s.m. Exs.: N. García 3714 (CONC).

\section{PapaVeraceae}

Argemone hunnemannii Otto \& A.Dietr.

Hierba anual, autóctona. Muy poco frecuente en el hábitat esclerofilo de valle a 600 m s.m. Exs.: N. García 4280 (CONC).

Eschscholzia californica Cham.

Hierba perenne, alóctona. Muy frecuente en el hábitat esclerofilo de valle. Exs.: N. García 3325 (CONC).

Fumaria agraria Lag.

Hierba anual, alóctona. Muy frecuente en el hábitat esclerofilo de valle. Exs.: N. García 3181 (CONC).

\section{Papaver somniferum L.}

Hierba anual, alóctona. Poco frecuente en el hábitat esclerofilo de valle. Exs.: N. García 3192 (CONC).

\section{RANUNCULACEAE}

\section{Barneoudia chilensis Gay}

Hierba perenne, endémica del Cono Sur. Poco frecuente en hábitat altomontano a 2.100 m s.m. Exs.: N. García 4170 (CONC), F. Díaz s.n. (CONC 169331).

\section{Myosurus apetalus Gay}

Hierba anual, autóctona. Muy poco frecuente en vega altomontana a 2.000 m s.m. Exs.: N. García 3616 (CONC).

Ranunculus bonariensis Poir. var. trisepalus (Gillies ex Hook. \& Arn.) Lourteig

Hierba anual, endémica del Cono Sur. Poco frecuente en vega altomontana a $2.000 \mathrm{~m}$ s.m. Exs.: N. García 3607 (CONC).

Ranunculus chilensis DC.

Hierba anual, endémica del Cono Sur. Muy poco frecuente en quebrada pantanosa a $1.200 \mathrm{~m}$ s.m. Exs.: N. García 3580 (CONC).

Ranunculus flagelliformis J.E.Sm.

Hierba anual, autóctona. Muy poco frecuente en quebrada pantanosa a 1.200 m s.m. Exs.: N. García 3454 (CONC).

Ranunculus peduncularis J.E.Sm. var. erodiifolius (Gay) Reiche

Hierba perenne, endémica del Cono Sur. Poco frecuente en vegas altomontanas a 2.100 m s.m. Exs.: N. García 3601 (CONC).

\section{Proteales \\ PROTEACEAE}

Lomatia hirsuta (Lam.) Diels ex J.F.Macbr.

Árbol o arbusto arborescente, autóctono. Muy poco frecuente en roquerío de la zona altomontana a $2.000 \mathrm{~m}$ s.m. Exs.: N. García 3829 (CONC). 
Flora vascular de Altos de Chicauma: GARCíA, N.

Gunnerales

GunNERACEAE

Gunnera tinctoria (Molina) Mirb.

Hierba perenne, autóctona. Frecuente en quebradas húmedas entre 600 y $1.500 \mathrm{~m}$ s.m. No recolectada.

\section{Saxifragales \\ Crassulaceae}

Crassula peduncularis (Sm.) F.Meigen

Hierba anual, autóctona. Muy poco frecuente, sólo en la orilla del tranque a $2.000 \mathrm{~m}$ s.m. Exs.: N. García 3617 (CONC).

Crassula tillaea Lest.-Garl.

Hierba anual, alóctona. Muy frecuente en praderas y terrenos desnudos en los hábitat esclerofilo de valle $\mathrm{y}$ xérico. Exs.: N. García 3101 (CONC).

\section{Ribes nubigenum Phil.}

\section{Grossulariaceae}

Arbusto, endémico de Chile. Poco frecuente en matorrales de periferia de vegas, en matorral de Discaria trinervis en ladera y en matorral de Adesmia resinosa, entre 2.000 y $2.100 \mathrm{~m}$ s.m. Esta especie ha sido tratada como sinónimo de Ribes cucullatum Hook \& Arn. (Hechenleitner 2007, Weigend 2008); sin embargo, $R$. nubigenum se separa muy bien de aquella por sus hojas con borde groseramente dentado (rara vez trilobadas), flores solitarias o en fascículos axilares, pedicelos largos (2-6 mm) y forma tubular del caliz con lóbulos de 2,5 mm long. Exs.: N. García 3627 (CONC).

Ribes polyanthes Phil.

Arbusto, endémico de Chile. Frecuente en el bosque caducifolio entre 1.800 y $2.000 \mathrm{~m}$ s.m. Exs.: N. García 3526, 3797 (CONC).

Ribes punctatum Ruiz \& Pav.

Arbusto, autóctono. Frecuente en el bosque caducifolio, ocasionalmente en el hábitat esclerofilo montano, entre 1.400 y 1.800 m s.m. Exs.: N. García 3508 (CONC).

Ribes trilobum Meyen

Arbusto, endémico de Chile. Poco frecuente en el bosque caducifolio y matorral altomontano, entre 1.400 y $2.100 \mathrm{~m}$ s.m. Exs.: N. García 3492, 3706, 3810 (CONC).

\section{Vitales \\ Vitaceae}

Cissus striata Ruiz \& Pav. subsp. striata

Liana, endémica del Cono Sur. Muy frecuente en quebradas boscosas entre 700 y 1.300 m s.m. Exs.: N. García 3403 (CONC).

$$
\begin{gathered}
\text { Zygophyllales } \\
\text { ZygOPHYLLACEAE }
\end{gathered}
$$

Porlieria chilensis I.M.Johnst.

Árbol o arbusto arborescente, endémico de Chile. Frecuente en laderas sombrías del hábitat esclerofilo montano, muy escasa en quebradas, entre 500 y 1.600 m s.m. Exs.: N. García 3362 (CONC).

\section{Celastrales \\ Celastraceae \\ Maytenus boaria Molina}

Árbol o arbusto arborescente, autóctono. Muy frecuente en toda el área de estudio, pero con baja abundancia, se ha registrado en todos los hábitats exceptuando el xérico, entre 500 y 2.200 m s.m. Exs.: N. García 3204 (CONC).

\section{Oxalidales \\ ELAEOCARPACEAE}

Aristotelia chilensis (Molina) Stuntz

Árbol o arbusto arborescente, endémico del Cono Sur. Muy frecuente en quebradas boscosas y en zonas húmedas del hábitat esclerofilo montano, muy escasa en roqueríos altomontanos, entre 700 y 2.100 m s.m. Exs.: N. García 3205, 3751 (CONC).

\section{OxALIDACEAE}

Oxalis arenaria Bertero ex Colla

Hierba perenne, endémica de Chile. Poco frecuente en quebradas boscosas y sitios húmedos del hábitat esclerofilo de valle, entre 700 y 1.000 m s.m. Exs.: N. García 3175 (CONC).

Oxalis campanensis Lourteig

Hierba perenne, endémica de Chile. Muy poco frecuente en sectores abiertos del hábitat caducifolio a $1.500 \mathrm{~m} \mathrm{s.m.}$ Es un endemismo del cordón Aconcagua-Maipo de la cordillera de la Costa (sensu García 2006), habita entre el cerro La Campana y Altos de Chicauma. Exs.: N. García 3523 (CONC).

\section{Oxalis cinerea Zucc.}

Hierba perenne, endémica del Cono Sur. Poco frecuente en el matorral altomontano entre 1.900 y 2.200 m s.m. Exs.: N. García 3687, 3722 (CONC).

Oxalis compacta Gillies ex Hook. \& Arn.

Hierba anual, endémica del Cono Sur. Poco frecuente en el matorral altomontano y en periferia de vegas, entre $2.000 \mathrm{y}$ 2.200 m s.m. Exs.: N. García 3532, 3784 (CONC).

Oxalis laxa Hook. \& Arn. var. hispidissima Barnéoud Hierba anual, autóctona. Poco frecuente en praderas de los hábitats esclerofilo de valle y xérico, entre 600 y $1.000 \mathrm{~m}$ s.m. Exs.: N. García 3278 (CONC). 
Oxalis megalorrhiza (Feuillée) Jacq.

Hierba perenne, autóctona. Poco frecuente en roqueríos del hábitat xérico entre 700 y 1.000 m s.m. Exs.: N. García 3337 (CONC).

Oxalis micrantha Bertero ex Savi

Hierba anual, autóctona. Poco frecuente en los hábitats esclerofilo de valle, esclerofilo montano y en periferia de vegas altomontanas, entre 800 y $2.000 \mathrm{~m}$ s.m. Exs.: N. García 3126, 3280, 3293, 3831 (CONC).

Oxalis perdicaria (Molina) Bertero

Hierba perenne, endémica del Cono Sur. Frecuente en praderas del hábitat esclerofilo de valle entre 600 y 1.200 m s.m. Exs.: N. García 4359 (CONC).

Oxalis rosea Jacq.

Hierba anual, endémica de Chile. Frecuente en quebradas boscosas y sitios húmedos del hábitat esclerofilo de valle, entre 700 y 1.000 m s.m. Exs.: N. García 3395 (CONC).

Oxalis squamata Zucc.

Hierba perenne, endémica del Cono Sur. Poco frecuente en el matorral altomontano entre 1.900 y 2.200 m s.m. Exs.: N. García 3827 (CONC).

Oxalis strictula Steud.

Hierba perenne, endémica de Chile. Poco frecuente en quebradas boscosas y en el bosque caducifolio, entre 1.000 y 1.500 m s.m. Exs.: N. García 3442, 3588 (CONC).

\section{Malpighiales

$$
\text { ElatinaceAe }
$$

Elatine triandra Schkuhr var. triandra

Hierba anual, autóctona. Poco frecuente al borde del tranque a 2.000 m s.m. Exs.: N. García 3618 (CONC).

\section{EUPHORBIACEAE}

Chiropetalum berterianum Schltdl.

Subarbusto, endémico de Chile. Frecuente en el matorral xérico entre 700 y 1.500 m s.m. Exs.: N. García 3149 (CONC).

Colliguaja integerrima Gillies \& Hook.

Arbusto, endémico del Cono Sur. Frecuente en los hábitats esclerofilo montano y altomontano entre 1.400 y $2.100 \mathrm{~m}$ s.m. No recolectada.

\section{Colliguaja odorifera Molina}

Arbusto, endémico de Chile. Dominante en el matorral xérico, muy frecuente en los hábitats esclerofilo de valle y montano, entre 500 y 1.500 m s.m. Exs.: N. García 3151 (CONC).

Colliguaja salicifolia Gillies \& Hook.

Arbusto, endémico de Chile. Frecuente en los hábitats esclerofilo montano y altomontano, entre 1.400 y $2.100 \mathrm{~m}$ s.m. Exs.: N. García 3530 (CONC).

Euphorbia collina Phil. var. collina

Hierba perenne, endémica del Cono Sur. Frecuente en el matorral altomontano entre 2.000 y $2.200 \mathrm{~m}$ s.m. Exs.: N. García 3672, 3735 (CONC).

\section{Euphorbia klotzschii Oudejans var. klotzschii}

Hierba anual, endémica del Cono Sur. Poco frecuente en el hábitat esclerofilo de valle y en vegas altomontanas, entre 500 y 2.100 m s.m. Exs.: N. García 3622 (CONC).

\section{Euphorbia peplus L.}

Hierba anual, alóctona. Muy frecuente en los hábitats de quebradas y esclerofilo de valle. Exs.: N. García 3215 (CONC).

\section{LinACEAE}

Linum macraei Benth. var. macraei

Hierba perenne, endémica de Chile. Muy poco frecuente en el matorral xérico entre 800 y 1.100 m s.m. Exs.: N. García 3091 (CONC).

\section{PASSifloraceae}

Malesherbia fasciculata D.Don var. fasciculata

Arbusto, endémico de Chile. Poco frecuente en matorral xérico entre 800 y 1.500 m s.m., sólo en la quebrada del Macho. Exs.: N. García 4276 (CONC).

\section{Malesherbia humilis Poepp. var. humilis}

Hierba anual, autóctona. Muy poco frecuente en matorral altomontano del sector Lo Amarillo a 2.100 m s.m. Exs.: F. Díaz s.n. (CONC 169334).

\section{Malesherbia linearifolia (Cav.) Pers.}

Subarbusto, endémico de Chile. Muy poco frecuente en laderas con exposición ecuatorial del hábitat esclerofilo montano entre 1.300 y 1.500 m s.m. Exs.: N. García 3554 (CONC).

\section{SAlicACEAE}

Azara dentata Ruiz \& Pav.

Árbol o arbusto arborescente, endémico de Chile. Muy poco frecuente en el hábitat esclerofilo montano a $1.500 \mathrm{~m}$ s.m. No recolectada.

Azara petiolaris (D. Don) I.M.Johnst.

Árbol o arbusto arborescente, endémico de Chile. Frecuente en los hábitats de quebradas, esclerofilo montano y caducifolio, entre 1.000 y 1.800 m s.m. Exs.: N. García 3229 (CONC).

Azara serrata Ruiz \& Pav. var. serrata

Árbol o arbusto arborescente, endémico de Chile. Poco 
frecuente en quebradas boscosas entre 700 y $1.500 \mathrm{~m}$ s.m. Exs.: N. García 3206, 3495 (CONC).

\section{Populus nigra L.}

Árbol o arbusto arborescente, alóctono. Poco frecuente en quebradas. No recolectada.

Salix humboldtiana Willd. var. humboldtiana

Árbol o arbusto arborescente, autóctona. Muy poco frecuente en quebradas boscosas entre 500 y 1.000 m s.m. No recolectada.

\section{ViOLACEAE}

Viola germainii Sparre

Hierba perenne, endémica de Chile. Muy poco frecuente en roquerío altomontano a $2.000 \mathrm{~m} \mathrm{s.m}$. Es un endemismo de la cordillera de la cuenca de Santiago, siendo éste el tercer registro de la especie, que se conocía sólo para el cerro San Ramón (Sparre 1949) y el Santuario de la Naturaleza Yerba Loca (Arroyo et al. 2002). Exs.: F. Díaz s.n. (CONC 169333).

Viola pusilla Poepp.

Hierba anual, endémica de Chile. Frecuente en el matorral xérico entre 800 y 1.200 m s.m. Exs.: N. García 3347 (CONC).

\section{Fabales \\ FABACEAE}

Acacia caven (Molina) Molina var. caven

Árbol o arbusto arborescente, autóctono. Muy frecuente en los hábitats esclerofilo de valle y xérico, donde domina en sectores que han sido históricamente utilizados para la ganadería, entre 500 y 1.200 m s.m. Exs.: N. García 3160 (CONC).

Adesmia aspera Gillies ex Hook. \& Arn.

Hierba perenne, endémica del Cono Sur. Frecuente en el bosque caducifolio y matorral altomontano, entre $1.700 \mathrm{y}$ 2.200 m s.m. Exs.: N. García 3655, 3823 (CONC).

Adesmia conferta Hook. \& Arn.

Hierba perenne, endémica de Chile. Frecuente en los hábitats esclerofilo de valle y xérico, muy escasa en el matorral altomontano, entre 700 y 1.900 m s.m. Exs.: N. García 3393, 4370 (CONC).

\section{Adesmia confusa Ulibarri}

Arbusto, endémico de Chile. Muy frecuente en el matorral xérico entre 700 y 1.500 m s.m. Exs.: N. García 3119 (CONC).

\section{Adesmia denudata Phil.}

Hierba perenne, endémica de Chile. Muy poco frecuente en el matorral altomontano a 2.000 m s.m. Exs.: N. García 628 (CONC, SI, SGO).

\section{Adesmia exilis Clos}

Hierba perenne, endémica del Cono Sur. Muy frecuente en el matorral altomontano entre 1.500 y 2.200 m s.m. Exs.: N. García 3694 (CONC).

\section{Adesmia filifolia Clos}

Hierba anual, endémica de Chile. Frecuente en praderas del hábitat xérico entre 600 y 900 m s.m. Exs.: N. García 3297 (CONC).

\section{Adesmia landbeckii Phil.}

Hierba perenne, endémica de Chile. Muy poco frecuente en el matorral altomontano entre 2.100 y $2.200 \mathrm{~m}$ s.m. Exs.: N. García 3723 (CONC).

\section{Adesmia mucronata Hook. \& Arn.}

Hierba perenne, endémica de Chile. Frecuente en el bosque caducifolio entre 1.400 y 1.800 m s.m. Exs.: N. García 3479 (CONC).

Adesmia resinosa (Phil. ex Reiche) Martic.

Arbusto, endémico de Chile. Frecuente en quebradas a partir de los $1.000 \mathrm{~m}$ s.m. Es muy abundante en el hábitat altomontano donde forma matorrales monoespecíficos en laderas sombrías, popularmente denominados "jarillares", entre 1.800 y 2.100 m s.m. Es un endemismo del cordón Aconcagua-Maipo de la cordillera de la Costa (sensu García 2006), habita desde el cerro El Roble de Caleu hasta el cerro Bustamante de Altos del Noviciado. Exs.: N. García 3569, 3675, 3822 (CONC).

\section{Adesmia tenella Hook. \& Arn. var. tenella}

Hierba anual, endémica de Chile. Frecuente en praderas del hábitat esclerofilo de valle entre 600 y 900 m s.m. Exs.: N. García 3285 (CONC).

Adesmia tenella Hook. \& Arn. var. misera (Phil.) Skottsb. Hierba anual, endémica de Chile. Poco frecuente en el hábitat esclerofilo de valle entre 700 y 1.000 m s.m. Exs.: N. García 3426 (CONC).

\section{Adesmia trifoliata Phil.}

Hierba perenne, endémica de Chile. Muy poco frecuente en suelos arenosos del hábitat altomontano a $2.000 \mathrm{~m} \mathrm{s.m}$. Es un endemismo de la cordillera de la Costa, habita desde la cordillera del Melón hasta Altos de Cantillana. Exs.: N. García 629 (CONC).

\section{Adesmia viscida Bertero ex Savi}

Hierba perenne, endémica de Chile. Frecuente en el hábitat esclerofilo de valle entre 800 y $1.200 \mathrm{~m}$ s.m. Exs.: N. García 3144, 3255, 3418, 3435 (CONC). 


\section{Adesmia sp.}

Hierba perenne. Poco frecuente en vegas altomontanas entre 1.900 y $2.100 \mathrm{~m}$ s.m. Por el hábito de crecimiento y morfología de sus frutos pertenece a Adesmia DC. ser. Confertae Burkart (Burkart 1967). Exs.: N. García 3597, 3738 (CONC, SI).

Anarthrophyllum andicola (Gillies ex Hook. \& Arn.) F.Phil. Arbusto, endémico de Chile. Poco frecuente en el matorral altomontano entre 1.900 y 2.200 m s.m. Exs.: N. García 3669 (CONC).

Astragalus darumbium (Bertero ex Colla) Clos Hierba perenne, endémica del Cono Sur. Poco frecuente en el matorral altomontano entre 2.100 y $2.200 \mathrm{~m} \mathrm{s.m.} \mathrm{Exs.:}$ N. García 3721 (CONC).

Astragalus looseri I.M.Johnst.

Hierba perenne, endémica del Cono Sur. Poco frecuente en vegas altomontanas a 2.100 m s.m. Exs.: N. García 3596, 3640, 3793 (CONC).

Lathyrus berteroanus Colla ex Savi

Enredadera, endémica de Chile. Frecuente en el hábitat esclerofilo de valle entre 700 y 900 m s.m. Exs.: N. García 3188 (CONC).

\section{Lathyrus hookeri D.Don}

Enredadera, autóctona. Frecuente en el bosque esclerofilo de valle, bosque caducifolio y matorral altomontano, entre 1.000 y 2.100 m s.m. Exs.: N. García 3241, 3433 (CONC).

\section{Lathyrus subandinus Phil.}

Hierba perenne, endémica de Chile. Poco frecuente en los hábitats esclerofilo montano, caducifolio y altomontano, entre 1.400 y 2.100 m s.m. Exs.: N. García 3518 (CONC).

\section{Lotus subpinnatus Lag.}

Hierba anual, endémica de Chile. Poco frecuente en el hábitat esclerofilo de valle entre 600 y 900 m s.m. Exs.: N. García 3290 (CONC).

\section{Lupinus microcarpus Sims}

Hierba anual, autóctona. Muy poco frecuente en el hábitat esclerofilo de valle a 700 m s.m. Exs.: N. García 3190 (CONC).

Medicago polymorpha L. var. brevispina (Benth.) Heyn. Hierba anual, alóctona. Frecuente en los hábitats esclerofilo de valle y esclerofilo montano. Exs.: N. García 3201 (CONC).
Melilotus indicus (L.) All.

Hierba anual, alóctona. Poco frecuente en hábitats de quebradas y esclerofilo de valle. Exs.: N. García 3570 (CONC).

Otholobium glandulosum (L.) J.W.Grimes

Árbol o arbusto arborescente, endémico de Chile. Muy frecuente en quebradas entre 600 y $1.400 \mathrm{~m}$ s.m. Exs.: N. García 3408 (CONC).

Prosopis chilensis (Molina) Stuntz

Árbol o arbusto arborescente, autóctono. Muy poco frecuente en la zona de estudio, sólo en espinales de la zona baja de la quebrada del Macho, a $500 \mathrm{~m}$ s.m. No obstante, es frecuente en planicies alrededor del estero Lampa donde ha sido fuertemente reemplazado por plantaciones agrícolas. No recolectada.

Trifolium chilense Hook. \& Arn.

Hierba anual, endémica de Chile. Muy poco frecuente en bosque caducifolio a $1.300 \mathrm{~m}$ s.m. Exs.: N. García 3457 (CONC).

Trifolium dubium Sibth.

Hierba anual, alóctona. Muy poco frecuente en quebrada. Exs.: N. García 3573 (CONC).

Trifolium glomeratum $\mathrm{L}$

Hierba anual, alóctona. Poco frecuente en pradera del hábitat eslcerofilo de valle. Exs.: N. García 3213, 3269 (CONC).

Trifolium incarnatum L.

Hierba anual, alóctona. Muy poco frecuente en pradera del hábitat esclerofilo de valle. Exs.: N. García 3372 (CONC).

Trifolium repens $\mathrm{L}$.

Hierba perenne, alóctona. Poco frecuente en vegas de quebrada y del hábitat altomontano, entre 1.500 y $2.100 \mathrm{~m}$ s.m. Exs.: N. García 3500 (CONC).

Trifolium suffocatum L.

Hierba anual, alóctona. Muy poco frecuente en pradera del hábitat esclerofilo de valle. Exs.: N. García 3371 (CONC).

Vicia leyboldii Phil.

Enredadera, endémica de Chile. Poco frecuente en bosque caducifolio entre 1.300 y $1.700 \mathrm{~m}$ s.m. Este taxón aparece bajo la sinonimia de Vicia nigricans Hook. \& Arn. en Zuloaga et al. (2008c); sin embargo, V. leyboldii se diferencia de aquélla por el extremo del estilo, cuyo lado interior lleva pelos notablemente más largos que el 
exterior (Reiche 1897), y por sus folíolos más angostos, que ocasionalmente presentan un par de dientes en la mitad apical. Exs.: N. García 3484, 3514 (CONC).

\section{Vicia magnifolia Clos}

Enredadera, endémica de Chile. Frecuente en los hábitats esclerofilo montano y caducifolio entre 1.200 y $1.500 \mathrm{~m}$ s.m. Este taxón aparece bajo la sinonimia de Vicia nigricans Hook. \& Arn. en Zuloaga et al. (2008c); sin embargo, $V$. magnifiolia se diferencia de aquella por sus estípulas más angostas de borde entero y folíolos con ápice ligeramente bilobado (Reiche 1897, Navas 1976). Exs.: N. García 3468 (CONC).

\section{Vicia vicina $\mathrm{Clos}$}

Enredadera, endémica de Chile. Frecuente en los hábitats esclerofilo de valle, esclerofilo montano y caducifolio, entre 1.000 y 1.600 m s.m. Exs.: N. García 3436, 3472, 3486, 3544, 3545 (CONC).

\section{Polygalaceae}

Monnina philippiana Chodat

Hierba perenne, endémica del Cono Sur. Muy poco frecuente en laderas secas del hábitat esclerofilo montano a 1.500 m s.m. Exs.: N. García 3567 (CONC).

Polygala gnidioides Willd.

Hierba perenne, endémica del Cono Sur. Poco frecuente en los hábitats esclerofilo montano, caducifolio y altomontano, entre 1.500 y 2.100 m s.m. Exs.: N. García 3489, 3561 (CONC).

\section{Quillaja saponaria Molina}

\section{Quillajaceae}

Árbol o arbusto arborescente, endémico de Chile. Muy frecuente, dominante en los hábitats de quebradas, esclerofilo de valle y esclerofilo montano. También está presente en los hábitats xérico, caducifolio y altomontano, entre 500 y 2.100 m s.m. Exs.: N. García 3819 (CONC).

$$
\text { Fagales }
$$

Nothofagaceae

Nothofagus macrocarpa (A.DC.) F.M.Vázquez \& R.A.Rodr.

Árbol o arbusto arborescente, endémico de Chile. Poco frecuente en quebradas a partir de los 900 m s.m., también en laderas sombrías del hábitat esclerofilo montano desde los $1.400 \mathrm{~m}$ s.m. Dominante en el hábitat del bosque caducifolio entre 1.200 y 2.000 m s.m. Exs.: N. García 3231 (CONC), 4296 (CONC, EIF).

\section{Rosales}

RHAMNACEAE

Colletia hystrix Clos

Arbusto, endémico del Cono Sur. Frecuente en los hábitats de quebradas, esclerofilo de valle y esclerofilo montano, ocasional en el matorral altomontano, entre 800 y $2.000 \mathrm{~m}$ s.m. Exs.: N. García 3448 (CONC).

Discaria trinervis (Gillies ex Hook. \& Arn.) Reiche Árbol o arbusto arborescente, endémico del Cono Sur. Frecuente en quebradas a partir de $1.200 \mathrm{~m}$ s.m., forma densos matorrales arborescentes en la periferia de vegas y laderas húmedas del hábitat altomontano, hasta los 2.100 m s.m. Exs.: N. García 3575, 3787 (CONC).

Retanilla stricta Hook. \& Arn.

Arbusto, endémico de Chile. Muy frecuente, dominante en laderas con exposición ecuatorial del hábitat esclerofilo montano. También presente en los hábitats de quebradas y esclerofilo de valle entre 700 y 1.700 m s.m. Exs.: N. García 3096 (CONC).

Retanilla trinervia (Gillies \& Hook.) Hook. \& Arn. Arbusto, endémico de Chile. Muy frecuente en el hábitat esclerofilo de valle entre 600 y 1.200 m s.m. Exs.: N. García 3098 (CONC).

Trevoa quinquenervia Gillies \& Hook.

Árbol o arbusto arborescente, endémico de Chile. Muy frecuente, dominante en sectores de loma en el hábitat esclerofilo de valle. También presente en el hábitat esclerofilo montano, entre 600 y 1.500 m s.m. Exs.: N. García 3150 (CONC).

\section{Rosaceae}

Acaena alpina Poepp. ex Walp.

Hierba perenne, endémica del Cono Sur. Muy poco frecuente en el matorral altomontano entre 2.100 y 2.200 m s.m. Exs.: N. García 3734 (CONC).

Acaena pinnatifida Ruiz \& Pav.

Hierba perenne, endémica del Cono Sur. Frecuente en los hábitats esclerofilo de valle, esclerofilo montano, caducifolio y altomontano, entre 900 y 2.200 m s.m. Exs.: N. García 3439, 3744 (CONC).

\section{Acaena poeppigiana Gay}

Hierba perenne, endémica del Cono Sur. Muy poco frecuente en la periferia de vega altomontana a $2.000 \mathrm{~m}$ s.m. Exs.: N. García 3760 (CONC).

Acaena splendens Hook. \& Arn.

Hierba perenne, autóctona. Muy frecuente en el bosque caducifolio y matorral altomontano, entre 1.500 y $2.200 \mathrm{~m}$ s.m. Exs.: N. García 3510 (CONC).

Aphanes cf. looseri (Rothm.) Rothm. Hierba anual, endémica de Chile. Frecuente en praderas 
del hábitat esclerofilo de valle entre 500 y 1.000 m s.m. Exs.: N. García 3318, 3327 (CONC).

Kageneckia angustifolia D.Don

Árbol o arbusto arborescente, endémico de Chile. Poco frecuente en los hábitats esclerofilo montano, caducifolio y altomontano, entre 1.400 y 2.100 m s.m. Exs.: N. García 3562 (CONC).

Kageneckia oblonga Ruiz \& Pav.

Árbol o arbusto arborescente, endémico de Chile. Muy frecuente, dominante en bosques de ladera en el hábitat esclerofilo de valle. También frecuente en los hábitats de quebradas y esclerofilo montano, muy escasa en el matorral altomontano; entre 500 y 2.000 m s.m. Exs.: N. García 3313, 3656 (CONC).

Rubus constrictus P.J.Müll. \& Lefèvre Arbusto, alóctono. Frecuente en quebradas de la zona baja. Exs.: N. García 3313, 3656 (CONC).

Tetraglochin alatum (Gillies ex Hook. \& Arn.) Kuntze var. alatum

Arbusto, autóctono. Frecuente en el bosque caducifolio y dominante en sectores del matorral altomontano, entre 1.200 a 2.200 m s.m. Exs.: N. García 3244 (CONC).

Ulmus sp.

\section{ULMACEAE}

Árbol o arbusto arborescente, alóctono. Muy poco frecuente en quebradas. No recolectada.

\section{URTICACEAE}

Parietaria debilis G.Forst.

Hierba anual, autóctona. Poco frecuente en el hábitat esclerofilo de valle entre 500 y 1.200 m s.m. Exs.: N. García 3283 (CONC).

Urtica mollis Steud.

Hierba perenne, endémica del Cono Sur. Poco frecuente en periferia de vegas y en ambientes hídricos altomontanos, entre 1.800 y 2.000 m s.m. Exs.: N. García 3695 (CONC).

Urtica urens L.

Hierba anual, alóctona. Muy frecuente en el hábitat esclerofilo de valle. Exs.: N. García 3164 (CONC).

\section{Geraniales}

Geraniaceae

Erodium botrys (Cav.) Bertol.

Hierba anual, alóctona. Frecuente en el hábitat esclerofilo de valle. Exs.: N. García 3271 (CONC).
Erodium cicutarium (L.) L'Hérit. ex Aiton

Hierba anual, alóctona. Frecuente en los hábitats esclerofilo de valle, xérico y altomontano. Exs.: N. García 3102 (CONC).

Erodium malacoides (L.) L'Hérit. ex Aiton Hierba anual, alóctona. Poco frecuente en el hábitat esclerofilo de valle. Exs.: N. García 3112 (CONC).

Erodium moschatum (L.) L'Hérit. ex Aiton Hierba anual, alóctona. Poco frecuente en el hábitat esclerofilo de valle. Exs.: N. García 3211 (CONC).

\section{Geranium berteroanum Colla}

Hierba perenne, endémica del Cono Sur. Poco frecuente en el hábitat esclerofilo de valle entre 700 y $1.200 \mathrm{~m}$ s.m. Exs.: N. García 3130, 3376 (CONC).

Geranium core-core Steud.

Hierba perenne, endémica del Cono Sur. Poco frecuente en los hábitats esclerofilo de valle, xérico, altomontano y ocasionalmente en vegas altomontanas, entre 800 y 2.100 m s.m. Exs.: N. García 3174, 3352, 3595 (CONC).

\section{Geranium robertianum $\mathrm{L}$.}

Hierba anual, alóctona. Poco frecuente en quebradas y bosque esclerofilo de valle. Exs.: N. García 3207 (CONC).

Geranium skottsbergii R.Knuth

Hierba perenne, endémica de Chile. Poco frecuente en bosque esclerofilo de valle a $900 \mathrm{~m}$ s.m. Exs.: N. García 4317 (CONC).

Tetilla hydrocotylifolia DC.

\section{Melianthaceae}

Hierba perenne, endémica de Chile. Poco frecuente, sólo en quebradas y ambientes húmedos del bosque esclerofilo de valle, entre 500 y 1.000 m s.m. Exs.: N. García 3263, 3402 (CONC).

\section{Vivianiaceae}

Balbisia gracilis (Meyen) Hunz. \& Ariza

Arbusto, endémico del Cono Sur. Poco frecuente en matorrales y roqueríos altomontanos, ocasional en quebradas, entre 1.000 y 2.200 m s.m. Exs.: N. García 3752 (CONC).

Viviania crenata (Hook.) G.Don

Arbusto, endémico de Chile. Poco frecuente en el hábitat esclerofilo de valle, pero muy abundante en el esclerofilo montano, entre 1.100 y 1.600 m s.m. Exs.: N. García 3143 (CONC). 
Viviania marifolia Cav.

Arbusto, endémico del Cono Sur. Muy frecuente en el matorral altomontano entre 1.900 y 2.200 m s.m. Exs.: N. García 3654 (CONC).

Viviania ovata Phil.

Arbusto, endémico del Cono Sur. Poco frecuente en el bosque caducifolio y matorral altomontano entre $1.700 \mathrm{y}$ 2.200 m s.m. Exs.: N. García 3512 (CONC).

\section{Myrtales \\ LyTHRACEAE}

Lythrum cf. maritimum Kunth

Hierba perenne, autóctona. Poco frecuente en vegas altomontanas entre 1.900 y 2.100 m s.m. Exs.: N. García 3769 (CONC).

Pleurophora polyandra Hook. \& Arn.

Hierba anual, endémica de Chile. Poco frecuente en matorral xérico entre 900 y 1.500 m s.m. Exs.: N. García 3093 (CONC).

\section{MyrTACEAE \\ Luma chequen (Molina) Gray}

Árbol o arbusto arborescente, endémico de Chile. Muy frecuente en quebradas boscosas entre 600 y $1.300 \mathrm{~m} \mathrm{s.m.}$ Exs.: N. García 3216 (CONC).

\section{OnAGRACEAE}

Camissonia dentata (Cav.) Reiche subsp. dentata Hierba anual, autóctona. Muy frecuente en praderas de los hábitats esclerofilo de valle, xérico y altomontano, ocasionalmente en vegas altomontanas, entre 500 y 2.100 m s.m. Exs.: N. García 3146, 3592 (CONC).

Clarkia tenella (Cav.) F.H.Lewis \& M.R.Lewis subsp. tenella

Hierba anual, endémica del Cono Sur. Muy frecuente en praderas de los hábitats esclerofilo de valle, esclerofilo montano, xérico y altomontano, entre 500 y 2.100 m s.m. Exs.: N. García 3289 (CONC).

Epilobium ciliatum Raf.

Hierba perenne, autóctona. Poco frecuente en vegas altomontanas a 2.100 m s.m. Exs.: N. García 3619 (CONC).

Epilobium subdentatum (Meyen) Lievens \& Hoch Hierba anual, autóctona. Frecuente en periferia de vegas altomontanas entre 1.900 y 2.100 m s.m. Usualmente se ha citado como Boisduvalia subulata (Ruiz \& Pav.) Raim. (e.g. Marticorena \& Quezada 1985). Exs.: N. García 3611, 3830 (CONC).
Oenothera acaulis Cav.

Hierba perenne, endémica de Chile. Poco frecuente en vegas altomontanas entre 1.900 y 2.100 m s.m. Exs.: N. García 3825 (CONC).

Oenothera picensis Phil. subsp. picensis

Hierba anual, endémica del Cono Sur. Poco frecuente en matorral altomontano a 2.000 m s.m. Exs.: N. García 3692 (CONC).

Brassicales

BRASSICACEAE

Brassica napus L.

Hierba anual, alóctona. Poco frecuente en el hábitat esclerofilo de valle. Exs.: N. García 3312 (CONC).

Capsella bursa-pastoris (L.) Medik.

Hierba anual, alóctona. Frecuente en el hábitat esclerofilo de valle. Exs.: N. García 3218 (CONC).

Cardamine bonariensis Pers.

Hierba perenne, autóctona. Frecuente en los hábitats de quebradas, esclerofilo montano y ambientes hídricos altomontanos, entre 700 y 2.000 m s.m. Exs.: N. García 3013, 3217, 3281, 3773 (CONC).

Cardamine tuberosa DC.

Hierba perenne, endémica de Chile. Poco frecuente en el bosque caducifolio entre 1.200 y $1.500 \mathrm{~m}$ s.m. Exs.: N. García 3450, 3470, 4167 (CONC).

Lepidium strictum (S.Watson) Rattan

Hierba anual, endémica de Chile. Poco frecuente en praderas del hábitat esclerofilo de valle entre 600 y 1.000 m s.m. Exs.: N. García 3274 (CONC).

Sisymbrium orientale L.

Hierba anual, alóctona. Poco frecuente en el hábitat esclerofilo de valle. Exs.: N. García 3209, 3445 (CONC).

\section{Tropaeolaceae}

Tropaeolum azureum Bertero ex Colla

Enredadera, endémica de Chile. Frecuente en el hábitat esclerofilo de valle entre 600 y 900 m s.m. Exs.: N. García 3194, 3331 (CONC).

Tropaeolum brachyceras Hook. \& Arn.

Enredadera, endémica de Chile. Frecuente en el hábitat esclerofilo de valle entre 600 y 900 m s.m. Exs.: N. García 3329, 3361, 4164 (CONC).

Tropaeolum sessilifolium Poepp. \& Endl. Hierba perenne, endémica de Chile. Poco frecuente en el 
matorral altomontano entre 2.000 y 2.200 m s.m. Exs.: N. García 3757 (CONC).

\section{Tropaeolum tricolor Sweet}

Enredadera, endémica de Chile. Muy frecuente en los hábitats de quebradas, esclerofilo de valle y esclerofilo montano, entre 500 y 1.500 m s.m. Exs.: N. García 3189 (CONC).

\section{Malvales \\ Malvaceae}

Andeimalva chilensis (Gay) J.A.Tate

Arbusto, endémico de Chile. Poco frecuente en los hábitats esclerofilo montano y altomontano, entre 1.500 y $2.100 \mathrm{~m}$ s.m. Exs.: N. García 3568, 3703 (CONC).

Corynabutilon ceratocarpum (Hook. \& Arn.) Kearney Arbusto, endémico de Chile. Frecuente en laderas sombrías del hábitat esclerofilo montano. Muy poco frecuente en quebradas boscosas y en roqueríos altomontanos; entre 900 y 2.000 m s.m. Exs.: N. García 3009, 4365 (CONC), F. Díaz s.n. (CONC 169335).

Cristaria dissecta Hook. \& Arn. var. dissecta Hierba anual, endémica del Cono Sur. Poco frecuente en el matorral xérico entre 900 y 1.200 m s.m. Exs.: N. García 3301 (CONC).

\section{Sapindales \\ AnACARdiaceae}

Lithrea caustica (Molina) Hook. \& Arn.

Árbol o arbusto arborescente, endémico de Chile. Muy frecuente, dominante en los hábitats de quebradas y esclerofilo de valle. También presente en los hábitats xérico, esclerofilo montano y caducifolio, entre 500 y $1.600 \mathrm{~m}$ s.m. Se presenta tanto $L$. caustica var. caustica como L. caustica var. pilosa Engl.; es probable que ésta corresponda a una variación a nivel poblacional que no justifique la distinción de dos taxones infraespecíficos. Exs.: N. García 3200, 3397 (CONC).

Schinus latifolia (Gillies ex Lindl.) Engl. var. tomentosa Fenzl ex Engl.

Árbol o arbusto arborescente, endémico de Chile. Muy poco frecuente, sólo se ha registrado un ejemplar en el bosque caducifolio a $1.500 \mathrm{~m}$ s.m. Este taxón ha sido tratado habitualmente como Schinus velutina (Turczs.) I.M. Johnst. (Johnston 1938, Barkley 1957, Marticorena \& Quezada 1985, Zuloaga et al. 2008b); sin embargo, se ha observado que las formas glabra y pubescente se presentan juntas en otras poblaciones, y que la presencia de tricomas no es tan constante como para considerarlo una especie distinta a S. latifolia. Exs.: N. García 3812 (CONC).
Schinus montana (Phil.) Engl.

Árbol o arbusto arborescente, endémico de Chile. Frecuente en los hábitats esclerofilo montano, caducifolio y altomontano, entre 1.300 y 2.100 m s.m. En Altos de Chicauma presenta una gran variabilidad fenotípica, puesto que se ha recolectado ejemplares totalmente glabros (como la forma típica), con hojas pubescentes, y con hojas, ramas y frutos pubescentes. Exs.: N. García 3230, 3251, 3466, 3483 (CONC).

Schinus $\boldsymbol{c f}$. patagonica (Phil.) I.M.Johnst.

Árbol o arbusto arborescente, endémico del Cono Sur. Poco frecuente en los hábitats esclerofilo de valle y caducifolio, entre 1.000 y $1.300 \mathrm{~m}$ s.m. Es un nuevo límite septentrional para esta especie (Barkley 1957, Zuloaga et al. 2008b); sin embargo, sería adecuado estudiar el material citado con mayor profundidad y su posible relación con $S$. montana. Exs.: N. García 3363, 3465 (CONC).

\section{Schinus polygama (Cav.) Cabrera var. polygama}

Árbol o arbusto arborescente, autóctono. Poco frecuente en los hábitats de quebradas y esclerofilo de valle, entre 500 y 1.200 m s.m. Exs.: N. García 3272 (CONC).

\section{SAPINDACEAE}

Bridgesia incisifolia Bertero ex Cambess.

Arbusto, endémico de Chile. Muy poco frecuente, sólo se ha registrado en matorral xérico de la quebrada del Macho, entre 700 y $1.100 \mathrm{~m}$ s.m. No recolectada.

Guindilia trinervis Gillies ex Hook. \& Arn.

Arbusto, endémico del Cono Sur. Frecuente en el bosque caducifolio y matorral altomontano, entre 1.500 y $2.100 \mathrm{~m}$ s.m. Exs.: N. García 3509 (CONC).

\section{Llagunoa glandulosa (Hook. \& Arn.) G.Don}

Arbusto, endémico de Chile. Muy poco frecuente, sólo se ha registrado en matorral xérico de la quebrada del Macho, entre 700 y 1.100 m s.m. Exs.: N. García 4272 (CONC).

\section{Santalales \\ LORANTHACEAE}

Ligaria cuneifolia (Ruiz \& Pav.) Tiegh.

Arbusto parásito, autóctono. Frecuente en espinales, parasita a Acacia caven y Prosopis chilensis, entre 500 y 600 m s.m. Exs.: N. García 4358 (CONC).

Tristerix aphyllus (Miers ex DC.) Barlow \& Wiens Arbusto parásito, endémico de Chile. Muy frecuente en el matorral xérico, parasita a Trichocereus chiloensis, entre 500 y 1.500 m s.m. No recolectada.

Tristerix corymbosus (L.) Kuijt

Arbusto parásito, endémico del Cono Sur. Muy frecuente, 
parasita a varias especies en los hábitats de quebradas, esclerofilo de valle, esclerofilo montano y caducifolio entre 500 y 1.800 m s.m. Exs.: N. García 3173, 3805 (CONC).

Tristerix verticillatus (Ruiz \& Pav.) Barlow \& Wiens Arbusto parásito, autóctono. Frecuente en el bosque caducifolio y matorral altomontano, parasita principalmente a Schinus montana, entre 1.500 y 2.200 m s.m. Exs.: N. García 3511 (CONC).

\section{MisOdendRACEAE}

\section{Misodendrum linearifolium DC.}

Arbusto parásito, endémico del Cono Sur. Muy frecuente y abundante en el bosque caducifolio, parasita exclusivamente a Nothofagus macrocarpa, entre 1.200 y 1.900 m s.m. Exs.: N. García 3233, 3796 (CONC).

\section{SAntalaceAe}

\section{Myoschilos oblongum Ruiz \& Pav.}

Arbusto, endémico del Cono Sur. Poco frecuente en quebradas, bosque caducifolio y matorral altomontano, entre 1.000 y 2.100 m s.m. Exs.: N. García 3493 (CONC).

\section{Quinchamalium chilense Molina}

Hierba perenne, autóctona. Frecuente en los hábitats esclerofilo de valle, esclerofilo montano y altomontano, entre 1.000 y 2.200 m s.m. Exs.: N. García 3488, 3660 (CONC).

\section{Caryophyllales}

AmaranthaceAe

\section{Chenopodium album $\mathrm{L}$.}

Hierba anual, alóctona. Poco frecuente en el matorral altomontano. No recolectada.

\section{Chenopodium chilense Schrad.}

Hierba perenne, autóctona. Muy poco frecuente en el matorral altomontano a 2.000 m s.m. Exs.: N. García 3761 (CONC).

\section{Chenopodium philippianum Aellen}

Hierba anual, autóctona. Frecuente en el matorral altomontano entre 2.000 y 2.200 m s.m. Exs.: N. García 3727 (CONC).

\section{Salsola kali L. var. kali}

Hierba anual, alóctona. Poco fecuente en orilla de caminos del hábitat esclerofilo de valle. Exs.: N. García 4281 (CONC).

\section{Cactaceae}

Pyrrhocactus curvispinus (Bertero ex Colla) A.Berger ex Backeb.

Hierba suculenta, endémica de Chile. Muy frecuente en roqueríos de los hábitat xérico, esclerofilo montano y altomontano entre 700 y 2.200 m s.m. Exs.: N. García 3549 (CONC).

\section{Pyrrhocactus engleri (F.Ritter) F. Ritter}

Hierba suculenta, endémica de Chile. Muy poco frecuente en roqueríos altomontanos a $2.100 \mathrm{~m}$ s.m. Es un endemismo de la cordillera de la Costa, habita entre Altos de Chicauma y Altos de Cantillana. No recolectada.

Trichocereus chiloensis (Colla) Britton \& Rose subsp. chiloensis

Suculenta columnar, endémica de Chile. Muy frecuente en hábitats esclerofilo de valle y xérico, entre 500 y $1.500 \mathrm{~m}$ s.m. No recolectada.

\section{Caryophyllaceae}

Cardionema ramosissima (Weinm.) A.Nelson \& J.F.Macbr. Hierba perenne, autóctona. Frecuente en hábitats esclerofilo de valle y xérico, entre 500 y 1.200 m s.m. Exs.: N. García 3169 (CONC).

\section{Cerastium arvense $\mathrm{L}$.}

Hierba perenne, alóctona. Muy frecuente en hábitats esclerofilo montano, caducifolio y altomontano. Exs.: N. García 3122 (CONC).

Cerastium fontanum Baumg. subsp. vulgare (Hartmann) Greuter \& Burdet

Hierba perenne, alóctona. Frecuente en el hábitat esclerofilo de valle. Exs.: N. García 3389 (CONC).

\section{Corrigiola crassifolia Chaudri}

Hierba perenne, endémica de Chile. Poco frecuente en laderas secas del hábitat esclerofilo montano a $1.300 \mathrm{~m}$ s.m. Exs.: N. García 3536 (CONC).

Microphyes minima (Miers ex Colla) Briq.

Hierba anual, endémica de Chile. Frecuente en los hábitats xérico y altomontano, y en periferia de vegas altomontanas, entre 700 y 2.100 m s.m. Exs.: N. García 3123, 3708 (CONC).

Paronychia chilensis DC. subsp. subandina (Phil.) Chaudri

Hierba perenne, endémica de Chile. Poco frecuente en el matorral altomontano a 1.100 m s.m. Exs.: N. García 3354 (CONC).

\section{Sagina apetala Ard. var. apetala}

Hierba anual, alóctona. Poco frecuente en el hábitat esclerofilo de valle y en vegas altomontanas. Exs.: N. García 3105, 3782 (CONC). 
Silene gallica L.

Hierba anual, alóctona. Muy frecuente en hábitat esclerofilo de valle. Exs.: N. García 3195, 3443 (CONC).

Stellaria arvalis Fenzl ex F.Phil.

Hierba perenne, endémica del Cono Sur. Muy frecuente en hábitats de quebradas, esclerofilo de valle, esclerofilo montano y ambientes hídricos altomontanos, entre $700 \mathrm{y}$ 1.900 m s.m. Exs.: N. García 3125 (CONC).

Stellaria media (L.) Vill.

Hierba anual, alóctona. Frecuente en hábitats de quebradas, esclerofilo de valle y ambientes hídricos altomontanos. Exs.: N. García 3120 (CONC).

\section{Montiaceae}

Calandrinia affinis Gillies ex Arn.

Hierba perenne, endémica del Cono Sur. Frecuente en vegas altomontanas entre 2.000 y $2.100 \mathrm{~m}$ s.m. Exs.: N. García 3745 (CONC).

Calandrinia compressa Schrad. ex DC.

Hierba anual, endémica de Chile. Muy frecuente en praderas del hábitat esclerofilo de valle entre 500 y 1.000 m s.m. Exs.: N. García 3165 (CONC).

Calandrinia nitida (Ruiz \& Pav.) DC.

Hierba anual, endémica de Chile. Muy poco frecuente en el hábitat esclerofilo de valle a 1.200 m s.m. Exs.: N. García 4367 (CONC)

Cistanthe arenaria (Cham.) Carolin ex Hershk.

Hierba anual, endémica del Cono Sur. Muy poco frecuente en el matorral xérico entre 700 y 800 m s.m. Exs.: N. García 3022 (CONC).

Cistanthe aff. grandiflora (Lindl.) Schltdl.

Hierba perenne, endémica de Chile. Frecuente en roqueríos de los hábitats esclerofilo montano, xérico y altomontano, entre 1.000 y $2.200 \mathrm{~m} \mathrm{s.m}$. Este taxón correspondería a Calandrinia mucronulata Meyen; sin embargo, no está claro si ésta es una especie distinta a Cistanthe grandiflora y se considera un nombre dudoso que podría ser transferido a Cistanthe (Peralta \& Ford-Wentz 2008). Exs.: N. García 639, 3197 (CONC).

Cistanthe picta (Gillies ex Arn.) Carolin ex Hershk. Hierba perenne, endémica del Cono Sur. Poco frecuente en el matorral altomontano entre 2.000 y 2.200 m s.m. Exs.: N. García 3671 (CONC).

Montiopsis capitata (Hook. \& Arn.) D.I.Ford Hierba anual, endémica del Cono Sur. Frecuente en el matorral xérico entre 600 y 1.500 m s.m. Exs.: N. García 3300, 3413 (CONC).

Montiopsis potentilloides (Barnéoud) D.I.Ford Hierba perenne, endémica del Cono Sur. Poco frecuente en el matorral altomontano entre 2.000 y 2.200 m s.m. Exs.: Exs.: N. García 622 (CONC).

Montiopsis ramosissima (Hook. \& Arn.) D.I.Ford Hierba anual, endémica de Chile. Muy frecuente en el matorral xérico y matorral altomontano, entre 800 y 2.100 m s.m. Exs.: N. García 3121, 3411 (CONC).

Montiopsis sericea (Hook. \& Arn.) D.I.Ford Hierba perenne, endémica de Chile. Frecuente en el matorral altomontano entre 1.800 y 2.200 m s.m. Exs.: N. García 3689 (CONC).

\section{Anisomeria coriacea D.Don}

\section{Phytolaccaceae}

Hierba perenne, endémica de Chile. Frecuente en el matorral altomontano entre 2.000 y $2.200 \mathrm{~m}$ s.m. Exs.: N. García 3658 (CONC).

Anisomeria littoralis (Poepp. \& Endl.) Moq. Arbusto, endémico de Chile. Muy poco frecuente en el hábitat esclerofilo de valle entre 600 y $800 \mathrm{~m}$ s.m. No recolectada.

\section{Plumbaginaceae}

Armeria maritima (Mill.) Willd.

Hierba perenne, endémica del Cono Sur. Muy poco frecuente en el bosque caducifolio a $1.500 \mathrm{~m}$ s.m. Exs.: N. García 3485 (CONC).

Chorizanthe virgata Benth.

\section{Polygonaceae}

Subarbusto, endémico de Chile. Frecuente en sitios secos del hábitat esclerofilo de valle entre 700 y 1.300 m s.m. Exs.: N. García 3814 (CONC).

\section{Lastarriaea chilensis J.Remy}

Hierba anual, endémica de Chile. Muy frecuente en praderas y sectores secos de los hábitats esclerofilo de valle y xérico, entre 500 y 1.000 m s.m. Exs.: N. García 3141 (CONC).

Muehlenbeckia hastulata (Sm.) I.M.Johnst. var. hastulata Arbusto, endémico del Cono Sur. Muy frecuente en los hábitats de quebradas, esclerofilo de valle, esclerofilo montano y altomontano, entre 500 y 2.000 m s.m. Exs.: N. García 3116 (CONC). 
Polygonum aviculare L.

Hierba anual, alóctona. Poco frecuente en el hábitat esclerofilo de valle. No recolectada.

\section{Polygonum bowenkampii Phil.}

Hierba perenne, endémica de Chile. Poco frecuente en vegas altomontanas entre 2.000 y $2.100 \mathrm{~m}$ s.m. Exs.: N. García 3589, 3690, 3765 (CONC).

Polygonum convolvulus L.

Hierba anual, alóctona. Muy poco frecuente en el matorral xérico. Exs.: N. García 3349 (CONC).

\section{Rumex acetosella $\mathrm{L}$.}

Hierba anual, alóctona. Poco frecuente en quebradas y matorral altomontano. Exs.: N. García 3497 (CONC).

Rumex longifolius DC.

Hierba perenne, alóctona. Poco frecuente en vegas altomontanas. Exs.: N. García 3778 (CONC).

\section{Portulacaceae}

Portulaca oleracea L.

Hierba anual, alóctona. Poco frecuente en hábitat esclerofilo de valle. Exs.: N.García 656 (CONC).

\section{Cornales}

LOASACEAE

Blumenbachia dissecta (Hook. \& Arn.) Weigend \& J.Grau Hierba perenne, endémica del Cono Sur. Frecuente en los hábitats esclerofilo montano, caducifolio y altomontano, entre 1.400 y 2.200 m s.m. Exs.: N. García 3653, 3756 (CONC).

Loasa floribunda Hook. \& Arn.

Hierba anual, endémica de Chile. Muy poco frecuente en matorral xérico entre 800 y 1.000 m s.m. Exs.: N. García 3092 (CONC).

\section{Loasa insons Poepp.}

Hierba anual, endémica del Cono Sur. Frecuente en los hábitats esclerofilo montano, caducifolio y altomontano, entre 1.400 y 2.100 m s.m. Exs.: N. García 3501, 3520, 3737, 3808 (CONC).

Loasa placei Lindl.

Hierba anual, endémica de Chile. Frecuente en el hábitat esclerofilo de valle entre 500 y 1.200 m s.m. Exs.: N. García 3168 (CONC).

\section{Loasa sclareifolia Juss.}

Hierba perenne, endémica del Cono Sur. Poco frecuente en quebradas boscosas y en el bosque caducifolio, entre $800 \mathrm{y}$ 1.600 m s.m. Exs.: N. García 3400, 3807 (CONC).
Loasa triloba Dombey ex Juss.

Hierba anual, endémica de Chile. Muy frecuente en los hábitats de quebradas boscosas, esclerofilo de valle y esclerofilo montano, entre 500 y $1.500 \mathrm{~m}$ s.m. Exs.: N. García 3166 (CONC).

Loasa volubilis Dombey ex Juss.

Hierba perenne, endémica de Chile. Muy poco frecuente en el matorral altomontano a $2.000 \mathrm{~m}$ s.m. Exs.: N. García 620 (CONC).

Scyphanthus elegans Sweet

Hierba anual, endémica de Chile. Muy poco frecuente en el matorral altomontano a $2.000 \mathrm{~m}$ s.m. Exs.: N. García 3767 (CONC).

\section{Ericales \\ Polemoniaceae}

Collomia biflora (Ruiz \& Pav.) Brand

Hierba anual, autóctona. Poco frecuente en el bosque caducifolio entre 1.200 y 1.500 m s.m. Exs.: N. García 3437 (CONC).

Gilia cf. laciniata Ruiz \& Pav.

Hierba anual, autóctona. Frecuente en praderas del hábitat esclerofilo de valle, en matorral xérico, matorrales y vegas altomontanas, entre 700 y 2.000 m s.m. Exs.: N. García 3139, 3341 (CONC).

Microsteris gracilis (Hook.) Greene Hierba anual, autóctona. Poco frecuente en el matorral altomontano entre 2.000 y 2.200 m s.m. Exs.: N. García 3474 (CONC).

Navarretia involucrata Ruiz \& Pav.

Hierba anual, autóctona. Poco frecuente en vegas altomontanas entre 2.000 y 2.100 m s.m. Exs.: N. García 3620 (CONC).

Polemonium micranthum Benth.

Hierba anual, autóctona. Poco frecuente en el bosque caducifolio, matorral altomontano y vegas, entre $1.700 \mathrm{y}$ 2.100 m s.m. Exs.: N. García 3491 (CONC).

\section{Primulaceae}

Anagallis alternifolia Cav. var. repens (d'Urv.) Knuth Hierba perenne, endémica del Cono Sur. Poco frecuente en vegas altomontanas entre 2.000 y $2.100 \mathrm{~m}$ s.m. Exs.: N. García 3788 (CONC).

Anagallis arvensis L.

Hierba anual, alóctona. Poco frecuente en el hábitat esclerofilo de valle. No recolectada. 


\begin{abstract}
Boraginales
BORAGINACEAE

Amsinckia calycina (Moris) Chater

Hierba anual, autóctona. Muy frecuente en praderas del hábitat esclerofilo de valle, muy escasa en vegas altomontanas, entre 500 y 2.000 m s.m. Exs.: N. García 3108 (CONC).
\end{abstract}

Cryptantha clandestina (Trevir.) I.M.Johnst.

Hierba anual, endémica de Chile. Frecuente en los hábitats esclerofilo de valle y xérico, entre 700 y $1.500 \mathrm{~m}$ s.m. Exs.: N. García 3106, 3138, 3693 (CONC).

Cryptantha globulifera (Clos) Reiche

Hierba anual, endémica del Cono Sur. Poco frecuente en el matorral altomontano entre 2.000 y 2.200 m s.m. Exs.: N. García 3643 (CONC).

Cryptantha linearis (Colla) Greene

Hierba anual, endémica de Chile. Frecuente en praderas del hábitat esclerofilo de valle entre 600 y 1.200 m s.m. Exs.: N. García 3128 (CONC).

\section{Cynoglossum creticum Mill.}

Hierba anual, alóctona. Frecuente en vegas y matorral altomontano, entre 2.000 y 2.100 m s.m. Exs.: N. García 3795 (CONC).

\section{Heliotropium paronychioides A.DC.}

Hierba anual, endémica del Cono Sur. Poco frecuente en la periferia de vegas altomontanas entre 2.000 y $2.100 \mathrm{~m} \mathrm{s.m.}$ Exs.: N. García 3786 (CONC).

Pectocarya linearis (Ruiz \& Pav.) DC.

Hierba anual, alóctona. Frecuente en suelos desnudos en los hábitats esclerofilo de valle y xérico, entre 700 y 1.200 m s.m. Exs.: N. García 3107 (CONC).

Phacelia brachyantha Benth.

Hierba perenne, autóctona. Muy poco frecuente en praderas del hábitat esclerofilo de valle entre 700 y 800 m s.m. Exs.: N. García 3187, 3333 (CONC).

Phacelia cumingii (Benth.) A. Gray

Hierba anual, endémica del Cono Sur. Poco frecuente en vegas y matorral altomontano, entre 1.900 y $2.100 \mathrm{~m} \mathrm{s.m.}$ Exs.: N. García 3699 (CONC).

Phacelia secunda J.F. Gmel. var. secunda Hierba perenne, autóctona. Frecuente en los hábitats esclerofilo de valle, esclerofilo montano, caducifolio y altomontano, entre 1.000 y 2.200 m s.m. Exs.: N. García 3430 (CONC).
Plagiobothrys fulvus (Hook. \& Arn.) I.M.Johnst. Hierba anual, autóctona. Frecuente en praderas del hábitat esclerofilo de valle entre 500 y $1.000 \mathrm{~m}$ s.m. Exs.: N. García 3264 (CONC).

Plagiobothrys myosotoides (Lehm.) Brand

Hierba anual, autóctona. Frecuente en el hábitat esclerofilo de valle entre 500 y 1.200 m s.m. Exs.: N. García 3109 (CONC).

Plagiobothrys polycaulis (Phil.) I.M.Johnst.

Hierba anual, endémica de Chile. Poco frecuente en vegas altomontanas entre 1.900 y 2.100 m s.m. Exs.: N. García 3624, 3775 (CONC).

Plagiobothrys procumbens (Colla) A.Gray

Hierba anual, endémica del Cono Sur. Poco frecuente en praderas del hábitat esclerofilo de valle entre 500 y 1.000 m s.m. Exs.: N. García 3257 (CONC).

Gentianales

APOCYNACEAE

Cynanchum chilense (Phil.) Malme

Hierba perenne, endémica del Cono Sur. Poco frecuente en el bosque caducifolio y matorral altomontano, entre 1.700 y 2.100 m s.m. Exs.: N. García 3513 (CONC).

Diplolepis geminiflora (Decne.) Liede \& Rapini Enredadera, endémica de Chile. Frecuente en el matorral xérico entre 700 y 1.000 m s.m. Exs.: N. García 3298 (CONC).

Diploplepis nummularifolia (Hook. \& Arn.) Liede \& Rapini var. nummularifolia

Subarbusto, endémico del Cono Sur. Muy poco frecuente en el matorral altomontano a 2.100 m s.m. Exs.: N. García 642 (CONC).

Tweedia birostrata (Hook. \& Arn.) Hook. \& Arn. Enredadera, endémica de Chile. Frecuente en el hábitat esclerofilo de valle entre 600 y $1.200 \mathrm{~m}$ s.m. Exs.: N. García 3158, 3374 (CONC).

Vinca major L.

Hierba perenne, alóctona. Muy poco frecuente en hábitat esclerofilo de valle. Exs.: N. García 3210 (CONC).

\section{Gentianaceae}

Centaurium cachanlahuen (Molina) B.L.Rob.

Hierba anual, autóctona. Frecuente en praderas del hábitat esclerofilo de valle entre 500 y $1.000 \mathrm{~m}$ s.m. Exs.: N. García 3425 (CONC). 


\section{Centaurium sp.}

Hierba anual. Frecuente en la periferia de vegas altomontanas entre 1.900 y $2.100 \mathrm{~m}$ s.m. Podría corresponder a un taxón nuevo para la ciencia o a una especie alóctona (e.g. europea) no determinada. Se diferencia de $C$. cachanlahuen por su hábito prostrado, preferencia de hábitat por vegas altomontanas, ausencia de un acinturamiento en la corola y forma del fruto. A este mismo taxón corresponde el siguiente material recolectado a $1.800 \mathrm{~m}$ s.m. en el cerro Vizcachas, al norte de nuestra área de estudio y dentro del mismo cordón de la cordillera de la Costa: F. Schlegel 14985, 14979 (CONC). Exs.: N. García 3594, 3780, 3834, 4300 (CONC).

\section{Galium aparine L.}

\section{RubiaceAe}

Hierba anual, alóctona. Poco frecuente en el hábitat esclerofilo de valle. Exs.: N. García 3155 (CONC).

\section{Galium araucanum Phil.}

Hierba perenne, endémica de Chile. Frecuente en el matorral xérico, matorral altomontano y periferia de vegas altomontanas, entre 1.500 y 2.200 m s.m. Exs.: N. García 3590, 3741, 3743 (CONC).

Galium hypocarpium (L.) Endl. ex Griseb. subsp. hypocarpium

Hierba perenne, autóctona. Poco frecuente en quebradas entre 700 y 1.400 m s.m. Exs.: N. García 3444 (CONC).

Galium murale (L.) All.

Hierba anual, alóctona. Poco frecuente en praderas del hábitat esclerofilo de valle. Exs.: N. García 3428 (CONC).

Galium suffruticosum Hook. \& Arn.

Subarbusto, endémico del Cono Sur. Frecuente en el bosque caducifolio y matorral altomontano, entre $1.200 \mathrm{y}$ 2.100 m s.m. Exs.: N. García 3467, 3506, 3639 (CONC).

\section{Galium trichocarpum DC.}

Enredadera, endémica de Chile. Frecuente en los hábitats esclerofilo de valle, esclerofilo montano y caducifolio, entre 800 y 1.500 m s.m. Exs.: N. García 3228, 3410 (CONC).

\section{Lamiales}

BignONIACEAE

Argylia adscendens DC. var. adscendens

Hierba perenne, endémica de Chile. Frecuente en el matorral altomontano entre 2.000 y 2.200 m s.m. Exs.: N. García 3634 (CONC).

Eccremocarpus scaber Ruiz \& Pav.

Enredadera, autóctona. Muy poco frecuente en los hábitats de quebradas boscosas y esclerofilo montano, entre 1.000 y 1.500 m s.m. Exs.: N. García 3342 (CONC).

\section{Calceolaria andina Benth.}

\section{Calceolariaceae}

Subarbusto, endémico de Chile. Poco frecuente en roqueríos sombríos del hábitat esclerofilo montano entre 1.200 y 1.600 m s.m. Exs.: N. García 4363 (CONC).

\section{Calceolaria angustifolia Sweet}

Arbusto, endémico de Chile. Poco frecuente en el hábitat esclerofilo de valle entre 800 y 1.200 m s.m. Exs.: N. García 3252 (CONC).

Calceolaria arachnoidea Graham subsp. nubigena (Poepp.) C.Ehrh.

Hierba perenne, endémica de Chile. Frecuente en el matorral altomontano y en la periferia de vegas, entre 2.000 y 2.100 m s.m. Comentario: La población de Altos de Chicauma presenta corolas maduras con una coloración que va desde el amarillo hasta naranjo-salmón, muy distinta a las poblaciones andinas que se caracterizan por sus flores rojo-purpúreas, muy oscuras (Ehrhart 2000). La coloración típica se ha observado sólo en botones florales, pero a medida que la flor se desarrolla va cambiando hacia el amarillo, pasando por el naranjo-salmón. Esta diferencia, aunque muy interesante, no nos parece suficiente como para justificar la descripción de un nuevo taxón infraespecífico. Exs.: N. García 3678 (CONC).

Calceolaria ascendens Lindl. subsp. exigua (Witasek) Nic.García

Subarbusto, endémico de Chile. Muy poco frecuente en roqueríos con exposición ecuatorial en el hábitat altomontano entre 2.000 y $2.100 \mathrm{~m}$ s.m. Es un endemismo de los sistemas del Melón y Aconcagua-Maipo de la cordillera de la Costa (sensu García 2006), habita en cerros alrededor de Catemu, cerro El Roble de Caleu, Altos de Colliguay y Altos de Chicauma (García 2010). Exs.: N. García 631 (CONC).

Calceolaria ascendens Lindl. subsp. glandulifera (Wittasek) C.Ehrh.

Arbusto, endémico de Chile. Frecuente en los hábitats esclerofilo de valle y xérico, entre 600 y 1.200 m s.m. Exs.: N. García 3114 (CONC).

\section{Calceolaria campanae Phil.}

Hierba perenne, endémica de Chile. Debe ser muy poco frecuente ya que no fue registrada en este estudio. Habita en el hábitat altomontano a $2.000 \mathrm{~m}$ de altitud aproximada. El material de referencia para Altos de Chicauma está citado en Ehrhart (2000). Es un endemismo del cordón Aconcagua-Maipo de la cordillera de la Costa (sensu 
García 2006), habita en el cerro La Campana y en Altos de Chicauma. Exs.: Morrison \& Wagenknecht 17117 (K).

Calceolaria corymbosa Ruiz \& Pav. subsp. corymbosa Hierba perenne, endémica de Chile. Muy frecuente en los hábitats de quebradas, esclerofilo de valle y esclerofilo montano, entre 600 y 1.500 m s.m. Exs.: N. García 3132, 3254 (CONC).

Calceolaria densifolia Phil. subsp. laxa C.Ehrh. Arbusto, endémico de Chile. Frecuente en laderas sombrías del hábitat esclerofilo montano entre 1.400 y 1.600 m s.m. Exs.: N. García 4366 (CONC).

Calceolaria filicaulis Clos subsp. luxurians (Witasek) C.Ehrh.

Hierba perenne, endémica del Cono Sur. Frecuente en vegas altomontanas entre 1.900 y $2.100 \mathrm{~m}$ s.m. Exs.: N. García 3600 (CONC).

\section{Calceolaria glandulosa Poepp. ex Benth}

Hierba perenne, endémica de Chile. Poco frecuente en sitios abiertos de los hábitats esclerofilo de valle y xérico, entre 700 y 1.000 m s.m. Exs.: N. García 3303 (CONC).

\section{Calceolaria hypericina Poepp. ex Benth.}

Arbusto, endémico de Chile. Muy poco frecuente en sectores rocosos del ámbito altomontano entre $2.100 \mathrm{y}$ 2.200 m s.m. Exs.: N. García 3717 (CONC).

\section{Calceolaria meyeniana Phil. subsp. meyeniana}

Arbusto, endémico de Chile. Muy frecuente en el bosque caducifolio y matorral altomontano, entre 1.500 y $2.200 \mathrm{~m}$ s.m. Exs.: N. García 3503 (CONC).

\section{Calceolaria nudicaulis Benth.}

Hierba perenne, endémica de Chile. Poco frecuente en el hábitat esclerofilo de valle entre 500 y 1.000 m s.m. Exs.: N. García 3391 (CONC).

\section{Calceolaria petioalaris Cav.}

Hierba perenne, endémica de Chile. Poco frecuente en quebradas y en estero altomontano, entre 800 y $1.900 \mathrm{~m}$ s.m. Exs.: N. García 3770 (CONC).

\section{Calceolaria polyfolia Hook}

Arbusto, endémico de Chile. Poco frecuente en el hábitat esclerofilo montano entre 1.200 y 1.700 m s.m. No recolectada.

\section{Calceolaria purpurea Graham}

Hierba perenne, endémica de Chile. Frecuente en los hábitats xérico, esclerofilo montano y altomontano, entre 900 y 2.200 m s.m. Exs.: N. García 3346 (CONC).
Calceolaria thyrsiflora Graham

Arbusto, endémico de Chile. Frecuente en los hábitats esclerofilo de valle y esclerofilo montano, entre $600 \mathrm{y}$ 1.500 m s.m. Exs.: N. García 3373 (CONC).

\section{LAMIACEAE}

Clinopodium chilense (Graham) Govaerts

Arbusto, endémico de Chile. Muy frecuente en los hábitats esclerofilo de valle, esclerofilo montano y sectores bajos del matorral altomontano, entre 800 y 1.700 m s.m. Usualmente se ha citado como Satureja gilliesii (Graham) Briq. (e.g. Navas 1979, Marticorena \& Quezada 1985, Teillier et al. 2005). Exs.: N. García 3803 (CONC).

\section{Lamium amplexicaule $\mathrm{L}$.}

Hierba anual, alóctona. Muy poco frecuente en praderas del hábitat esclerofilo de valle. Exs.: N. García 3221 (CONC).

\section{Marrubium vulgare L.}

Hierba perenne, alóctona. Muy poco frecuente en praderas del hábitat esclerofilo de valle. Exs.: N. García 3322 (CONC).

Stachys grandidentata Lindl.

Hierba perenne, endémica de Chile. Frecuente en los hábitats esclerofilo de valle y altomontano, entre 600 y 2.200 m s.m. Exs.: N. García 3135, 3667, 3718 (CONC).

Stachys macraei Benth.

Hierba perenne, endémica de Chile. Poco frecuente en el bosque caducifolio entre 1.500 y $1.800 \mathrm{~m}$ s.m. Exs.: N. García 3507 (CONC).

\section{Teucrium bicolor Sm.}

Arbusto, endémico de Chile. Frecuente en los hábitats esclerofilo de valle y esclerofilo montano, muy escasa en el matorral altomontano, entre 900 y 2.100 m s.m. No recolectada.

\section{OrobanchacEae}

Castilleja laciniata Hook. \& Arn.

Hierba anual, autóctona. Frecuente en praderas del hábitat esclerofilo de valle entre 500 y $1.000 \mathrm{~m}$ s.m. Exs.: N. García 3185 (CONC).

\section{Mimulus glabratus Kunth}

\section{Phrymaceae}

Hierba anual, autóctona. Poco frecuente en pequeños cursos de agua y vegas, entre 600 y $2.100 \mathrm{~m}$ s.m. Exs.: N. García 3359, 3498, 3645 (CONC).

Mimulus luteus L. var. luteus

Hierba anual, endémica del Cono Sur. Muy poco frecuente 
en quebradas y en estero altomontano, entre 1.300 y 2.000 m s.m. Exs.: N. García 3772 (CONC).

\section{Plantaginaceae}

Callitriche lechleri (Hegelm.) Fassett var. lechleri

Hierba anual, endémica del Cono Sur. Poco frecuente en charcos temporales, pequeños cursos de agua y esteros altomontanos, entre 600 y 1.900 m s.m. Exs.: N. García 3202, 3774 (CONC).

Linaria canadensis (L.) Dum.Cours.

Hierba perenne, alóctona. Poco frecuente en los hábitats xérico y altomontano. Exs.: N. García 3302, 3644 (CONC).

Melosperma andicola Benth.

Subarbusto, endémico del Cono Sur. Poco frecuente en el matorral altomontano entre 2.000 y 2.200 m s.m. Exs.: N. García 3668 (CONC).

\section{Plantago firma Kunze ex Walp.}

Hierba anual, endémica de Chile. Poco frecuente en praderas del hábitat esclerofilo de valle entre 500 y $800 \mathrm{~m}$ s.m. Exs.: N. García 3385 (CONC).

\section{Plantago grandiflora Meyen}

Hierba perenne, endémica del Cono Sur. Poco frecuente en roqueríos altomontanos entre 2.100 y $2.200 \mathrm{~m}$ s.m. Exs.: N. García 637 (CONC).

\section{Plantago hispidula Ruiz \& Pav.}

Hierba anual, endémica de Chile. Muy frecuente en praderas de los hábitats esclerofilo de valle y xérico, entre 500 y 1.500 m s.m. Exs.: N. García 3267, 3320, 3364 (CONC).

Plantago lanceolata L.

Hierba perenne, alóctona. Poco frecuente en el hábitat esclerofilo de valle. Exs.: N. García 3405 (CONC).

\section{Veronica anagallis-aquatica $\mathrm{L}$.}

Hierba anual, alóctona. Poco frecuente en quebradas y vegas de sectores bajos. Exs.: N. García 3461 (CONC).

\section{Veronica arvensis L.}

Hierba anual, alóctona. Poco frecuente en praderas del hábitat esclerofilo de valle. Exs.: N. García 3219 (CONC).

Veronica peregrina L. subsp. xalapensis (Kunth) Pennell Hierba anual, alóctona. Poco frecuente en quebradas y vegas altomontanas. Exs.: N. García 3574, 3614 (CONC).
Veronica persica L.

Hierba anual, alóctona. Poco frecuente en praderas del hábitat esclerofilo de valle. Exs.: N. García 3222 (CONC).

\section{SCROPHULARIACEAE}

Alonsoa meridionalis (L.f.) Kuntze

Subarbusto, autóctono. Poco frecuente en los hábitats esclerofilo de valle, esclerofilo montano y altomontano, entre 900 y 2.100 m s.m. Exs.: N. García 3104 (CONC).

\section{Buddleja globosa Hope}

Arbusto, endémico del Cono Sur. Poco frecuente en quebradas entre 800 y 1.500 m s.m. Exs.: N. García 3401 (CONC).

\section{Limosella australis R.Br.}

Hierba anual, autóctona. Poco frecuente en la orilla del tranque a 2.000 m s.m. Exs.: N. García 3623 (CONC).

\section{Verbascum virgatum Stockes}

Hierba anual, alóctona. Poco frecuente en los hábitats de quebradas, esclerofilo de valle, matorral altomontano y ambientes hídricos altomontanos. Exs.: N. García 3316 (CONC).

\section{VERBENACEAE}

Diostea juncea (Gillies ex Hook.) Miers

Arbusto, autóctono. Frecuente en el matorral altomontano entre 2.000 y 2.200 m s.m. Exs.: N. García 3676 (CONC).

\section{Glandularia berteroi (Meisn.) M.Muñoz}

Hierba perenne, autóctona. Frecuente en los hábitats esclerofilo de valle, esclerofilo montano, xérico y altomontano, entre 800 y $2.200 \mathrm{~m}$ s.m. Exs.: N. García 3147, 3339, 3406, 3691 (CONC).

Junellia spathulata (Gillies \& Hook. ex Hook.) Moldenke var. spathulata

Arbusto, endémico del Cono Sur. Frecuente en el matorral altomontano entre 2.000 y $2.200 \mathrm{~m}$ s.m. Exs.: N. García 3632 (CONC).

Phyla canescens (Kunth) Greene

Hierba perenne, autóctona. Poco frecuente en vega altomontana a 2.000 m s.m. Exs.: N. García 3707 (CONC).

Verbena litoralis Kunth var. litoralis Hierba perenne, autóctona. Poco frecuente en quebrada a 700 m s.m. Exs.: N. García 3311 (CONC). 


\section{Solanales \\ Convolvulaceae}

Convolvulus arvensis $\mathrm{L}$.

Enredadera, alóctona. Poco frecuente en los hábitats esclerofilo de valle y altomontano. Exs.: N. García 3582 (CONC).

Convolvulus demissus Choisy

Hierba perenne, endémica del Cono Sur. Poco frecuente en el matorral altomontano entre 2.000 y $2.200 \mathrm{~m}$ s.m. Exs.: N. García 3670, 3710 (CONC).

Cuscuta chilensis Ker Gawl.

Parásita anual, autóctona. Frecuente en los hábitats esclerofilo de valle, esclerofilo montano y altomontano, entre $500 \mathrm{y}$ 2.100 m s.m. Exs.: N.García 3378, 3636 (CONC).

\section{Cestrum parqui L'Hér.}

\section{SolAnACEAE}

Arbusto, autóctono. Frecuente en los hábitats de quebradas y esclerofilo de valle, entre 500 y 1.200 m s.m. Exs.: N. García 3265 (CONC).

Fabiana imbricata Ruiz \& Pav.

Arbusto, endémico del Cono Sur. Frecuente en quebradas, matorral altomontano y en la periferia de vegas, entre 1.000 y 2.100 m s.m. Exs.: N. García 3494 (CONC).

Lycium chilense Miers ex Bertero var. chilense Arbusto, endémico del Cono Sur. Muy poco frecuente en el hábitat esclerofilo de valle a 700 m s.m. Exs.: N. García 3379 (CONC).

Nicotiana acuminata (Graham) Hook. var. acuminata Hierba perenne, endémica del Cono Sur. Poco frecuente en laderas sombrías del hábitat esclerofilo montano y en la periferia de vegas altomontanas, entre 1.400 y $2.100 \mathrm{~m}$ s.m. Exs.: N. García 3764 (CONC).

Nicotiana corymbosa J.Remy

Hierba anual, endémica del Cono Sur. Poco frecuente en el matorral xérico a 700 m s.m. Exs.: N. García 3295 (CONC).

\section{Nicotiana glauca Graham}

Árbol o arbusto arborescente, alóctono. Muy poco frecuente en orilla de camino del sector bajo. No recolectada

Salpiglossis sinuata Ruiz \& Pav.

Hierba perenne, endémica del Cono Sur. Frecuente en los hábitats esclerofilo montano, xérico y altomontano, entre 1.100 y 2.100 m s.m. Exs.: N. García 3535, 3548, 3711 (CONC).
Schizanthus hookeri Gillies ex Graham Hierba anual, endémica del Cono Sur. Frecuente en el bosque caducifolio y matorral altomontano, entre $1.500 \mathrm{y}$ 2.200 m s.m. Exs.: N. García 3522, 3647, 3799 (CONC).

Schizanthus pinnatus Ruiz \& Pav.

Hierba anual, endémica de Chile. Frecuente en los hábitats esclerofilo de valle y xérico, entre 600 y 900 m s.m. Exs.: N. García 3294 (CONC).

Solanum crispum Ruiz et Pav.

Arbusto, endémico del Cono Sur. Frecuente en los hábitats esclerofilo de valle, esclerofilo montano, caducifolio y altomontano, entre 600 y $2.100 \mathrm{~m}$ s.m. Usualmente se ha citado como Solanum ligustrinum Lodd. (e.g. Navas 1979, Teillier et al. 2005). Exs.: N. García 3266 (CONC).

Solanum furcatum Dunal

Hierba perenne, autóctona. Muy poco frecuente en el hábitat esclerofilo de valle a $700 \mathrm{~m}$ s.m. Exs.: N. García 3284 (CONC).

\section{Asterales \\ AsteraceAe}

Agoseris chilensis (Less.) Greene

Hierba perenne, endémica de Chile. Frecuente en el hábitat esclerofilo de valle entre 500 y 1.000 m s.m. Exs.: N. García 3279 (CONC).

\section{Anthemis arvensis L.}

Hierba anual, alóctona. Frecuente en praderas del hábitat esclerofilo de valle y en vegas altomontanas. Exs.: N. García 3212, 3833 (CONC).

\section{Baccharis confertifolia Colla var. confertifolia}

Arbusto, endémico de Chile. Muy frecuente en quebradas entre 500 y 1.500 m s.m. Exs.: N. García 3324, 3357 (CONC).

Baccharis linearis (Ruiz \& Pav.) Pers. subsp. linearis Arbusto, endémico del Cono Sur. Muy frecuente en el hábitat esclerofilo de valle entre 500 y 1.000 m s.m. Exs.: N. García 3305 (CONC).

Baccharis neaei DC.

Arbusto, endémico del Cono Sur. Frecuente en el bosque caducifolio y matorral altomontano, entre 1.500 y $2.200 \mathrm{~m}$ s.m. Exs.: N. García 3451, 3633 (CONC).

Baccharis paniculata DC.

Arbusto, endémico de Chile. Frecuente en los hábitats esclerofilo de valle, esclerofilo montano y xérico, entre 500 y 1.500 m s.m. No recolectada. 


\section{Baccharis pingraea DC.}

Hierba perenne, autóctona. Poco frecuente en espinal del hábitat esclerofilo de valle y en borde de tranque, entre 900 y $2.000 \mathrm{~m}$ s.m. No recolectada.

Baccharis racemosa (Ruiz \& Pav.) DC.

Arbusto, endémico del Cono Sur. Poco frecuente en los hábitats esclerofilo montano, caducifolio y altomontano, entre 1.400 y $2.000 \mathrm{~m}$ s.m. No recolectada.

\section{Baccharis rhomboidalis J. Remy}

Arbusto, endémico del Cono Sur. Muy poco frecuente en matorral altomontano, sólo en el sector de Lo Amarillo, a 2.000 m s.m. Exs.: F. Díaz s.n. (CONC 169332).

Baccharis sagittalis (Less.) DC.

Subarbusto, endémico del Cono Sur. Poco frecuente en quebradas y esteros altomontanos, entre 1.000 y $2.000 \mathrm{~m}$ s.m. Exs.: N. García 3578 (CONC).

\section{Calorezia nutans (Less.) Panero}

Hierba perenne, endémica del Cono Sur. Poco frecuente en el bosque caducifolio y matorral altomontano, entre 1.800 y 2.200 m s.m. Exs.: N. García 3679 (CONC).

\section{Carduus pycnocephalus L.}

Hierba anual, alóctona. Frecuente en el hábitat esclerofilo de valle. Exs.: N. García 3358 (CONC).

Centaurea chilensis Hook. \& Arn.

Subarbusto, endémico de Chile. Frecuente en roqueríos sombríos del hábitat esclerofilo montano entre $1.200 \mathrm{y}$ 1.700 m s.m. Exs.: F. Díaz s.n. (CONC 169337).

\section{Centaurea melitensis L.}

Hierba anual, alóctona. Muy frecuente en el hábitat esclerofilo de valle. Exs.: N. García 3367 (CONC).

Chaetanthera ciliata Ruiz \& Pav.

Hierba anual, endémica de Chile. Muy frecuente en praderas del hábitat esclerofilo de valle entre 500 y 1.000 m s.m. Exs.: N. García 3369 (CONC).

\section{Chaetanthera flabellata D.Don}

Hierba anual, endémica de Chile. Poco frecuente en el matorral altomontano entre 2.000 y 2.200 m s.m. Exs.: N. García 3674, 3726 (CONC).

\section{Chaetanthera glandulosa J.Remy}

Subarbusto, endémico de Chile. Poco frecuente en el matorral altomontano entre 2.000 y $2.200 \mathrm{~m}$ s.m. Exs.: N. García 3716, 3748, 3768 (CONC).
Chaetanthera limbata (D.Don) Less.

Hierba anual, endémica del Cono Sur. Poco frecuente en el matorral altomontano entre 1.800 y 2.200 m s.m. Exs.: N. García 640 (CONC).

Chaetanthera linearis Poepp. ex Less. var. linearis Hierba anual, endémica de Chile. Frecuente en los hábitats esclerofilo de valle y esclerofilo montano, entre 500 y 1.500 m s.m. Exs.: N. García 3556, 3817 (CONC).

Chaetanthera microphylla (Cass.) Hook. \& Arn. var. microphylla

Hierba anual, endémica del Cono Sur. Muy poco frecuente en el hábitat esclerofilo de valle a $900 \mathrm{~m}$ s.m. Exs.: N. García 3412 (CONC).

Chaetanthera moenchioides Less.

Hierba anual, endémica de Chile. Frecuente en los hábitats esclerofilo de valle y esclerofilo montano, muy escasa en el matorral altomontano, entre 500 y 2.100 m s.m. Exs.: N. García 3273, 3365, 3375 (CONC).

Chaetanthera tenella Less. var. tenella

Hierba anual, endémica de Chile. Poco frecuente en el hábitat esclerofilo de valle entre 700 y 1.000 m s.m. Exs.: N. García 3416, 3420 (CONC).

Chuquiraga oppositifolia D.Don

Arbusto, endémico del Cono Sur. Dominante en el matorral altomontano, frecuente en el bosque caducifolio, entre 1.700 y 2.200 m s.m. Exs.: N. García 4297 (CONC).

Cirsium vulgare (Savi) Ten.

Hierba anual, alóctona. Poco frecuente en el hábitat esclerofilo de valle y en vegas altomontanas, entre $500 \mathrm{y}$ $2.000 \mathrm{~m}$ s.m. No recolectada.

Conyza andina J.Remy

Subarbusto, endémico de Chile. Poco frecuente en el matorral altomontano entre 2.000 y 2.200 m s.m. Exs.: N. García 3665 (CONC).

Conyza arabidifolia J.Remy

Hierba perenne, endémica de Chile. Poco frecuente en los hábitats esclerofilo montano y caducifolio, entre $1.200 \mathrm{y}$ 1.500 m s.m. Exs.: N. García 3565 (CONC).

Conyza cf. bustillosiana J.Remy

Hierba perenne, endémica de Chile. Muy poco frecuente en el hábitat esclerofilo montano a $1.300 \mathrm{~m}$ s.m. Exs.: N. García 3584 (CONC).

Conyza gayana Phil.

Subarbusto, endémico de Chile. Muy poco frecuente en el 
bosque caducifolio a 1.200 m s.m. Exs.: N. García 3478 (CONC).

Conyza cf. spiculosa (Hook. \& Arn.) Zardini Hierba anual, endémica de Chile. Poco frecuente en los hábitats de quebradas, esclerofilo de valle y esclerofilo montano, entre 600 y 1.400 m s.m. Exs.: N. García 3275, 4275 (CONC).

Conyza sumatrensis (Retz.) E.Walker var. leiotheca (S.F.Blake) Pruski \& G.Sancho

Hierba anual, autóctona. Muy poco frecuente en estero altomontano a 1.900 m s.m. Exs.: N. García 3779 (CONC).

Eupatorium glechonophyllum Less.

Arbusto, autóctono. Muy frecuente en los hábitats esclerofilo de valle y esclerofilo montano, entre $600 \mathrm{y}$ 1.500 m s.m. Exs.: N. García 3100 (CONC).

\section{Eupatorium salvium Colla}

Arbusto, endémico de Chile. Muy frecuente en el hábitat esclerofilo de valle entre 600 y $1.200 \mathrm{~m}$ s.m. Exs.: N. García 3176 (CONC).

Facelis retusa (Lam.) Sch.Bip. var. retusa

Hierba anual, autóctona. Frecuente en el hábitat esclerofilo de valle entre 500 y 1.200 m s.m. Exs.: N. García 3131 (CONC).

Flourensia thurifera (Molina) DC.

Arbusto, endémico de Chile. Muy frecuente en el matorral xérico entre 600 y 1.200 m s.m. Exs.: N. García 3292 (CONC).

Gamochaeta americana (Mill.) Wedd.

Hierba perenne, autóctona. Poco frecuente en vegas altomontanas entre 2.000 y 2.100 m s.m. Exs.: N. García 3628, 3696 (CONC).

Gamochaeta berteriana (DC.) Cabrera Hierba perenne, endémica de Chile. Muy frecuente en todos los hábitats, excepto en ambientes hídricos altomontanos, entre 500 y 2.100 m s.m. Exs.: N. García 3145, 3287, 3315, 3351, 3481, 3482, 3673 (CONC).

Gamochaeta monticola (Phil. ex Reiche) Cabrera Hierba anual, endémica del Cono Sur. Frecuente en los hábitats esclerofilo de valle, xérico y en vegas altomontanas, entre 500 y 2.100 m s.m. Exs.: N. García 3368, 3591 (CONC).

Gamochaeta oligantha (Phil.) L.E.Navas

Hierba anual, endémica de Chile. Poco frecuente en el hábitat esclerofilo de valle entre 600 y 1.200 m s.m. Exs.: N. García 3099, 3319 (CONC).

Gamochaeta simplicicaulis (Willd. ex Spreng.) Cabrera Hierba anual, autóctona. Muy poco frecuente en quebradas entre 700 y 1.400 m s.m. Exs.: N. García 3816 (CONC).

Gnaphalium aldunateoides J.Remy

Hierba anual, endémica del Cono Sur. Poco frecuente en vegas altomontanas entre 2.000 y $2.100 \mathrm{~m} \mathrm{s.m.} \mathrm{Exs.:} \mathrm{N.}$ García 3613 (CONC).

Gnaphalium andicola Phil.

Hierba perenne, endémica del Cono Sur. Poco frecuente en el matorral altomontano entre 2.000 y 2.200 m s.m. Exs.: N. García 3753 (CONC).

Gnaphalium cabrerae S.E.Freire

Hierba perenne, endémica del Cono Sur. Frecuente en los hábitats esclerofilo de valle, esclerofilo montano y altomontano, entre 900 y 2.200 m s.m. Exs.: N. García 3134, 3162 (CONC).

Gnaphalium gayanum J.Remy

Hierba perenne, endémica de Chile. Poco frecuente en periferia de vegas y en matorral altomontano, entre 2.000 y 2.200 m s.m. Exs.: N. García 3630 (CONC).

Gnaphalium cf. cheiranthifolium Lam.

Hierba perenne, autóctona. Muy poco frecuente en el matorral xérico a 900 m s.m. Exs.: N. García 3336 (CONC).

Gnaphalium viravira Molina

Hierba perenne, endémica de Chile. Muy poco frecuente en el matorral xérico a $900 \mathrm{~m}$ s.m.

Exs.: N. García 3335 (CONC).

Gochnatia foliolosa (D.Don) D.Don ex Hook. \& Arn. Arbusto, endémico de Chile. Muy frecuente en los hábitats esclerofilo de valle, esclerofilo montano, caducifolio y altomontano, entre 500 y 2.000 m s.m. Exs.: N. García 3809 (CONC).

Haplopappus aff. decurrens J.Remy

Arbusto, endémico de Chile. Poco frecuente en roqueríos sombríos del hábitat esclerofilo montano entre $1.200 \mathrm{y}$ 1.600 m s.m. Exs.: N. García 4362, 4364 (CONC).

Haplopappus diplopappus J.Remy subsp. villosus (Phil.) Klingenb.

Subarbusto, endémico del Cono Sur. Frecuente en el matorral altomontano entre 1.900 y 2.200 m s.m. Exs.: N. García 3683, 4299 (CONC). 
Haplopappus integerrimus (Hook. \& Arn.) H.M.Hall Arbusto, endémico de Chile. Muy poco frecuente en el hábitat esclerofilo montano a 1.200 m s.m. Exs.: N. García 4166 (CONC).

Haplopappus ochagavianus Phil.

Arbusto, endémico de Chile. Muy poco frecuente en roqueríos del hábitat altomontano entre 2.000 y 2.100 m s.m. Es un endemismo del cordón transversal de Chacabuco y del cordón Aconcagua-Maipo de la cordillera de la Costa (sensu García 2006); habita entre el cerro La Campana y Altos de Chicauma, y en el cerro Colunquén (García 2006, Klingenberg 2007), que es la cumbre más alta del cordón transversal de Chacabuco. Exs.: N. García 630 (CONC).

Haplopappus poeppigianus (Hook. \& Arn.) A.Gray Arbusto, endémico de Chile. Muy poco frecuente en el hábitat esclerofilo montano a 1.200 m s.m. Exs.: N. García 3534 (CONC).

Haplopappus taeda Reiche

Arbusto, endémico de Chile. Poco frecuente en los hábitat esclerofilo montano, caducifolio y altomontano, entre 1.400 y 2.200 m s.m. Exs.: N. García 3728, 4294 (CONC).

Haplopappus uncinatus Phil.

Arbusto, endémico de Chile. Frecuente en los hábitats esclerofilo montano y xérico, entre 1.000 y $1.500 \mathrm{~m}$ s.m. Exs.: N. García 3344, 3558 (CONC).

Haplopappus velutinus J.Remy subsp. velutinus Arbusto, endémico de Chile. Frecuente en los hábitats esclerofilo de valle, caducifolio y altomontano, entre 800 y 2.200 m s.m. Exs.: N. García 3404, 3517, 3661 (CONC).

Helenium aromaticum (Hook.) Bailey

Hierba anual, autóctona. Frecuente en los hábitats esclerofilo de valle, xérico y altomontano, también en vegas altomontanas, entre 700 y 2.100 m s.m. Exs.: N. García 3296 (CONC).

Helenium glaucum (Cav.) Stuntz

Hierba perenne, endémica de Chile. Muy poco frecuente en la periferia de vegas altomontanas a $2.000 \mathrm{~m} \mathrm{s.m.} \mathrm{Exs.:}$ N. García 3766 (CONC).

Hypochaeris apargioides Hook. \& Arn.

Hierba perenne, endémica de Chile. Muy poco frecuente en el hábitat esclerofilo de valle a 1.000 m s.m. Exs.: N. García 3438 (CONC).

Hypochaeris cf. chondrilloides (A.Gray) Cabrera

Hierba perenne, autóctona. Frecuente en el matorral altomontano entre 1.800 y 2.200 m s.m. Exs.: N. García 625, 3686 (CONC), C. Villagrán 4718 (CONC).

\section{Hypochaeris glabra L.}

Hierba anual, alóctona. Frecuente en los hábitats esclerofilo de valle y altomontano, también en vegas altomontanas. Exs.: N. García 3224, 3270 (CONC).

Hypochaeris scorzonerae (DC.) F.Muell.

Hierba perenne, endémica de Chile. Poco frecuente en el matorral xérico entre 700 y 1.500 m s.m. Exs.: N. García 3291, 3350 (CONC).

Hypochaeris tenuifolia (Hook. \& Arn.) Griseb.

Hierba perenne, endémica del Cono Sur. Poco frecuente en vegas altomontanas entre 2.000 y $2.100 \mathrm{~m}$ s.m. Exs.: N. García 3698, 3712 (CONC).

\section{Lactuca serriola L.}

Hierba anual, alóctona. Poco frecuente en los hábitats esclerofilo de valle y altomontano, también en vegas altomontanas. Exs.: N. García 3380 (CONC).

Leucheria cerberoana J.Remy

Hierba anual, endémica de Chile. Poco frecuente en los hábitats esclerofilo de valle y esclerofilo montano, entre 800 y 1.500 m s.m. Exs.: N. García 3005 (CONC).

\section{Leucheria glandulosa D.Don}

Hierba perenne, endémica de Chile. Muy poco frecuente en el hábitat esclerofilo de valle a $700 \mathrm{~m}$ s.m. Exs.: N. García 3334 (CONC).

\section{Leucheria hieracioides Cass.}

Hierba perenne, endémica de Chile. Frecuente en los hábitats esclerofilo de valle, esclerofilo montano y caducifolio, entre 700 y 1.700 m s.m. Exs.: N. García 3469, 3576, 4371 (CONC).

Leucheria rosea Poepp. ex Less.

Hierba perenne, endémica del Cono Sur. Poco frecuente en los hábitats esclerofilo montano y altomontano, entre 1.400 y 2.200 m s.m. Exs.: N. García 3685 (CONC).

\section{Leucheria runcinata D.Don}

Hierba perenne, endémica del Cono Sur. Muy poco frecuente en el matorral altomontano entre 2.000 y 2.200 m s.m. Exs.: N. García 3637, 3750 (CONC).

Leucheria tenuis Less.

Hierba anual, endémica de Chile. Muy frecuente en praderas del hábitat esclerofilo de valle entre 500 y 1.000 m s.m. Exs.: N. García 3129 (CONC). 
Logfia gallica (L.) Coss. \& Germ.

Hierba anual, alóctona. Frecuente en los hábitats esclerofilo de valle y xérico. Exs.: N. García 3110 (CONC).

\section{Lucilia eriophora J.Remy}

Hierba perenne, endémica de Chile. Muy poco frecuente en el hábitat esclerofilo montano a 1.300 m s.m. Exs.: N. García 3813 (CONC).

Madia chilensis (Nutt.) Reiche

Hierba anual, endémica de Chile. Muy frecuente en el hábitat esclerofilo de valle entre 500 y 1.000 m s.m. Exs.: N. García 3196 (CONC).

\section{Madia sativa Molina}

Hierba anual, autóctona. Poco frecuente en los hábitats caducifolio y altomontano, también en vegas altomontanas, entre 1.200 y 2.200 m s.m. Exs.: N. García 3475, 3604 (CONC).

\section{Microseris pygmaea D.Don}

Hierba anual, alóctona. Poco frecuente en el ámbito esclerofilo de valle. Exs.: N. García 3384 (CONC).

Moscharia pinnatifida Ruiz \& Pav.

Hierba anual, endémica de Chile. Muy frecuente en los hábitats esclerofilo de valle y xérico, entre 500 y $1.200 \mathrm{~m}$ s.m. Exs.: N. García 3159 (CONC).

Mutisia acerosa Poepp. ex Less.

Arbusto, endémico del Cono Sur. Frecuente en el matorral altomontano entre 1.500 y 2.200 m s.m. Exs.: N. García 3802, 3828 (CONC).

\section{Mutisia ilicifolia Cav.}

Enredadera, endémica de Chile. Muy frecuente en el bosque caducifolio y matorral altomontano, entre $1.500 \mathrm{y}$ 2.200 m s.m. Exs.: N. García 3648, 3789 (CONC).

\section{Mutisia latifolia D.Don}

Enredadera, endémica de Chile. Muy frecuente en los hábitats de quebradas, esclerofilo de valle, esclerofilo montano y caducifolio, entre 700 y 1.500 m s.m. Exs.: N. García 3103, 3434 (CONC).

\section{Mutisia rosea Poepp. ex Less.}

Enredadera, endémica de Chile. Poco frecuente en el hábitat esclerofilo montano entre 1.100 y 1.500 m s.m. Exs.: N. García 3543 (CONC).

\section{Mutisia subulata Ruiz \& Pav. f. subulata}

Enredadera, endémica del Cono Sur. Poco frecuente en los hábitats esclerofilo de valle y esclerofilo montano, entre 800 y 1.500 m s.m. No recolectada.
Mutisia subulata Ruiz \& Pav. f. rosmarinifolia (Poepp. \& Endl.) Cabrera

Subarbusto, endémico de Chile. Poco frecuente en el matorral altomontano entre 1.800 y 2.200 m s.m. Exs.: N. García 3747 (CONC).

Nardophyllum lanatum (Meyen) Cabrera

Arbusto, endémico de Chile. Poco frecuente en el matorral altomontano entre 2.000 y 2.200 m s.m. Exs.: N. García 3715, 3754 (CONC).

Perezia carthamoides (D.Don) Hook. \& Arn.

Hierba perenne, endémica del Cono Sur. Frecuente en el matorral altomontano entre 2.000 y $2.200 \mathrm{~m} \mathrm{s.m}$. Exs.: N. García 3677 (CONC).

Perezia poeppigii Less.

Hierba perenne, endémica de Chile. Muy poco frecuente en el límite superior del bosque caducifolio a $2.000 \mathrm{~m}$ s.m. Exs.: N. García 3798 (CONC).

Podanthus mitiqui Lindl.

Arbusto, endémico de Chile. Muy frecuente en los hábitats esclerofilo de valle y esclerofilo montano, entre 500 y 1.500 m s.m. Exs.: N. García 3117 (CONC).

Proustia cinerea Phil.

Árbol o arbusto arborescente, endémico de Chile. Muy poco frecuente en los hábitats esclerofilo de valle y xérico, entre 700 y 1.500 m s.m. Exs.: N. García 3348 (CONC).

\section{Proustia cuneifolia D.Don}

Arbusto, autóctono. Frecuente en los hábitats esclerofilo de valle y xérico, entre 500 y $1.500 \mathrm{~m}$ s.m. No recolectada.

\section{Proustia pyrifolia DC. var. pyrifolia}

Liana, endémica de Chile. Poco frecuente en quebradas boscosas entre 800 y 1.200 m s.m. Exs.: N. García 4277 (CONC).

Psilocarphus tenellus Nutt. var. globiferus (Bertero ex DC.) Morefield

Hierba anual, endémica de Chile. Poco frecuente en praderas del hábitat esclerofilo de valle entre 500 y 1.200 m s.m. Exs.: N. García 3261 (CONC).

Senecio adenotrichius DC.

Hierba perenne, endémica de Chile. Poco frecuente en los hábitats esclerofilo de valle y esclerofilo montano, entre 500 y 1.200 m s.m. Exs.: N. García 3332 (CONC).

Senecio anthemidiphyllus J.Remy

Arbusto, endémico del Cono Sur. Frecuente en el bosque 
caducifolio y en matorral altomontano, entre 1.700 y 2.200 m s.m. Exs.: N. García 3662, 3801 (CONC).

Senecio cumingii Hook. \& Arn. var. cumingii Subarbusto, endémico de Chile. Muy poco frecuente en bosque caducifolio a $1.500 \mathrm{~m}$ s.m. Exs.: N. García 3563 (CONC).

Senecio davilae Phil.

Subarbusto, endémico de Chile. Poco frecuente en matorral altomontano entre 2.000 y 2.200 m s.m. Exs.: N. García 3729 (CONC).

Senecio eruciformis J.Remy var. brachycephalus (Phil.) Cabrera

Arbusto, endémico del Cono Sur. Muy frecuente en bosque caducifolio, matorral altomontano y periferia de vegas, entre 1.800 y 2.200 m s.m. Exs.: N. García 3785, 4298 (CONC).

Senecio farinifer Hook. \& Arn.

Subarbusto, endémico de Chile. Muy poco frecuente en roqueríos del hábitat esclerofilo montano entre $1.200 \mathrm{y}$ $1.500 \mathrm{~m}$ s.m. No recolectada.

\section{Senecio gayanus DC.}

Subarbusto, endémico de Chile. Poco frecuente en matorral altomontano entre 2.100 y 2.200 m s.m. Exs.: N. García 3719 (CONC).

Senecio hakeifolius Bertero ex DC. var. hakeifolius Subarbusto, endémico de Chile. Muy poco frecuente en hábitats esclerofilo de valle y esclerofilo montano, entre 1.000 y 1.200 m s.m. Exs.: N. García 3017, 3529 (CONC).

Senecio polygaloides Phil.

Subarbusto, endémico del Cono Sur. Muy frecuente en bosque caducifolio y en matorral altomontano, entre 1.800 y $2.200 \mathrm{~m}$ s.m. No recolectada.

\section{Senecio pseuderucoides Cabrera}

Subarbusto, endémico de Chile. Poco frecuente en bosque caducifolio, matorral de Adesmia resinosa y matorral de Discaria trinervis, entre 1.800 y 2.100 m s.m. Es un endemismo del cordón Aconcagua-Maipo de la cordillera de la Costa (sensu García 2006), habita exclusivamente en la Región Metropolitana desde el cerro Vizcachas hasta Altos de Chicauma. Este es el segundo registro para esta especie (Cabrera 1949). Exs.: N. García 3646 (CONC).

\section{Senecio vulgaris L.}

Hierba anual, alóctona. Poco frecuente en el hábitat esclerofilo de valle. Exs.: N. García 3225 (CONC).
Senecio yegua (Colla) Cabrera var. pilotus (Phil.) Cabrera Árbol o arbusto arborescente, endémico de Chile. Frecuente en los hábitats de quebradas boscosas y esclerofilo montano, entre 1.200 y 1.500 m s.m. Exs.: N. García 654 (CONC).

\section{Solidago chilensis Meyen}

Hierba perenne, autóctona. Frecuente en vegas altomontanas entre 1.900 y 2.100 m s.m. Exs.: N. García 4301 (CONC).

Soliva sessilis Ruiz \& Pav.

Hierba anual, autóctona. Muy frecuente en praderas del hábitat esclerofilo de valle entre 500 y 1.200 m s.m. Exs.: N. García 3142 (CONC).

\section{Sonchus asper (L.) Hill}

Hierba anual, alóctona. Poco frecuente en los hábitats esclerofilo de valle y en vegas altomontanas. Exs.: N. García 3462 (CONC).

Taraxacum officinale G.Weber ex F.H.Wigg.

Hierba perenne, alóctona. Frecuente en vegas de zonas bajas y altomontanas. Exs.: N. García 3577 (CONC).

Trichocline aurea (D.Don) Reiche

Hierba perenne, endémica de Chile. Poco frecuente en los hábitats esclerofilo de valle y esclerofilo montano, entre 700 y 1.500 m s.m. Exs.: N. García 3539 (CONC).

Triptilion capillatum (D.Don) DC.

Hierba anual, endémica del Cono Sur. Frecuente en los hábitats esclerofilo de valle, esclerofilo montano, xérico y caducifolio, entre 1.000 y 1.800 m s.m. Exs.: N. García 3521, 3804 (CONC).

Triptilion spinosum Ruiz \& Pav.

Hierba perenne, endémica de Chile. Muy frecuente en praderas húmedas del hábitat esclerofilo de valle entre 700 y 1.200 m s.m. Exs.: N. García 3407 (CONC).

Urospermum picroides (L.) Scop. ex F.W.Schmidt Hierba anual, alóctona. Poco frecuente en el hábitat esclerofilo de valle. Exs.: N. García 3288 (CONC).

\section{Calyceraceae}

Calycera sessiliflora Phil. var. sessiliflora

Hierba anual, endémica de Chile. Poco frecuente en matorral altomontano entre 2.000 y $2.200 \mathrm{~m}$ s.m. Exs.: N. García 3824 (CONC).

\section{Campanulaceae}

Downingia pusilla (G.Don ex A.DC.) Torr. Hierba anual, autóctona. Poco frecuente en la orilla del tranque a 2.000 m s.m. Exs.: N. García 3625 (CONC). 
Lobelia excelsa Bonpl.

Arbusto, endémico de Chile. Poco frecuente en los hábitats de quebradas y esclerofilo montano, entre 900 y $1.500 \mathrm{~m}$ s.m. Exs.: N. García 4274 (CONC).

Lobelia polyphylla Hook. \& Arn

Arbusto, endémico de Chile. Poco frecuente en el matorral xérico entre 1.000 y 1.500 m s.m. Exs.: N. García 3355 (CONC).

\section{Escalloniales \\ ESCALlONIACEAE}

Escallonia alpina Poepp. ex DC. var. carmelitana (Meyen) Acevedo \& Kausel

Arbusto, endémico del Cono Sur. Poco frecuente en roqueríos del hábitat altomontano entre 2.000 y $2.100 \mathrm{~m}$ s.m. Exs.: N. García 3638 (CONC).

\section{Escallonia illinita K.Presl}

Arbusto, endémico de Chile. Muy frecuente en quebradas entre 500 y 1.400 m s.m. Exs.: N. García 3323 (CONC).

Escallonia myrtoidea Bertero ex DC.

Árbol o arbusto arborescente, endémico del Cono Sur. Frecuente en quebradas entre 1.000 y 1.700 m s.m. Exs.: N. García 3234 (CONC).

Escallonia pulverulenta (Ruiz \& Pav.) Pers. var. glabra Engl. Árbol o arbusto arborescente, endémico de Chile. Muy frecuente en el hábitat esclerofilo de valle entre 800 y 1.200 m s.m. Exs.: N. García 3821 (CONC).

\section{Dipsacales \\ CAPrifoliaceae}

Valeriana bridgesii Hook. \& Arn.

Hierba perenne, endémica de Chile. Muy frecuente en los hábitats esclerofilo de valle, esclerofilo montano y altomontano, entre 700 y 2.100 m s.m. Exs.: N. García 3180, 3248, 3377, 3399, 3453, 3459, 3666 (CONC).

\section{Valeriana crispa Ruiz \& Pav.}

Hierba anual, endémica de Chile. Frecuente en los hábitats de quebradas y esclerofilo de valle, entre 700 y $1.500 \mathrm{~m}$ s.m. Exs.: N. García 3306, 3417 (CONC).

\section{Valeriana lepidota $\mathrm{Clos}$}

Subarbusto, endémico de Chile. Poco frecuente en los hábitats esclerofilo montano y caducifolio entre $1.400 \mathrm{y}$ 2.000 m s.m. Exs.: N. García 3227, 3232, 3502 (CONC).

Valeriana papilla Bertero ex DC.

Hierba perenne, endémica de Chile. Muy poco frecuente en el hábitat esclerofilo de valle entre 1.100 y 1.200 m s.m. Exs.: N. García 3458 (CONC).

\section{Valeriana samolifolia (DC.) Colla}

Hierba perenne, endémica del Cono Sur. Muy poco frecuente en praderas del hábitat esclerofilo de valle entre 800 y 1.000 m s.m. Exs.: N. García 3260 (CONC).

\section{Valeriana stricta Clos}

Subarbusto, endémico del Cono Sur. Muy frecuente en los hábitats esclerofilo de valle, esclerofilo montano, xérico y altomontano, entre 900 y 2.200 m s.m. Exs.: N. García 3249, 3421, 3586, 3631 (CONC).

\section{Valeriana vaga $\mathrm{Clos}$}

Hierba perenne, endémica de Chile. Muy poco frecuente en matorral xérico a 1.100 m s.m. Exs.: N. García 3343 (CONC).

Apiales
APIACEAE

Anthriscus caucalis Bieb.

Hierba anual, alóctona. Muy frecuente en los hábitats esclerofilo de valle y esclerofilo montano. Exs.: N. García 3182 (CONC).

Asteriscium chilense Cham. \& Schltdl.

Hierba perenne, endémica de Chile. Poco frecuente en los hábitats esclerofilo montano y xérico, entre 1.200 y 1.500 m s.m. Exs.: N. García 3553 (CONC).

\section{Bowlesia uncinata Colla}

Hierba anual, endémica de Chile. Frecuente en el hábitat esclerofilo de valle entre 800 y 1.200 m s.m. Exs.: N. García 3004, 3124 (CONC).

Ciclospermum laciniatum (DC.) Constance Hierba anual, autóctona. Poco frecuente en la periferia de vegas altomontanas entre 2.000 y $2.100 \mathrm{~m}$ s.m. Exs.: N. García 3642 (CONC).

\section{Conium maculatum L.}

Hierba anual, alóctona. Poco frecuente en el hábitat esclerofilo de valle. Exs.: N. García 3429 (CONC).

Eryngium paniculatum Cav. \& Dombey ex F.Delaroche Hierba perenne, autóctona. Frecuente en los hábitats esclerofilo de valle, esclerofilo montano y altomontano, entre 1.000 y 2.100 m s.m. Exs.: N. García 3550 (CONC).

Gymnophyton isatidicarpum (C.Presl ex DC.) Mathias \& Constance

Arbusto, endémico de Chile. Muy poco frecuente, sólo se ha registrado en matorral xérico de la quebrada del Macho, entre 700 y 1.100 m s.m. Exs.: N. García 4271 (CONC). 
Homalocarpus dichotomus (Poepp. ex DC.) Mathias \& Constance

Hierba anual, endémica de Chile. Frecuente en matorral xérico entre 700 y 1.500 m s.m. Exs.: N. García 3338 (CONC).

Hydrocotyle modesta Cham. \& Schltdl.

Hierba perenne, endémica del Cono Sur. Frecuente en quebradas entre 1.000 y 1.500 m s.m. Exs.: N. García 4305 (CONC).

Hydrocotyle ranunculoides L.f.

Hierba perenne, autóctona. Muy poco frecuente en estero altomontano a 1.900 m s.m. Exs.: N. García 3771 (CONC).

Laretia acaulis (Cav.) Gillies ex Hook.

Arbusto acojinado, endémico del Cono Sur. Poco frecuente en laderas sombrías del hábitat altomontano entre 2.100 y 2.200 m s.m. Exs.: N. García 3732 (CONC).

Mulinum spinosum (Cav.) Pers.

Arbusto, endémico del Cono Sur. Frecuente en los hábitats esclerofilo montano, caducifolio y altomontano, entre 1.200 y 2.200 m s.m. Exs.: N. García 3681, 4295 (CONC).

Osmorhiza chilensis Hook. \& Arn.

Hierba perenne, autóctona. Poco frecuente en bosque caducifolio a 1.500 m s.m. Exs.: N. García 3480 (CONC).

\section{Pozoa coriacea Lag.}

Hierba perenne, endémica del Cono Sur. Muy poco frecuente en matorral altomontano a $2.100 \mathrm{~m}$ s.m. Exs.: N. García 3713 (CONC).

\section{Sanicula crassicaulis Poepp. ex DC.}

Hierba perenne, autóctona. Frecuente en los ámbitos de quebradas boscosas y esclerofilo de valle, entre $700 \mathrm{y}$ 1.200 m s.m. Exs.: N. García 3177 (CONC).

Sanicula graveolens Poepp. ex DC.

Hierba perenne, autóctona. Frecuente en los hábitats esclerofilo de valle, caducifolio y altomontano, entre 800 y 2.100 m s.m. Exs.: N. García 3179, 3414, 3800 (CONC).

Torilis nodosa (L.) Gaertn.

Hierba anual, alóctona. Poco frecuente en el hábitat esclerofilo de valle. Exs.: N. García 4361 (CONC).

\section{AGRADECIMIENTOS}

En primer lugar estoy muy agradecido de Mary T. Kalin Arroyo, quien apoyó este proyecto personal en sus inicios; mediante ella el trabajo en terreno entre 2002 y 2004 fue parcialmente financiado por la Iniciativa Científico Milenio de Chile (ICM) Proyecto P99-P 103 F ICM y por una beca para tesista del Proyecto FONDECYT 1020956. El trabajo en terreno entre 2008 y 2009 fue parte del proyecto "Escenario de Zonificación para la Conservación de la Naturaleza en Altos de Chicauma" financiado por la Fundación "Conservation, Research and Education Opportunities" (CREO) de la University of Washington. Por permitir el acceso e investigación en sus terrenos a José Álvarez, Orica S.A. e Inversiones Campanario S.A. Por su ayuda en la recopilación de información y/ o determinación de especies a Clodomiro Marticorena (CONC), Alicia Marticorena (CONC), María Negritto (CONC), Mélica Muñoz (SGO), Inés Meza (SGO), Gerald Wheeler (MI) y Orfeo Crosa (MVFA). Por aportar con el hallazgo de algunas especies y por su compañía en terreno le agradezco muy especialmente a Fernando Díaz. Por la ayuda en terreno a Luis Faúndez, Fernanda Salinas, Carlos Valdivia, Sergio Araya, Alejandra Carmona, Alejandro Contreras, Juan Larraín, Inelia Escobar, a los arrieros Siriaco Pérez y Don Carluchín, y a la Fundación Roble Alto de Lampa. Por la digitalización de la lista y ayuda con las imágenes a Tania Villaseñor. Por la elaboración de la figura de ubicación a Taryn Fuentes. Por la revisión del manuscrito y/o aporte de ideas a Rodolfo Gajardo, Roberto Rodríguez, Sebastián Teillier y Federico Luebert.

\section{BIBLIOGRAFÍA}

APG III. 2009. An update of the Angiosperm Phylogeny Group classification for the orders and families of flowering plants: APG III. Botanical Journal of the Linnean Society 161: 105-121.

Aravena, X. 2002. Caracterización florística y vegetacional del Santuario de la Naturaleza Yerba Loca (Lo Barnechea, Región Metropolitana). Memoria de Título, Facultad de Ciencias Forestales, Universidad de Chile, Santiago, Chile. 102 pp.

Armesto, J., C. Smith-Ramírez, P. León \& M.T.K. Arroyo. 1992. Biodiversidad y conservación del bosque templado en Chile. Ambiente y Desarrollo 8(4): 19-24.

Arroyo, M.T.K. \& L. Cavieres. 1997. The Mediterranean-type climate flora of central Chile - What do we know and how can we assure its protection? - Noticiero de Biología (Chile) 5: 48-56.

Arroyo, M.T.K., R. Rozzi, J. Simonetti, P. Marquet \& M. Salaberry. 1999. Central Chile. In: R.A. Mittermeier, N. Myers \& C.G. Mittermeier (eds.), Hotspots: Earth's biologically richest and most endangered terrestrial ecosystems, pp. 161-171. CEMEX, México, Distrito Federal.

Arroyo, M.T.K., C. Marticorena, O. Matthei, M. MuñozSchick \& P. Pliscoff. 2002. Analysis of the contribution and efficiency of the Santuario de la Naturaleza Yerba Loca, $33^{\circ} \mathrm{S}$ in protecting the regional vascular plant 
flora (Metropolitan and Fifth regions of Chile). Revista Chilena de Historia Natural 75: 767-792.

AviLEZ, R.H. 2001. Estudio de la flora y vegetación de la Reserva Nacional "Roblería del Cobre de Loncha". Memoria de Título, Universidad de Talca, Facultad de Ciencias Forestales, Talca, Chile. 186 pp.

Baeza, M., E. Barrera, J. Flores, C. Ramírez \& R. Rodríguez. 1998. Categorías de Conservación de Pteridophyta nativas de Chile. Boletín del Museo Nacional de Historia Natural (Chile) 47: 23 - 46.

BARKLEY, F.A. 1957. A study of Schinus L. Lilloa 28: 5-110.

Baroni-Urbani, C. \& M.W. Buser. 1976. Similarity of binary data. Systematic Zoology 25: 251-259.

BAYer, E. 1987. Die gattung Alstroemeria in Chile. Mitt. Staatssamml. München 24: 1-362.

Benoit, I. 1989 (ed.). Libro rojo de la flora terrestre de Chile. CONAF, Santiago, Chile. 157 pp.

Braun-Blanquet, J. 1979. Fitosociología. Bases para el estudio de las comunidades vegetales. Traducido por J. Lalucat; Revisado por J. Oriol de Bolòs. H. Blume Ediciones, Madrid. $820 \mathrm{pp}$.

Burkart, A. 1967. Sinopsis del género sudamericano de Leguminosas Adesmia DC. (Contribución al estudio del género Adesmia, VII). Darwiniana 14: 463-568.

Cabrera, A.L. 1949. El género Senecio en Chile. Lilloa 15: 27501.

Caley, M.J. \& D. Schluter. 1997. The relationship between local and regional diversity. Ecology 78(1): 70-80.

CONAMA. 2004. Estrategia para la Conservación de la Biodiversidad en la Región Metropolitana de Santiago. Santiago, Chile. 98 pp.

Cowling, R.M., P.W. Rundel, B.B. Lamont, M.T.K. Arroyo \& M. Arianoutsou. 1996. Plant diversity in mediterraneanclimate regions. Trends in Ecology and Evolution 11: 362-366.

Crosa, O. \& E. Marchesi. 2002. Presencia de Ipheion tweedianum (Baker) Traub (Alliaceae) en Uruguay. Agrociencia (Uruguay) 6: 92-97.

Cunill, P. 1971. Factores en la destrucción del paisaje chileno: recolección, caza y tala coloniales. Universidad de Chile, Santiago, Chile. Informaciones Geográficas, número especial: 235-264.

Di CAstri, F. \& E.R. HAJek. 1976. Bioclimatología de Chile. Editorial Universidad Católica de Chile. Santiago, Chile. 128 pp.

Ehrhart, C. 2000. Die Gattung Calceolaria (Scrophulariaceae) in Chile. Bibliotheca Botanica 153: 1-283.

EspinOSA, M.R. 1927. Nota preliminar sobre una excursión a las roblerías de Caleu y Vichiculén. Revista Chilena de Historia Natural 31: 291-292.

EspinosA, M.R. 1935. Apuntes botánicos. I. La roblería más cercana de Santiago. Revista Chilena de Historia Natural 39: 282-283.

EsPinosa, M.R. 1936. Apuntes botánicos sobre helechos chilenos. Boletín del Museo Nacional 15: 89-106.

Fuentes, E.R. \& E.R. Hajek. 1979. Patterns of landscape modification in relation to agricultural practice in Central Chile. Environmental Conservation 6: 265-271.

GaJARDO, R. 1994. La vegetación natural de Chile. Clasificación y distribución geográfica. Editorial Universitaria, Santiago, Chile. 165 pp.
Gajardo, R. 2001. Antecedentes sobre el "roble de Santiago" o "roble blanco" (Nothofagus macrocarpa) y sus problemas de conservación. Revista Bosque Nativo (Valdivia) 28: 3-7.

García, N. 2006. Análisis florístico comparativo de la vegetación alto-andina de la cordillera de la Costa y de los Andes de Chile central. Memoria de Título, Facultad de Ciencias Agronómicas, Universidad de Chile, Santiago, Chile. 61 pp.

García, N. 2007. Cinco nuevos registros para la flora vascular de Chile continental. Gayana Botánica 64(2): 184-191.

García, N. 2010. Calceolaria ascendens subsp. exigua comb. et stat. nov. (Calceolariaceae), endémica de la cordillera de la Costa de Chile central. Gayana Botánica 67 (1): 138-141.

GiúDice, G.E. 1999. Sinopsis de las especies argentinas del género Adiantum (Pteridaceae, Pteridophyta). Darwiniana 37: 279-300.

Guaglianone, E.R. 1972. Sinopsis de las especies de Ipheion Raf. y Nothoscordum Kunth (Liliaceae) de Entre Ríos y regiones vecinas. Darwiniana 17: 159-240.

Hechenleitner, P. 2007. Systematics of Chilean Ribes (Grossulariaceae). Thesis MSc, University of Edinburgh, Edinburgh. $86 \mathrm{pp}$.

Holmgren, P., W. Keuken \& K. Schofield. 1981. Index Herbariorum. Part I. The herbaria of the world. Scheltema \& Holkema, Bohn. 452 pp.

Hoffmann, A.E. \& O. Herrera-MacBryde. 1997. Mediterranean region and La Campana national park in central Chile. In: S.D. Davis, V.H. Heywood, O. Herrera-MacBryde, J. Villa-Lobos \& A.C. Hamilton, (eds.), Centres of plant diversity, Volume 3, The Americas, pp. 536-541. The World Wildlife Fund for Nature - The World Conservation Union, USA.

HunzIKER, A.T. 1985. Estudios sobre Amaryllidaceae. VI. Sobre la inexistencia en Argentina del género Phycella. Lorentzia 5: 13-15.

Jaffuel, F. \& A. Pirion. 1921. Plantas fanerógamas del valle del Marga-Marga. Revista Chilena de Historia Natural 25: 350-405.

Johnston, I.M. 1938. New or noteworthy plants from temperate South America. Journal of the Arnold Arboretum 19: 248-263.

Judd, W.S., C.S. Campbell, E.A. Kellogg, P.F. Stevens \& M.J. Donoghue. 2008. Plant Systematics: A Phylogenetic Approach, $3^{\text {rd }}$ edition. Sinauer Associates, Massachusetts, USA. $611 \mathrm{pp}$.

Klingenberg, L. 2007. Monographie der südamerikanischen Gattungen Haplopappus Cass. und Notopappus L. Klingenberg (Asteraceae-Astereae). Bibliotheca Botanica 157: $1-331$.

Krebs, C.J. 1989. Ecological Methodology. Harper Collins Publishers, New York, USA. 654 pp.

Looser, G. 1932. Excursión botánica y zoológica a la alta cordillera de Las Condes. Anales de la Universidad de Chile (3ra Serie) 2: 275-301.

Looser, G. 1940. Las localidades de los tipos de los helechos chilenos. Revista Universitaria (Santiago) 25(3): 155204

Lourteig, A. 2000. Oxalis L. subgéneros Monoxalis (Small) Lourt., Oxalis y Trifidus Lourt. Bradea 7: 201-629. 
Luebert, F. \& P. BeCERRA. 1998. Representatividad vegetacional del Sistema Nacional de Áreas Silvestres Protegidas del Estado (SNASPE) en Chile. Ambiente y Desarrollo 14: 62-69.

Luebert, F. \& P. Pliscoff. 2006. Sinopsis bioclimática y vegetacional de Chile. Editorial Universitaria, Santiago, Chile. 307 pp., 8 lám.

Luebert, F., M. Muñoz \& A. Moreira. 2002. Vegetación y flora de La Campana. En: S. Elórtegui y A. Moreira (eds.), Parque Nacional La Campana. Origen de una Reserva de la Biosfera en Chile central, pp. 36-69. Taller La Era - Fondo de la Américas, Santiago, Chile.

Márquez A.L., R. Real, J.M. Vargas \& A.E. Salvo. 1997. On identifying common distribution patterns and their causal factors: a probabilistic method applied to pteridophytes in the Iberian Peninsula. Journal of Biogeography 24: 613-631.

Márquez A.L., R. Real \& J.M. Vargas. 2001. Methods for comparison of biotic regionalizations: case of pteridophytes in the Iberian Peninsula. Ecography 24: 659-670.

Marticorena, C. \& M. Quezada. 1985. Catálogo de la flora vascular de Chile. Gayana Botánica 42: 1-157.

Matthei, O. 1996. Manual de las malezas que crecen en Chile. Alfabeta Impresores, Santiago. $545 \mathrm{pp}$.

Muñoz, M. 1999. Flora de Caleu. En: A. Moreira (ed.), Guía de campo de Caleu y Cerro El Roble, pp. 84 - 105. Comisión Nacional del Medio Ambiente, Santiago, Chile.

Muñoz, M. \& A. Moreira. 2003. Alstroemerias de Chile. Diversidad, distribución y conservación. Taller La Era, Santiago, Chile. 140 pp.

Muñoz, M., H. NúÑEz \& J. YÁÑEz (eds.). 1996. Libro rojo de los sitios prioritarios para la conservación de la diversidad biológica en Chile. CONAF, Santiago, Chile.

Muñoz, M., A. Moreira, C. Villagrán \& F. Luebert. 2000. Caracterización florística y pisos de vegetación en los Andes de Santiago, Chile central. Boletín del Museo de Historia Natural (Chile) 49: 9-50.

Myers, N., R.A. Mittermeier, C.G. Mittermeier, G.A.B. DA Fonseca \& J. Kent. 2000. Biodiversity hotspots for conservation priorities. Nature 403: 853-858.

Navas, L.E. 1973. Flora de la cuenca de Santiago de Chile. Tomo I. Pteridophyta, Gimnospermae, Monocotyledonae. Ediciones de la Universidad de Chile, Santiago, Chile. $301 \mathrm{pp}$.

Navas, L.E. 1976. Flora de la cuenca de Santiago de Chile. Tomo II. Dicotyledonae Archichlamydeae. Ediciones de la Universidad de Chile, Santiago, Chile. 559 pp.

Navas, L E. 1979. Flora de la cuenca de Santiago de Chile. Tomo III. Ediciones de la Universidad de Chile, Santiago, Chile. 509 pp.

NovoA, P. 2007. Nueva localidad y nuevo límite norte de distribución geográfica para Alstroemeria garaventae Ehr. Bayer (Alstroemeriaceae), una especie endémica para Chile. Chloris Chilensis Año 10. N 2. URL: http:// www.chlorischile.cl.

Peralta, I.E. \& D.I. Ford-Wentz. 2008. Portulacaceae. En: F.O. Zuloaga, O. Morrone \& M.J. Belgrano (eds.), Catálogo de las Plantas Vasculares del Cono Sur (Argentina, Sur de Brasil, Chile, Paraguay y Uruguay).
Volumen 3. Dicotyledonae: Fabaceae (Senna - Zygia) Zygophyllaceae. Monographs in Systematic Botany from the Missouri Botanical Garden 107: 2796-2817.

Ponce, M.M., J. Prado \& G.E. Giúdice. 2008. Pteridaceae. En: F.O. Zuloaga, O. Morrone \& M.J. Belgrano (eds.), Catálogo de las Plantas Vasculares del Cono Sur (Argentina, Sur de Brasil, Chile, Paraguay y Uruguay). Volumen 1. Pteridophyta, Gymnospermae y Monocotyledonae. Monographs in Systematic Botany from the Missouri Botanical Garden 107: 115-136.

Ravenna, P.F. 1978. Studies in the Allieae II. Plant Life 34: 130151.

Ravenna, P.F. 2003. Elucidation and systematics of the Chilean genera of Amaryllidaceae. Botanica Australis 2: 1-20.

Ravenna, P.F., S. Teillier, J. Macaya, R.R. Rodríguez \& O. ZöLLNER. 1998. Categorías de conservación de las plantas bulbosas nativas de Chile. Boletín del Museo Nacional de Historia Natural (Chile) 47: 47-68.

ReIcHe, K. 1897. Estudios críticos sobre la flora de Chile. Anales de la Universidad de Chile 98: 117-175.

ReIche, K. 1907. Grundzüge der Pflanzenverbreitung in Chile. Die Vegetation der Erde 8: 1-394.

Rivas-MartínEZ, S. 2005. Avances en geobotánica. Phytosociological Research Center, Madrid, España. 128 pp.

Rodríguez, R. 1995. Pteridophyta. En: C. Marticorena \& R. Rodríguez (eds.), Flora de Chile, Vol. 1, pp. 119-309. Ediciones de la Universidad de Concepción, Concepción, Chile.

Romero, F. 2002. Caracterización de la flora y la vegetación altoandina del cordón Altos de Cantillana, cordillera de la Costa, Región Metropolitana. Monografía para optar al grado académico de Licenciado en Ciencias y Artes Ambientales. Escuela de Ecología y Paisajismo de la Universidad Central de Chile. 117 pp.

Romero, F. \& S.Teillier. 2009. Caracterización de las comunidades vegetales subandinas y andinas en los altos de Cantillana. Cordillera de la Costa, Región Metropolitana. Chile. Chloris Chilensis Año 12. $\mathrm{N}^{\mathrm{o}} 1$. URL://www.chlorischile.cl

SCHLEgEl, F.M. 1963. Estudio florístico y fitosociológico de la Quebrada de la Plata, hacienda Rinconada de lo Cerda, Maipú, Provincia de Santiago, Departamento de Santiago, Comuna de Maipú. Tesis Ingeniero Forestal, Facultad de Ciencias Forestales, Universidad de Chile, Santiago, Chile. $221 \mathrm{pp}$.

SCHLEgEl, F.M. 1966. Pflanzensoziologische und floristische Untersuchungen über Hartlaubgehölze im La PlataTal bei Santiago de Chile. Bericht der Oberhessischen Gesellschaft für Natur- und Heilkunde zu Giessen, Naturwissenschaftl. Abteilung 34 (3-4): 183-204.

Sota, E.R. DE LA. 1972. Sinopsis de las Pteridófitas del noroeste de Argentina. I. Darwiniana 17: 11-103.

SpARRE, B.B. 1949. Systematical and nomenclaturistical studies in the genus Viola. I. An attempt at a revision of the section Chilenium. Lilloa 17: 27-416.

TeIllier, S. \& A. Tomé. 2004. Contribución al conocimiento de la flora de la cuenca de la quebrada de Ramón, Región Metropolitana, Chile. Boletín del Museo Nacional de Historia Natural (Chile) 53: 17-36. 
Teillier, S., G. Aldunate, P. Riedemann \& H. Niemeyer. 2005. Flora de la Reserva Nacional Río Clarillo. Guía de identificación de especies. Impresos Socías Ltda., Santiago, Chile. 367 pp.

Tryon, R.M. \& R.G. Stolze. 1993. Aspleniaceae-Polypodiaceae. Pteridophyta of Peru, Part V. Fieldiana, Bot. 32: 1-190.

Universidad de Chile. 2007. Profundización de la línea de base ambiental y ecológica del sector de mayor valor ecológico del cordón de Cantillana. Elaborado para CONAMAGEF-PNUD. Proyecto "Conservación de la Biodiversidad en los Altos de Cantillana, Chile". 257 pp.

VILLAR, E.H. DEL. 1929. Geobotánica. Editorial Labor, Barcelona. $339 \mathrm{pp}$.

Villaseñor, R. \& I. Serey. 1980/81. Estudio fitosociológico de la vegetación del Cerro La Campana (Parque Nacional La Campana) en Chile central. Atti Instituto Botanico Laboratori Crittogamico di Pavia, serie 6, 14: 69-91.

Weigend, M. 2008. Grossulariaceae. En: F.O. Zuloaga, O. Morrone \& M.J. Belgrano (eds.), Catálogo de las Plantas Vasculares del Cono Sur (Argentina, Sur de Brasil, Chile, Paraguay y Uruguay). Volumen 3. Dicotyledonae: Fabaceae (Senna - Zygia) - Zygophyllaceae. Monographs in Systematic Botany from the Missouri Botanical Garden 107: 2346-2348.

Zuloaga, F.O., O. Morrone \& M.J. Belgrano (eds.). 2008a. Catálogo de las Plantas Vasculares del Cono Sur (Argentina, Sur de Brasil, Chile, Paraguay y Uruguay). Volumen 1. Pteridophyta, Gymnospermae y Monocotyledonae. Monographs in Systematic Botany from the Missouri Botanical Garden 107: 1-983.

Zuloaga, F.O., O. Morrone \& M.J. Belgrano (eds.). 2008b. Catálogo de las Plantas Vasculares del Cono Sur (Argentina, Sur de Brasil, Chile, Paraguay y Uruguay). Volumen 2. Dicotyledonae: Acanthaceae - Fabaceae (Abarema - Schizolobium). Monographs in Systematic Botany from the Missouri Botanical Garden 107: 9852286.

Zuloaga, F.O., O. Morrone \& M.J. Belgrano (eds.). 2008c. Catálogo de las Plantas Vasculares del Cono Sur (Argentina, Sur de Brasil, Chile, Paraguay y Uruguay). Volumen 3. Dicotyledonae: Fabaceae (Senna - Zygia) Zygophyllaceae. Monographs in Systematic Botany from the Missouri Botanical Garden 107: 2287-3348. 